\title{
AGR-1 Compact 1-3-1 Post-Irradiation Examination Results
}

Paul A. Demkowicz

Scott A. Ploger

Philip L. Winston

Jason M. Harp

December 2016

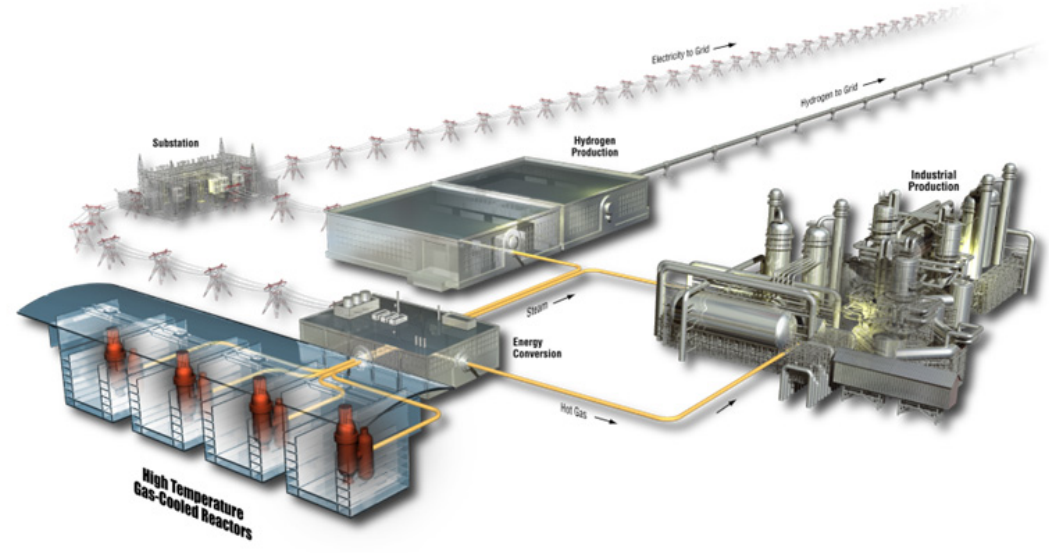

Idaho National Laboratory 


\section{DISCLAIMER}

This information was prepared as an account of work sponsored by an agency of the U.S. Government. Neither the U.S. Government nor any agency thereof, nor any of their employees, makes any warranty, expressed or implied, or assumes any legal liability or responsibility for the accuracy, completeness, or usefulness, of any information, apparatus, product, or process disclosed, or represents that its use would not infringe privately owned rights. References herein to any specific commercial product, process, or service by trade name, trade mark, manufacturer, or otherwise, does not necessarily constitute or imply its endorsement, recommendation, or favoring by the U.S. Government or any agency thereof. The views and opinions of authors expressed herein do not necessarily state or reflect those of the U.S. Government or any agency thereof. 
INL/EXT-15-36365

Revision 0

\title{
AGR-1 Compact 1-3-1 Post-Irradiation Examination Results
}

\author{
Paul A. Demkowicz \\ Scott A. Ploger \\ Philip L. Winston \\ Jason M. Harp
}

December 2016

\begin{abstract}
Idaho National Laboratory
INL ART Program

Idaho Falls, Idaho 83415
\end{abstract}

http://www.inl.gov

Prepared for the

U.S. Department of Energy

Office of Nuclear Energy

Under DOE Idaho Operations Office

Contract DE-AC07-05ID14517 

INL ART Program

\title{
AGR-1 Compact 1-3-1 Post-Irradiation Examination Results
}

\author{
INL/EXT-15-36365 \\ Revision 0
}

December 2016

Reviewed by:
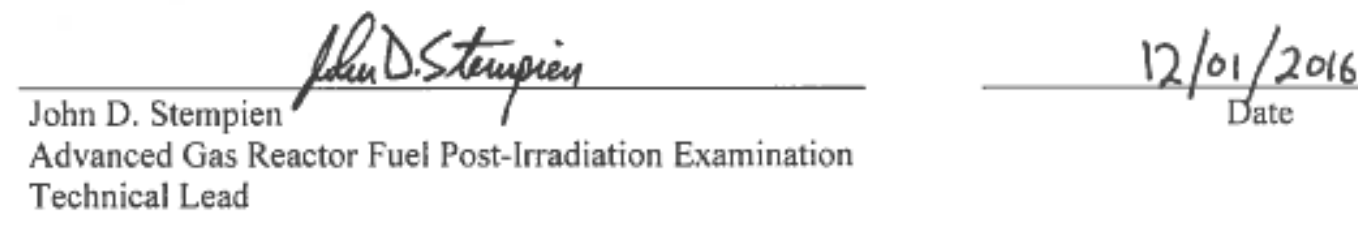

Approved by:

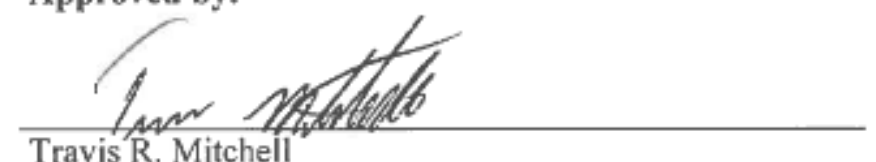

Travis R. Mitchell

ART INL Project Manager

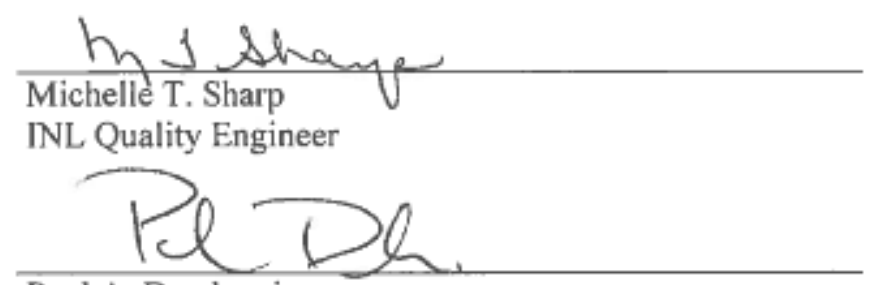

Paul A. Demkowicz

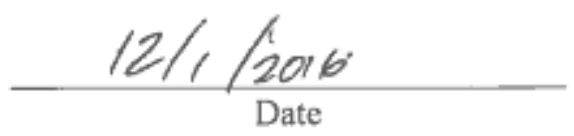

Advanced Gas Reactor Fuel Program Lead

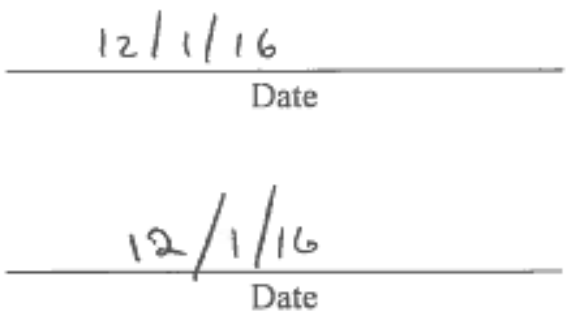





\section{SUMMARY}

Destructive post-irradiation examination was performed on Advanced Gas Reactor (AGR)-1 fuel Compact 1-3-1, which was irradiated to a final compactaverage burnup of $16.14 \%$ fissions per initial metal atom (FIMA) and a timeaveraged, volume-averaged temperature of $1092^{\circ} \mathrm{C}$. Analysis of this compact focused on characterizing the extent of fission product release from the particles, examining the particles to determine the condition of the kernels and coating layers, and experimentally verifying the fuel burnup. Work included deconsolidation of the compact and leach-burn-leach analysis, visual inspection and gamma counting of individual particles, measurement of isotopic inventories in the fuel by mass spectrometry and subsequent burnup calculations, metallurgical preparation of selected particles, and examination of particle cross sections with optical microscopy.

Deconsolidation-leach-burn-leach (DLBL) analysis revealed no particles with failed tristructural isotropic (TRISO) or failed silicon carbide ( $\mathrm{SiC}$ ) layers (as indicated by very low uranium inventory in all leach solutions). DLBL analysis data also provided information on the inventory of fission products retained in the compact outside the $\mathrm{SiC}$ layers. The total fraction of the predicted Ag- $110 \mathrm{~m}$ inventory in the DLBL solutions was $3.56 \times 10^{-3}$, indicating significant release from the particles and retention in the compact matrix or outer pyrolytic carbon (OPyC) layers during irradiation. The ratio of measured-to-calculated Ag- $110 \mathrm{~m}$ activity in a subset of 60 particles ranged from 0.46 to less than 0.06 , indicating that all particles exhibited significant silver release, with many experiencing nearly $100 \%$ release.

DLBL analysis data also indicated appreciable release of palladium through intact coatings and subsequent retention in the compact matrix. The fraction of the Pd-105 inventory in the compact outside the SiC layers was approximately $8 \times 10^{-3}$, which is similar to the fraction determined for the Ag- $110 \mathrm{~m}$ inventory. Cesium inventory was very low. The fraction of the compact inventory in the DLBL solutions was $5.36 \times 10^{-6}$ and $6.03 \times 10^{-6}$ for Cs-134 and Cs-137, respectively. Based on the inventory measured in the compact from DLBL analysis, the rare earth metals and strontium exhibited modest but measureable release through the intact TRISO coatings, with the amount varying by the specific element. Values determined for radioactive isotopes were $1.5 \times 10^{-4}$ for Ce-144, $6.3 \times 10^{-3}$ for Eu-154, $7.9 \times 10^{-3}$ for Eu-155, and 2.6 $\times 10^{-3}$ for Sr-90. Values for lanthanum, neodymium, and samarium isotopes determined from mass spectrometry were in a similar range.

Selected particles were crushed to expose the kernels, which were oxidized and leached in acid. Mass spectrometry was performed on the solutions to determine the inventory of actinides and fission products. The burnup determined using mass spectrometry (16.3\% FIMA) was in good agreement with the predicted burnup and values determined previously from gamma spectrometry measurements. Several methods for oxidizing and leaching the kernels were explored in this study to determine the most effective method for recovering uranium and plutonium. It was determined that small additions of hydrofluoric acid to the nitric acid leach solution resulted in better actinide recovery.

Morphology of the kernel, buffer layers, and inner pyrolytic carbon (IPyC) layers in several deconsolidated Compact 1-3-1 particles examined was generally 
similar to that observed during ceramography of AGR-1 compact cross sections. Specifically, many particles displayed a continuous gap between the buffer and IPyC layers in the plane of polish that was driven by buffer densification and followed by buffer-IPyC debonding during irradiation. Partial debonding occurred in many other particles along the observable buffer-IPyC interface in the cross sections. Approximately one-fourth of the particles exhibited fractures in the buffer layer (the first two Variant 3 particles with fractures through the entire IPyC layer were discovered in the Compact 1-3-1 particle cross sections). Variant 3 IPyC thus evidently had approximately the same fracture resistance as Baseline and Variant 2 IPyC layers (all significantly better than the lower-density Variant 1 IPyC).

Approximately 150 particles were examined at multiple polish planes to explore the morphology of the kernels and coating layers in three dimensions. Mounting the particle ensembles in translucent epoxy and then backlighting them enabled sharp silhouette images of the $\mathrm{SiC}$ exteriors to be obtained. This aided in determining the distance of the polish plane from the true particle midplane.

Examining particles at multiple cross-sectional levels was more likely to reveal small areas of residual buffer-IPyC bonding compared to examining a single polish plane. Examining more levels also increased the likelihood of detecting buffer fractures.

A total of 56 particles with intact buffers were measured in cross section at four levels. After fitting the radii to spheres, it was determined that the average kernel volume expanded during irradiation by approximately $26 \%$ and buffer volumes decreased on average by approximately $39 \%$. In the process, an average gap thickness of $26 \mu \mathrm{m}$ was opened between the buffer exterior and IPyC interior. 


\section{ACKNOWLEDGEMENTS}

The valuable contributions of numerous Idaho National Laboratory staff members in performing experimental work and data analysis are acknowledged. This includes Martin Kearns (performing deconsolidation-leach-burn-leach analysis, particle inspection, particle gamma counting, and mount loading); Jeffrey Berg (providing technical direction and performing data analysis of deconsolidation-leach-burn-leach results); Dr. Jeffrey Giglio and Daniel Cummings (performing inductively-coupled plasma-mass spectroscopy experiments and data analysis); Brian Storms (performing particle gamma counting and Sr-90 analysis); and Brian Frickey and Cad Christensen (preparing ceramographic mounts). 


\section{CONTENTS}

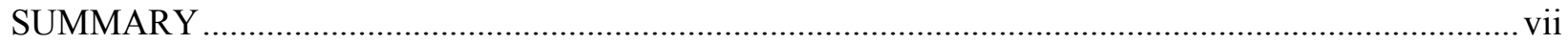

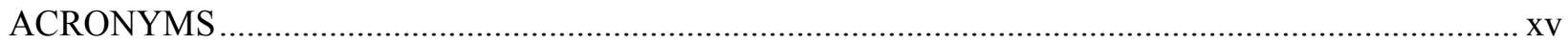

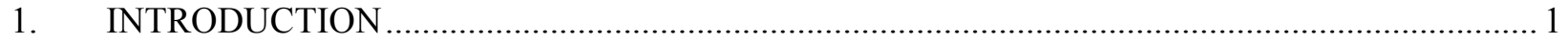

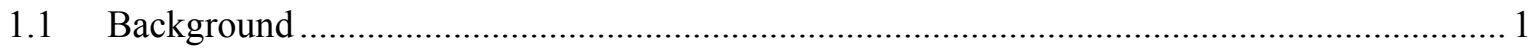

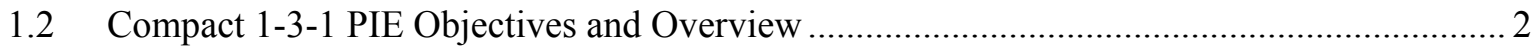

2. DECONSOLIDATION-LEACH-BURN-LEACH ANALYSIS …............................................ 3

3. PARTICLE VISUAL INSPECTION AND GAMMA COUNTING ............................................ 9

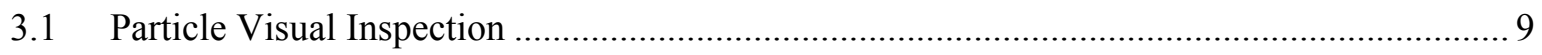

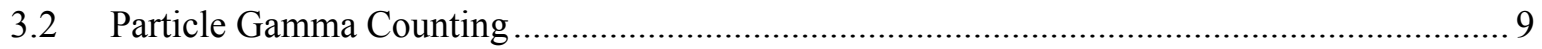

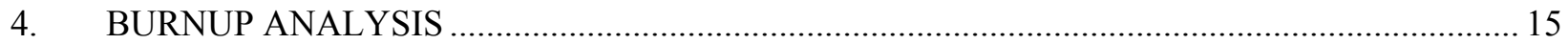

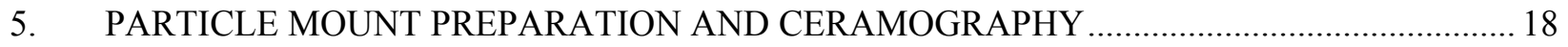

5.1 Single-Particle Mounts 25V Through 30V …................................................................... 18

5.1.1 Particle AGR1-131-111 (Mount 25V) …............................................................... 20

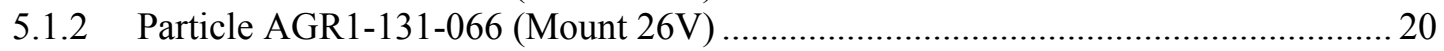

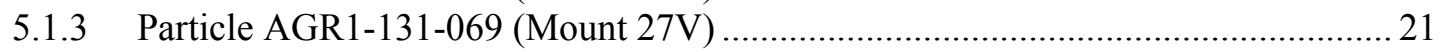

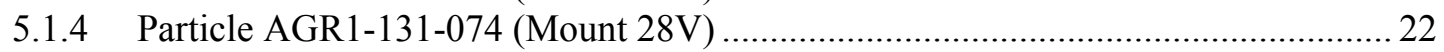

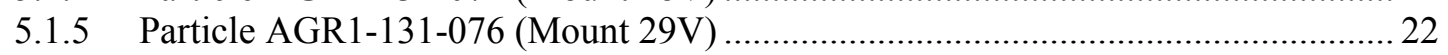

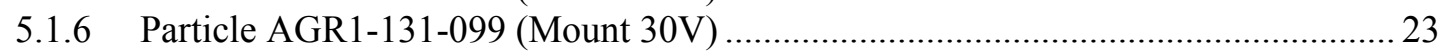

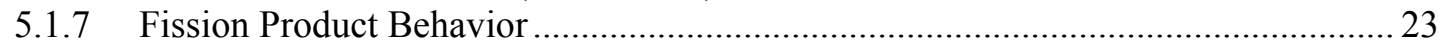

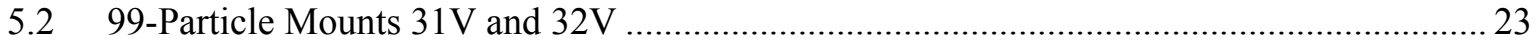

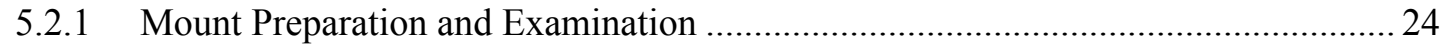

5.2.2 Morphology Results from Ceramography on Mounts 31V and 32V ….................... 27

5.2.3 Radial Measurements on Mount 31V Images ........................................................... 30

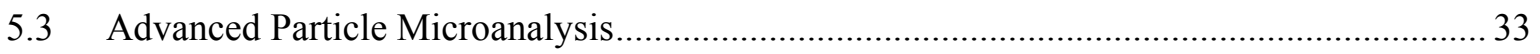

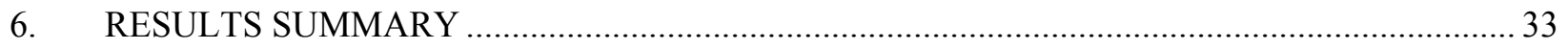

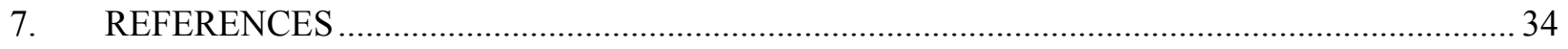

Appendix A Deconsolidation-leach-burn-leach Procedure ….......................................................... 37

Appendix B Particle Visual Inspection and Irradiated Microsphere Gamma Analysis ............................ 41

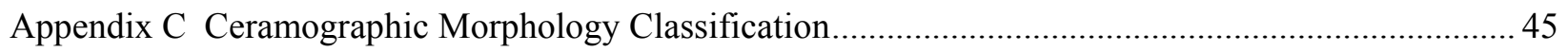




\section{FIGURES}

Figure 1. Photograph (left) and x-radiograph (right) of an unirradiated AGR-1 fuel compact. UCO kernels and non-fueled end caps are clearly visible in the x-radiograph. 1

Figure 2. Post-irradiation examination flowchart for Compact 1-3-1. 3

Figure 3. Cs-137/Ce-144 and Cs-134/Ce-144 decay-corrected activity ratios, normalized to the mean and plotted in the order they were gamma counted. Note the low Cs-137/Ce-144 values for the first eight particles, suspected to have been influenced by changes in Cs137 levels in the hot cell.

Figure 4. Measured-to-calculated activity ratios for 60 gamma-counted particles from AGR-1 Compact 1-3-1. Red data represent particles for which no Ag-110m was detected; the minimum detectable activity was therefore used to calculate the $\mathrm{M} / \mathrm{C}$ ratio. The location of specific particles chosen for mounting and microanalysis is labeled on distribution.

Figure 5. Average reported minimum detectable activity for particles with Ag-110m activity below detection limit as function of counting time. Error bars are 1 sigma.

Figure 6. Measured-to-calculated activity ratios for 32 particles from AGR-1 Compact 1-3-1 gamma counted for 14 or 72 hours. Red data represent particles for which no Ag-110m was detected; the minimum detectable activity was therefore used to calculate the $\mathrm{M} / \mathrm{C}$ ratio.

Figure 7. Cross-sectional diagram through center of a Compact 1-3-1 single-particle mount.

Figure 8. Type Ai morphology in particle AGR1-131-111 (left) and complex fracture pattern near its kernel-buffer interface (right).

Figure 9. Aspherical Type ABi particle AGR1-131-066 (left) and gap between kernel and residual uranium carbide skin (right).

Figure 10. Type Ai morphology in particle AGR1-131-069. 21

Figure 11. Buffer tearing and kernel porosity in Type ABi particle AGR1-131-074. .22

Figure 12. Thick low porosity periphery in kernel of Type ABi particle AGR1-131-076. .22

Figure 13. Thick low porosity kernel periphery and IPyC crack in Type Ai particle AGR1-131-099.

Figure 14. Cross-section diagram showing the design and particle loading arrangement in Mounts $31 \mathrm{~V}$ and $32 \mathrm{~V}$. 24

Figure 15. Montage of the first polished level on Mount 31V. .25

Figure 16. Images of AGR1-131-031 at all four levels examined along with approximate positions of these cross sections within a depth diagram for this particle. .26

Figure 17. Montage of the first polished level on Mount 32V. .27

Figure 18. Multi-level classification results for particles in Mounts $31 \mathrm{~V}$ and $32 \mathrm{~V}$. .27

Figure 19. IPyC fractures in two Type ABf particles in Mount $31 \mathrm{~V}$. .28

Figure 20. Frequency of IPyC cracks by particle type for six cross-sectioned AGR-1 compacts and deconsolidated particles from Compacts 4-1-1, 5-3-1, and 1-3-1. .28 
Figure 21. Regions of little or no porosity inside two particles from Mount 31V with fractured buffers

Figure 22. Isolated examples of kernels with low porosity peripheries in Compact 6-3-3 cross sections.

Figure 23. Output with radial results from the silhouette and four polished layers in particle AGR1-131-098. 30

Figure 24. Buffer separation across the buffer-IPyC gap in Level 4 of particle AGR1-131-041 in Mount 31V.

Figure 25. Distribution of irradiated kernel volumes from 56 particles cross sectioned at four levels. 32

Figure 26. Irradiated buffer volumes from 56 particles cross sectioned at four levels. ............................ 32

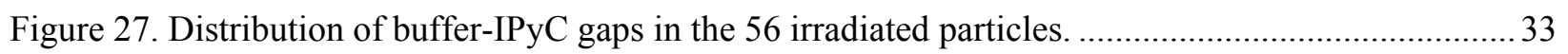

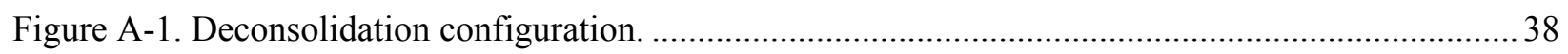

Figure A-2. Framework with deconsolidation tube/vial (left) and two Soxhlet extractor stations............. 39

Figure B-1. Cutaway view of camera optical orientation without shielding. ......................................... 41

Figure B-2. Assembled isometric view of macroscope stages and shielding. ........................................ 42

Figure B-3. Post-deconsolidation particle viewed on end of vacuum tweezer needle.............................. 43

Figure B-4. Materials and Fuels Complex Analytical Laboratory Hot Cell 4 spectrometer

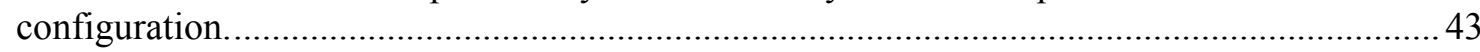

Figure C-1. Particle morphologies observed in AGR-1 fuel particle cross sections, where "i" denotes intact buffer and "f" denotes fractured buffer (Ploger et al. 2012)...

\section{TABLES}

Table 1. Compact ID and irradiation conditions for AGR-1 Compact 1-3-1. 2

Table 2. Predicted inventory of isotopes in AGR-1 Compact 1-3-1 based on physics calculations (Sterbentz 2013).

Table 3. Fission products in deconsolidation and leach solutions from Compact 1-3-1 expressed as decay-corrected activity $(\mathrm{Bq})$ and compact fraction (based on calculated inventories [Sterbentz 2013]).

Table 4. Uranium and plutonium inventory in deconsolidation and leach solutions from Compact 1-3-1 expressed as total mass $(\mu \mathrm{g})$ and compact fraction (based on calculated inventories [Sterbentz 2013]).

Table 5. Inventory of selected fission products determined by inductively-coupled plasma mass spectroscopy analysis of Compact 1-3-1 deconsolidation-leach-burn-leach solutions expressed as total mass $(\mu \mathrm{g})$ and compact fraction (based on calculated inventories [Sterbentz 2013]).

Table 6. Decay-corrected activity $(\mathrm{Bq})$ for isotopes measured by gamma counting of particles from irradiated Compact 1-3-1.

Table 7. Average measured-to-calculated activity ratios for 60 gamma-counted particles. 12 
Table 8. Description of sample processing steps used for each set of three particle batches (identified by Analytical Laboratory log number).

Table 9. Mass spectrometry burnup data for Compact 1-3-1 compared to other techniques in $\%$ FIMA. 16

Table 10. Comparison of measured actinide content to simulation for Compact 1-3-1. .17

Table 11. Compact 1-3-1 particle mounts. 18 


\section{ACRONYMS}

AGR Advanced Gas Reactor

AL Analytical Laboratory

ATR Advanced Test Reactor

$\mathrm{C} / \mathrm{E} \quad$ calculated-to-experimental

DLBL deconsolidation-leach-burn-leach

EML Electron Microscopy Laboratory

EOI end of irradiation

FIMA fissions per initial metal atom

HF hydrofluoric acid

HFEF Hot Fuel Examination Facility

ICP-MS inductively-coupled plasma mass spectroscopy

INL Idaho National Laboratory

IPyC inner pyrolytic carbon

$\mathrm{M} / \mathrm{C} \quad$ measured-to-calculated

MFC Materials and Fuel Complex

N/A not applicable

OPyC outer pyrolytic carbon

PIE post-irradiation examination

$\mathrm{SiC} \quad$ silicon carbide

TRISO tristructural isotropic

UCO Uranium oxide, uranium carbide fuel 


\section{AGR-1 Compact 1-3-1 Post-Irradiation Examination Results}

\section{INTRODUCTION}

\subsection{Background}

The Advanced Gas Reactor (AGR) Fuel Development and Qualification Program was established to perform the requisite research and development on tristructural isotropic (TRISO) coated particle fuel to support deployment of a high-temperature gas-cooled reactor. The work continues as part of the Advanced Reactor Technologies TRISO Fuel Program. The overarching program goal is to provide a baseline fuel qualification data set to support licensing and operation of a high-temperature gas-cooled reactor. To achieve this goal, the program includes the elements of fuel fabrication, irradiation, postirradiation examination (PIE) and safety testing, fuel performance modeling, and fission product transport (INL 2015).

A series of fuel irradiation experiments is being planned and conducted in the Advanced Test Reactor (ATR) at Idaho National Laboratory (INL). These experiments will provide data on fuel performance under irradiation, support fuel process development, qualify the fuel for normal operating conditions, provide irradiated fuel for safety testing, and support development of fuel performance and fission product transport models. The first of these irradiation tests, designated AGR-1, began in ATR in December 2006 and ended in November 2009. The AGR-1 experiment was conducted primarily to act as a shakedown test of the multicapsule test train design and provide early data on fuel performance for use in fuel fabrication process development. It also provided samples for post-irradiation safety testing, where fission product retention of the fuel at high temperatures will be experimentally measured. Capsule design and details of the AGR-1 experiment were presented previously (Grover et al. 2010; Maki 2009).

The AGR-1 uranium oxide, uranium carbide (UCO) fuel kernels were fabricated by Babcock \& Wilcox (now BWX Technologies) Nuclear Operations Group (Barnes et al. 2008). Kernels were nominally $350 \mu \mathrm{m}$ in diameter and U-235 enrichment was $19.74 \%$. The TRISO coatings were applied at Oak Ridge National Laboratory. Nominal coating thicknesses were $100 \mu \mathrm{m}$ for the porous carbon buffer, $40 \mu \mathrm{m}$ for the inner pyrolytic carbon (IPyC) layer, $35 \mu \mathrm{m}$ for the silicon carbide ( $\mathrm{SiC}$ ) layer, and $40 \mu \mathrm{m}$ for the outer pyrolytic carbon (OPyC) layer. The coated particles were formed into right cylindrical compacts at Oak Ridge National
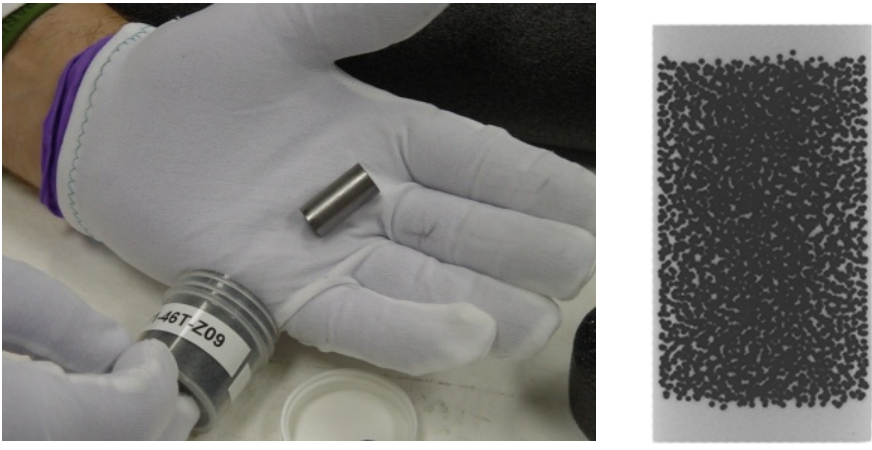

Figure 1. Photograph (left) and x-radiograph (right) of an unirradiated AGR-1 fuel compact. UCO kernels and non-fueled end caps are clearly visible in the $\mathrm{x}$-radiograph. Laboratory that were nominally $12.4 \mathrm{~mm}$ in diameter and $25.1 \mathrm{~mm}$ in length. The fuel compacts have about $1.5-\mathrm{mm}$-thick fuel-free end caps at the top and bottom as shown in Figure 1. A baseline fuel type and three fuel variants were included in the AGR-1 irradiation, with each variant fabricated by varying one step of the coating process to produce slightly different IPyC or SiC coating properties (Hunn et al. 2008). A summary of particle and compact properties is presented in the AGR-1 Test Plan (Maki 2009). One key goal of the AGR-1 experiment is to identify any fuel performance differences between the fuel types, either during irradiation or postirradiation high-temperature safety tests, to support optimization of the fuel fabrication process and eventual selection of a reference fuel for qualification. 
A total of 72 compacts were irradiated in the AGR-1 experiment. The experiment completed 620 effective full-power days in ATR and achieved a peak calculated compact-average burnup of 19.6\% fissions per initial metal atom (FIMA) with zero particle failures observed, based on the measured fission gas release-to-birth rate ratios (Grover et al. 2010). At completion of irradiation, the test train was shipped to the Materials and Fuels Complex (MFC) at INL to initiate PIE and safety testing. The primary objectives of AGR-1 PIE and safety testing are to:

1. Assess the overall performance of the test train and components and provide data to verify the test train thermal analyses

2. Evalute the fission product retention of the fuel during irradiation and high-temperature postirradiation safety tests

3. Characterize the fuel compacts and individual particles to assess the condition of the matrix material, kernels, and coatings and to document any concerns.

Details of activities planned as part of PIE and safety testing, including planned activities for specific compacts, are described in the AGR-1 PIE Plan (Demkowicz 2010).

Upon receipt of the AGR-1 test train at the MFC Hot Fuel and Examination Facility (HFEF), the test train was unpackaged, visually inspected, and examined using gamma spectrometry. The test train was then sectioned into individual capsules that were opened to remove the fuel compacts and other internal capsule components for PIE. The fuel compacts, graphite fuel holders, and metal capsule shells were measured to determine the degree of dimensional change that occurred during the irradiation. Results of test train inspection and nondestructive examination, disassembly, and dimensional measurements are presented in the report titled, AGR-1 Irradiated Test Train Preliminary Inspection and Disassembly First Look (Demkowicz et al. 2011). All irradiated AGR-1 fuel compacts were also gamma scanned in axial increments to determine the inventory of fission products and experimentally measure the burnup prior to proceeding with destructive PIE (Harp 2014, Harp et al. 2014).

\subsection{Compact 1-3-1 PIE Objectives and Overview}

Compact 1-3-1 is composed of Variant 3 fuel particles and was located in Level 3, Stack 1 of Capsule 1 in the AGR-1 experiment (Maki 2009). Details of fuel fabrication and properties are presented in the AGR-1 Variant 3 particle and compact data packages (Hunn and Lowden 2006; Hunn et al. 2006). Some of the irradiation conditions for Compact 1-3-1 are listed in Table 1.

Table 1. Compact ID and irradiation conditions for AGR-1 Compact 1-3-1.

\begin{tabular}{|c|c|c|c|c|c|}
\hline $\begin{array}{c}\text { Compact } \\
\text { Identification }^{\mathrm{a}}\end{array}$ & $\begin{array}{c}\text { Fabrication } \\
\text { Identification }\end{array}$ & Fuel Type & $\begin{array}{c}\text { Burnup } \\
\left(\% \text { FIMA }^{\text {b }}\right)\end{array}$ & $\begin{array}{c}\text { Fast Fluence } \\
\times 10^{25} \\
\left(\mathbf{n} / \mathbf{m}^{2}\right)^{\mathbf{b}} \\
\end{array}$ & $\begin{array}{c}\text { Irradiation } \\
\text { Temperature } \\
\left({ }^{\circ} \mathrm{C}\right)^{\mathbf{c}}\end{array}$ \\
\hline AGR-1 1-3-1 & LEU01-48T-Z02 & Variant 3 & 16.14 & 3.22 & 1092 \\
\hline
\end{tabular}

Specific PIE objectives for Compact 1-3-1 are as follows:

1. Perform deconsolidation-leach-burn-leach (DLBL) analysis to (a) identify the number of particles with failed $\mathrm{SiC}$ layers that may be present in the compact, (b) determine the inventory of fission products outside the $\mathrm{SiC}$ layers, and (c) provide particles for subsequent examination.

2. Perform gamma-ray spectrometry on a subset of particles to quantify the inventory of major fission products to examine variations in fission product retention. 
3. Examine kernel and coating microstructures of selected particles to better understand fuel irradiation behavior and mechanisms of fission product diffusion and release. Examination methods include optical microscopy, electron microscopy (e.g., scanning electron microscopy and transmission electron microscopy), and elemental analysis (e.g., energy dispersive spectroscopy and wavelength dispersive spectroscopy).

4. Perform burnup analysis on a subset of particles using mass spectrometry and compare values to those calculated based on physics simulations of the AGR-1 irradiation.

A flow chart of PIE that has been completed on Compact 1-3-1 is provided in Figure 2.

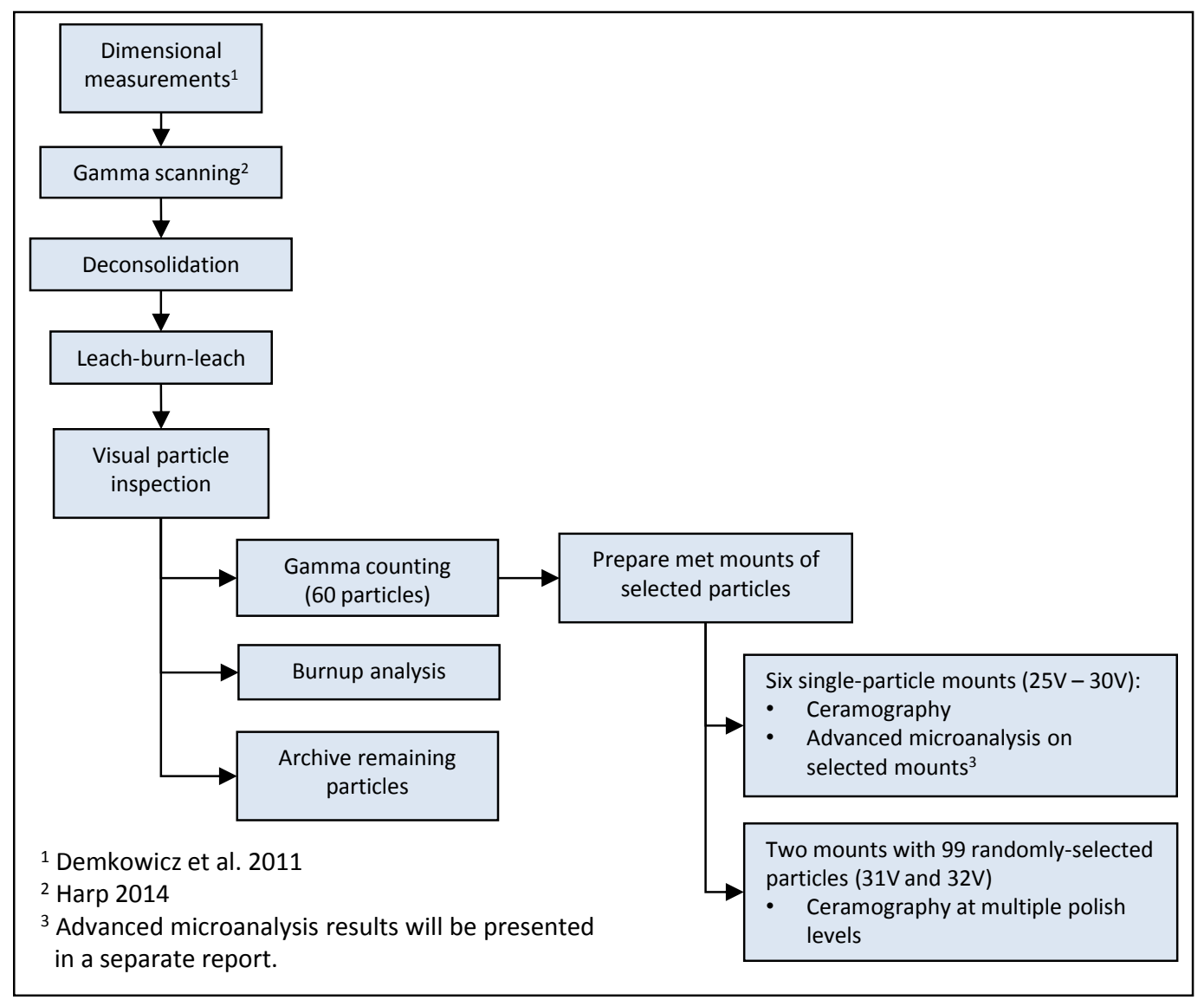

Figure 2. Post-irradiation examination flowchart for Compact 1-3-1.

\section{DECONSOLIDATION-LEACH-BURN-LEACH ANALYSIS}

The general process for compact DLBL analysis is given in Appendix A. Compact 1-3-1 was received in the MFC Analytical Laboratory (AL) in MFC-752 on March 27, 2012. Receipt weight was $5.5702 \mathrm{~g}$. The DLBL analysis process was performed in Hot Cell 5 in the AL A-wing. Deconsolidation was performed on April 3, 2012. Total deconsolidation time was 135 minutes. During deconsolidation, the power supply was in constant voltage mode set at $10 \mathrm{~V}$. Deconsolidation average power input was $7.75 \mathrm{~W}$. Particles began to drop through the perforated support grid and continued to do so rather slowly for the next 25 minutes, whereupon the solution became too dark to observe particles falling. Strong turbidity continued until an elapsed time of 75 minutes, at which point the process was stopped to observe the degree of compact deconsolidation. Approximately $20 \%$ of the compact remained, so the process was resumed for another 60 minutes. 
The first two 24-hour pre-burn leaches were performed on April 4 and 9, 2012. The period for the siphon cycle during the first pre-burn leach was nominally 9 minutes. The thimble drained approximately $40 \%$ (i.e., $60 \%$ remained in the thimble). The siphon cycle time for the second pre-burn leach was 10 minutes and approximately $70 \%$ remained in the thimble during each cycle. Both leach steps were performed with 24-hour durations.

Following the second pre-burn leach step, the thimble was transferred to the Vulcan muffle furnace. The furnace operating temperature of $750^{\circ} \mathrm{C}$ was reached on April 10, 2012. The oxidation step was completed on April 13, 2012. The furnace external ventilation fan was adjusted to yield a flow rate that caused the pinwheel mounted above the exhaust chimney to barely rotate.

The two post-burn leaches were started on April 16, 2012 and April 17, 2012. Both leach steps had 24-hour durations. Siphon cycle time for the first post-burn leach was 22 minutes. Siphon cycle time for the second post-burn leach was consistent at 20 minutes. The approximately $20 \%$ of the solution remained in the thimble during first cycle of the first leach, dropping to $5 \%$ after the first cycle. During the second leach, approximately $5 \%$ remained in the thimble for each cycle.

No grab samples of the particles were taken at intermediate steps. The net weight of the resulting post-burn-leach particles was $2.4193 \mathrm{~g}$.

The deconsolidation solution and pre-burn and post-burn leach solutions were analyzed using gamma ray spectrometry and mass spectrometry. This was accomplished by taking $10-\mathrm{mL}$ aliquots of all deconsolidation and leach solutions from the nominal $150-$ to $200-\mathrm{mL}$ leach volumes. The diluted aliquots were transferred to the B-wing counting rooms of the AL to facilitate gamma spectrometry with less background interference than would be observed in the A-wing Hot Cell 4 spectrometer. In the B-wing, the solutions were counted on Detector B. Detector B, located in Laboratory B-30, is a $+3000-\mathrm{V}$ high-purity germanium coaxial detector connected to a Canberra digital multi-channel analyzer that uses APEX peak analysis software. The detector resides within a steel vault that has walls approximately $25 \mathrm{~cm}$ thick to provide shielding. This detector is calibrated for use with a maximum sample-to-detector distance of $1 \mathrm{~m}$. Samples are placed in a jig to ensure repeatable geometry between calibration and various samples. A multi-line gamma source ranging from 59.4 to $1,836 \mathrm{keV}$ was used to calibrate the detector.

To measure the Sr-90 content of the solutions, strontium was separated onto a solid crown-ether ion exchange medium, then eluted from the media and precipitated as a carbonate. A Tennelec gas-flow proportional unit was used to determine the amount of beta activity per mass of precipitate to determine sample Sr-90 content. Mass spectrometric analysis of the DLBL solutions was performed using a VG plasma quad inductively-coupled plasma mass spectrometer (ICP-MS).

The measured fission product radioisotope activities were decay corrected to November 7, 2009, 12:00 GMT, the end of irradiation (EOI) for AGR-1 plus 1 day. Decay corrections discussed in this report were calculated using the equation:

$A=A_{o} e^{-\lambda t}$

where $A$ is the activity at time $t, A_{o}$ is the activity at $t=0$, and $\lambda$ is the decay constant $\left(\lambda=\ln (2) / t_{1 / 2}\right.$, and $t_{1 / 2}$ is the half-life). Isotope half-life data were taken from the ENDF/B-VII.1 library (Chadwick et al. 2011). Values were then compared to the predicted compact inventory at EOI plus 1 day based on ECAR-958, Revision 2 (Sterbentz 2013), to calculate the fraction of the compact inventory. Predicted inventory of key isotopes presented in this report for Compact 1-3-1 are given in Table 2. 
Table 2. Predicted inventory of isotopes in AGR-1 Compact 1-3-1 based on physics calculations (Sterbentz 2013).

\begin{tabular}{|c|c|c|c|}
\hline Isotope & $\begin{array}{l}\text { Inventory (Bq) at } \\
\text { EOI Plus } 1 \text { Day }\end{array}$ & Isotope & $\begin{array}{l}\text { Inventory (g) at } \\
\text { EOI Plus } 1 \text { Year }\end{array}$ \\
\hline Ag-110m & $1.58 \mathrm{E}+08$ & Sr- 88 & $1.84 \mathrm{E}-03$ \\
\hline Ce-144 & $2.06 \mathrm{E}+11$ & Pd-105 & $9.57 \mathrm{E}-04$ \\
\hline Cs- 134 & $1.82 \mathrm{E}+10$ & Ag-109 & $1.64 \mathrm{E}-04$ \\
\hline Cs-137 & $1.67 \mathrm{E}+10$ & $\mathrm{Cd}-111$ & $5.31 \mathrm{E}-05$ \\
\hline Eu-154 & $6.02 \mathrm{E}+08$ & Cd-112 & $2.85 \mathrm{E}-05$ \\
\hline Eu-155 & $4.37 \mathrm{E}+08$ & $\mathrm{Cd}-114$ & $4.03 \mathrm{E}-05$ \\
\hline Ru-106 & $4.77 \mathrm{E}+10$ & La-139 & $5.56 \mathrm{E}-03$ \\
\hline $\mathrm{Sb}-125$ & $1.20 \mathrm{E}+09$ & Ce-140 & $5.50 \mathrm{E}-03$ \\
\hline \multirow[t]{9}{*}{$\mathrm{Sr}-90$} & $1.45 \mathrm{E}+10$ & Nd-143 & $3.27 \mathrm{E}-03$ \\
\hline & & Nd-145 & $3.10 \mathrm{E}-03$ \\
\hline & & Sm-152 & $5.80 \mathrm{E}-04$ \\
\hline & & $\mathrm{U}-234$ & $1.82 \mathrm{E}-03$ \\
\hline & & $\mathrm{U}-235$ & $3.28 \mathrm{E}-02$ \\
\hline & & U-236 & $2.34 \mathrm{E}-02$ \\
\hline & & $\mathrm{U}-238$ & $6.97 \mathrm{E}-01$ \\
\hline & & $\mathrm{Pu}-239$ & $8.06 \mathrm{E}-03$ \\
\hline & & $\mathrm{Pu}-240$ & $4.16 \mathrm{E}-03$ \\
\hline
\end{tabular}

The inventory of selected fission products in each of the five DLBL solutions determined by gamma counting is given in Table 3, both as decay-corrected activity and equivalent Compact 1-3-1 fraction. The inventory of uranium and plutonium isotopes and fission products determined by ICP-MS is given in Table 4 and Table 5 in absolute measured mass and equivalent compact fraction. No decay correction has been applied to the isotope masses in Table 4 and Table 5 due to the negligible impact on values; however, the values are compared with the predicted compact inventories 1 year after EOI (November 6 , 2010, 12:00 GMT) to account for minor increases in predicted inventory due to decay of parent isotopes. Note that in Table 3, Table 4, and Table 5, a compact fraction of $2.42 \times 10^{-4}$ is equivalent to a singleparticle inventory based on 4,126 particles per compact (Hunn et al. 2006). In cases where the activity or mass was below the detection limit for the method, the reported detection limit was used to calculate the values in Table 3, Table 4, and Table 5 and these values were included in the process totals. If the entries based on detection limits accounted for greater than $50 \%$ of the total, then the total was listed as a threshold value (preceded by “<”). 
Table 3. Fission products in deconsolidation and leach solutions from Compact 1-3-1 expressed as decay-corrected activity (Bq) and compact fraction (based on calculated inventories [Sterbentz 2013]).

\begin{tabular}{|c|c|c|c|c|c|c|c|c|c|}
\hline & \multicolumn{9}{|c|}{ Activity $(\mathrm{Bq})^{\mathrm{a}}$} \\
\hline & Ag-110m & Ce-144 & Cs-134 & Cs-137 & Eu-154 & Eu-155 & Ru-106 & Sb-125 & Sr-90 \\
\hline Deconsolidation & $1.54 \mathrm{E}+5$ & $<1 \mathrm{E}+6$ & $5.89 \mathrm{E}+3$ & $7.12 \mathrm{E}+3$ & $1.07 \mathrm{E}+6$ & $1.00 \mathrm{E}+6$ & $<6 \mathrm{E}+5$ & $<4 \mathrm{E}+4$ & $1.53 \mathrm{E}+7$ \\
\hline Pre-burn leach 1 & $<8 \mathrm{E}+4$ & $<5 \mathrm{E}+5$ & $<1 \mathrm{E}+4$ & $<4 \mathrm{E}+3$ & $2.15 \mathrm{E}+5$ & $1.92 \mathrm{E}+5$ & $<3 \mathrm{E}+5$ & $<3 \mathrm{E}+4$ & $2.71 \mathrm{E}+6$ \\
\hline Pre-burn leach 2 & $<5 \mathrm{E}+4$ & $<2 \mathrm{E}+5$ & $<6 \mathrm{E}+3$ & $2.61 \mathrm{E}+3$ & $3.43 \mathrm{E}+4$ & $3.50 \mathrm{E}+4$ & $<2 \mathrm{E}+5$ & $<2 \mathrm{E}+4$ & $1.59 \mathrm{E}+5$ \\
\hline Post-burn leach 1 & $2.62 \mathrm{E}+5$ & $2.83 \mathrm{E}+7$ & $7.26 \mathrm{E}+4$ & $8.27 \mathrm{E}+4$ & $2.46 \mathrm{E}+6$ & $2.20 \mathrm{E}+6$ & $<9 \mathrm{E}+5$ & $4.76 \mathrm{E}+4$ & $2.01 \mathrm{E}+7$ \\
\hline \multirow[t]{3}{*}{ Post-burn leach 2} & $<4 \mathrm{E}+4$ & $9.30 \mathrm{E}+4$ & $3.45 \mathrm{E}+3$ & $4.35 \mathrm{E}+3$ & $4.10 \mathrm{E}+3$ & $<6 \mathrm{E}+3$ & $<2 \mathrm{E}+5$ & $<8 \mathrm{E}+3$ & $2.47 \mathrm{E}+4$ \\
\hline & \multicolumn{9}{|c|}{ Compact Fraction $^{\mathrm{b}}$} \\
\hline & Ag-110m & Ce-144 & Cs-134 & Cs-137 & Eu-154 & Eu-155 & Ru-106 & Sb-125 & Sr-90 \\
\hline Deconsolidation & $9.73 \mathrm{E}-4$ & $<5 \mathrm{E}-6$ & $3.23 \mathrm{E}-7$ & $4.26 \mathrm{E}-7$ & $1.77 \mathrm{E}-3$ & $2.29 \mathrm{E}-3$ & $<2 \mathrm{E}-5$ & $<3 \mathrm{E}-5$ & $1.05 \mathrm{E}-3$ \\
\hline Pre-burn leach 1 & $<5 \mathrm{E}-4$ & $<3 \mathrm{E}-6$ & $<6 \mathrm{E}-7$ & $<3 \mathrm{E}-7$ & $3.57 \mathrm{E}-4$ & $4.40 \mathrm{E}-4$ & $<6 \mathrm{E}-6$ & $<2 \mathrm{E}-5$ & $1.87 \mathrm{E}-4$ \\
\hline Pre-burn leach 2 & $<3 \mathrm{E}-4$ & $<1 \mathrm{E}-6$ & $<4 \mathrm{E}-7$ & $1.56 \mathrm{E}-7$ & $5.70 \mathrm{E}-5$ & $8.02 \mathrm{E}-5$ & $<4 \mathrm{E}-6$ & $<2 \mathrm{E}-5$ & $1.10 \mathrm{E}-5$ \\
\hline Post-burn leach 1 & $1.65 \mathrm{E}-3$ & $1.37 \mathrm{E}-4$ & $3.99 \mathrm{E}-6$ & $4.95 \mathrm{E}-6$ & $4.10 \mathrm{E}-3$ & $5.03 \mathrm{E}-3$ & $<2 \mathrm{E}-5$ & $3.96 \mathrm{E}-5$ & $1.39 \mathrm{E}-3$ \\
\hline Post-burn leach 2 & $<3 \mathrm{E}-4$ & $4.51 \mathrm{E}-7$ & $1.89 \mathrm{E}-7$ & $2.60 \mathrm{E}-7$ & $6.81 \mathrm{E}-6$ & $<2 \mathrm{E}-5$ & $<3 \mathrm{E}-6$ & $<7 \mathrm{E}-6$ & $1.70 \mathrm{E}-6$ \\
\hline Process totals & $3.56 \mathrm{E}-3$ & $1.45 \mathrm{E}-4$ & $5.36 \mathrm{E}-6$ & $6.03 \mathrm{E}-6$ & $6.29 \mathrm{E}-3$ & $7.85 \mathrm{E}-3$ & $<4 \mathrm{E}-5$ & $<2 \mathrm{E}-4$ & $2.64 \mathrm{E}-3$ \\
\hline Particle equivalent & $1.48 \mathrm{E}+1$ & $6.03 \mathrm{E}-1$ & $2.23 \mathrm{E}-2$ & $2.50 \mathrm{E}-2$ & $2.61 \mathrm{E}+1$ & $3.26 \mathrm{E}+1$ & $<2 \mathrm{E}-1$ & $<5 \mathrm{E}-1$ & $1.10 \mathrm{E}+1$ \\
\hline
\end{tabular}

Table 4. Uranium and plutonium inventory in deconsolidation and leach solutions from Compact 1-3-1 expressed as total mass $(\mu \mathrm{g})$ and compact fraction (based on calculated inventories [Sterbentz 2013]).

\begin{tabular}{|c|c|c|c|c|c|c|}
\hline & \multicolumn{6}{|c|}{$\operatorname{Mass}(\mu g)^{\mathrm{a}}$} \\
\hline & U-234 & U-235 & U-236 & U-238 & Pu-239 & Pu-240 \\
\hline Deconsolidation & $<2 \mathrm{E}-3$ & $1.30 \mathrm{E}-2$ & $1.60 \mathrm{E}-3$ & $2.11 \mathrm{E}-1$ & $5.00 \mathrm{E}-3$ & $<2 \mathrm{E}-3$ \\
\hline Pre-burn leach 1 & $<2 \mathrm{E}-3$ & $2.26 \mathrm{E}-2$ & $<3 \mathrm{E}-3$ & $2.92 \mathrm{E}-1$ & $9.14 \mathrm{E}-3$ & $<2 \mathrm{E}-3$ \\
\hline Pre-burn leach 2 & $<3 \mathrm{E}-3$ & $1.36 \mathrm{E}-2$ & $<9 \mathrm{E}-4$ & $1.23 \mathrm{E}-1$ & $6.35 \mathrm{E}-3$ & $<3 \mathrm{E}-3$ \\
\hline Post-burn leach 1 & $3.46 \mathrm{E}-2$ & $6.10 \mathrm{E}-1$ & $4.57 \mathrm{E}-1$ & $1.33 \mathrm{E}+1$ & $7.05 \mathrm{E}-1$ & $9.76 \mathrm{E}-1$ \\
\hline \multirow[t]{3}{*}{ Post-burn leach 2} & $<2 \mathrm{E}-3$ & $2.49 \mathrm{E}-2$ & $<2 \mathrm{E}-3$ & $2.64 \mathrm{E}-1$ & $1.32 \mathrm{E}-2$ & $4.47 \mathrm{E}-3$ \\
\hline & \multicolumn{6}{|c|}{ Compact Fraction $^{\mathrm{b}}$} \\
\hline & U-234 & U-235 & U-236 & $\mathrm{U}-238$ & Pu-239 & Pu-240 \\
\hline Deconsolidation & $<8 \mathrm{E}-7$ & $3.96 \mathrm{E}-7$ & $6.82 \mathrm{E}-8$ & $3.03 \mathrm{E}-7$ & $6.20 \mathrm{E}-7$ & $<4 \mathrm{E}-7$ \\
\hline Pre-burn leach 1 & $<2 \mathrm{E}-6$ & $6.89 \mathrm{E}-7$ & $<1 \mathrm{E}-7$ & $4.19 \mathrm{E}-7$ & $1.13 \mathrm{E}-6$ & $<5 \mathrm{E}-7$ \\
\hline Pre-burn leach 2 & $<2 \mathrm{E}-6$ & $4.15 \mathrm{E}-7$ & $<4 \mathrm{E}-8$ & $1.77 \mathrm{E}-7$ & $7.88 \mathrm{E}-7$ & $<6 \mathrm{E}-7$ \\
\hline Post-burn leach 1 & $1.90 \mathrm{E}-5$ & $1.86 \mathrm{E}-5$ & $1.95 \mathrm{E}-5$ & $1.91 \mathrm{E}-5$ & $8.75 \mathrm{E}-5$ & $2.34 \mathrm{E}-4$ \\
\hline Post-burn leach 2 & $<1 \mathrm{E}-6$ & $7.59 \mathrm{E}-7$ & $<8 \mathrm{E}-8$ & $3.79 \mathrm{E}-7$ & $1.64 \mathrm{E}-6$ & $1.07 \mathrm{E}-6$ \\
\hline Process totals & $2.30 \mathrm{E}-5$ & $2.09 \mathrm{E}-5$ & $1.98 \mathrm{E}-5$ & $2.04 \mathrm{E}-5$ & $9.17 \mathrm{E}-5$ & $2.37 \mathrm{E}-4$ \\
\hline Particle equivalent & $9.53 \mathrm{E}-2$ & $8.66 \mathrm{E}-2$ & $8.20 \mathrm{E}-2$ & $8.45 \mathrm{E}-2$ & $3.80 \mathrm{E}-1$ & $9.82 \mathrm{E}-1$ \\
\hline
\end{tabular}


Table 5. Inventory of selected fission products determined by inductively-coupled plasma mass spectroscopy analysis of Compact 1-3-1 deconsolidation-leach-burn-leach solutions expressed as total mass ( $\mu \mathrm{g})$ and compact fraction (based on calculated inventories [Sterbentz 2013]).

\begin{tabular}{|c|c|c|c|c|c|c|c|c|c|c|c|}
\hline & \multicolumn{11}{|c|}{$\operatorname{Mass}(\mu \mathrm{g})^{\mathrm{a}}$} \\
\hline & Sr-88 & Pd-105 & Ag-109 & Cd-111 & Cd-112 & Cd-114 & La-139 & Ce-140 & Nd-143 & Nd-145 & Sm-152 \\
\hline Deconsolidation & $3.33 \mathrm{E}+0$ & $<7 \mathrm{E}-3$ & $3.42 \mathrm{E}-1$ & $1.62 \mathrm{E}-1$ & $4.45 \mathrm{E}-1$ & $4.55 \mathrm{E}-1$ & $2.21 \mathrm{E}-1$ & $5.19 \mathrm{E}-1$ & $1.14 \mathrm{E}-2$ & $8.70 \mathrm{E}-3$ & $7.61 \mathrm{E}-2$ \\
\hline Pre-burn leach 1 & $6.30 \mathrm{E}-1$ & $<3 \mathrm{E}-2$ & $7.49 \mathrm{E}-2$ & $8.86 \mathrm{E}-2$ & $1.88 \mathrm{E}-1$ & $2.06 \mathrm{E}-1$ & $7.34 \mathrm{E}-2$ & $1.24 \mathrm{E}-1$ & $<4 \mathrm{E}-3$ & $<5 \mathrm{E}-3$ & $1.57 \mathrm{E}-2$ \\
\hline Pre-burn leach 2 & $8.72 \mathrm{E}-2$ & $1.48 \mathrm{E}-1$ & $1.03 \mathrm{E}-2$ & $3.09 \mathrm{E}-2$ & $5.48 \mathrm{E}-2$ & $6.24 \mathrm{E}-2$ & $<1 \mathrm{E}-2$ & $<2 \mathrm{E}-2$ & $<4 \mathrm{E}-3$ & $<5 \mathrm{E}-3$ & $4.62 \mathrm{E}-3$ \\
\hline Post-burn leach 1 & $2.50 \mathrm{E}+0$ & $5.21 \mathrm{E}+0$ & $5.01 \mathrm{E}-1$ & $4.91 \mathrm{E}-1$ & $2.61 \mathrm{E}-1$ & $2.18 \mathrm{E}-1$ & $1.03 \mathrm{E}-0$ & $2.18 \mathrm{E}+0$ & $4.80 \mathrm{E}-1$ & $5.03 \mathrm{E}-1$ & $5.06 \mathrm{E}-1$ \\
\hline \multirow[t]{3}{*}{ Post-burn leach 2} & $4.19 \mathrm{E}-2$ & $1.67 \mathrm{E}+0$ & $1.41 \mathrm{E}-2$ & $1.49 \mathrm{E}-1$ & $2.92 \mathrm{E}-1$ & $3.45 \mathrm{E}-1$ & $<1 \mathrm{E}-2$ & $1.18 \mathrm{E}-2$ & $<3 \mathrm{E}-3$ & $<4 \mathrm{E}-3$ & $<2 \mathrm{E}-3$ \\
\hline & \multicolumn{11}{|c|}{ Compact Fraction $^{\mathrm{b}}$} \\
\hline & Sr-88 & Pd-105 & Ag-109 & Cd-111 & Cd-112 & Cd-114 & La-139 & Ce-140 & Nd-143 & Nd-145 & Sm-152 \\
\hline Deconsolidation & $1.81 \mathrm{E}-3$ & $<9 \mathrm{E}-6$ & $2.08 \mathrm{E}-3$ & $3.05 \mathrm{E}-3$ & $1.56 \mathrm{E}-2$ & $1.13 \mathrm{E}-2$ & $3.98 \mathrm{E}-5$ & $9.43 \mathrm{E}-5$ & $3.48 \mathrm{E}-6$ & $2.80 \mathrm{E}-6$ & $1.31 \mathrm{E}-4$ \\
\hline Pre-burn leach 1 & $3.43 \mathrm{E}-4$ & $<3 \mathrm{E}-5$ & $4.55 \mathrm{E}-4$ & $1.67 \mathrm{E}-3$ & $6.59 \mathrm{E}-3$ & $5.12 \mathrm{E}-3$ & $1.32 \mathrm{E}-5$ & $2.25 \mathrm{E}-5$ & $<2 \mathrm{E}-6$ & $<2 \mathrm{E}-6$ & $2.71 \mathrm{E}-5$ \\
\hline Pre-burn leach 2 & $4.75 \mathrm{E}-5$ & $1.80 \mathrm{E}-4$ & $6.26 \mathrm{E}-5$ & $5.82 \mathrm{E}-4$ & $1.92 \mathrm{E}-3$ & $1.55 \mathrm{E}-3$ & $<2 \mathrm{E}-6$ & $<4 \mathrm{E}-6$ & $<2 \mathrm{E}-6$ & $<2 \mathrm{E}-6$ & $7.97 \mathrm{E}-6$ \\
\hline Post-burn leach 1 & $1.36 \mathrm{E}-3$ & $6.35 \mathrm{E}-3$ & $3.05 \mathrm{E}-3$ & $9.25 \mathrm{E}-3$ & $9.14 \mathrm{E}-3$ & $5.42 \mathrm{E}-3$ & $1.85 \mathrm{E}-4$ & $3.96 \mathrm{E}-4$ & $1.47 \mathrm{E}-4$ & $1.62 \mathrm{E}-4$ & $8.73 \mathrm{E}-4$ \\
\hline Post-burn leach 2 & $2.28 \mathrm{E}-5$ & $2.04 \mathrm{E}-3$ & $8.57 \mathrm{E}-5$ & $2.81 \mathrm{E}-3$ & $1.02 \mathrm{E}-2$ & $8.57 \mathrm{E}-3$ & $<2 \mathrm{E}-6$ & $2.14 \mathrm{E}-6$ & $<1 \mathrm{E}-6$ & $<2 \mathrm{E}-6$ & $<4 \mathrm{E}-6$ \\
\hline Process totals & $3.59 \mathrm{E}-3$ & $8.61 \mathrm{E}-3$ & $5.73 \mathrm{E}-3$ & $1.74 \mathrm{E}-2$ & $4.35 \mathrm{E}-2$ & $3.20 \mathrm{E}-2$ & $2.42 \mathrm{E}-4$ & $5.19 \mathrm{E}-4$ & $1.54 \mathrm{E}-4$ & $1.69 \mathrm{E}-4$ & $1.04 \mathrm{E}-3$ \\
\hline Particle equivalent & $1.49 \mathrm{E}+1$ & $3.57 \mathrm{E}+1$ & $2.38 \mathrm{E}+1$ & $7.21 \mathrm{E}+1$ & $1.80 \mathrm{E}+2$ & $1.33 \mathrm{E}+2$ & $1.00 \mathrm{E}+0$ & $2.15 \mathrm{E}+0$ & $6.37 \mathrm{E}-1$ & $7.03 \mathrm{E}-1$ & $4.33 \mathrm{E}+0$ \\
\hline
\end{tabular}


The uranium inventory in all solutions was very low, indicating that no kernels were exposed during any of the leaching steps. This is consistent with data from the AGR-1 irradiation indicating that there were no particles with failed TRISO layers in Capsule 1 (Collin 2015) and the observation that there were no elevated levels of cesium found adjacent to Compact 1-3-1 in the graphite holder from Capsule 1 (Demkowicz et al. 2013) that might indicate particles with failed $\mathrm{SiC}$ layers. While the compact fraction of plutonium isotopes in the first post-burn leach solution were relatively high (especially Pu-240, which was near the level of a single-particle inventory), it is believed that this is driven largely by the low predicted inventory in the compact (Table 2), which results in the plutonium compact fraction being particularly sensitive to small amounts of contamination in the solutions. Due to the much higher inventory of U-238 in the fuel (more than two orders of magnitude higher than Pu-240), it is considered a more reliable indicator of kernel dissolution.

The total inventory of Ag- $110 \mathrm{~m}$ found in all solutions amounted to a compact fraction of $3.56 \times 10^{-3}$, equivalent to the inventory in about 15 average particles. The total cesium inventory was very low $\left(5.36 \times 10^{-6}\right.$ and $6.03 \times 10^{-6}$ for Cs- 134 and Cs-137, respectively) and the compact fractions for Cs- 134 and $\mathrm{Cs}-137$ were in good agreement. This is consistent with very low release of cesium through intact $\mathrm{SiC}$. On the other hand, the total inventory for Eu-154, Eu-155, and Sr-90 were appreciable, and all were at a level significantly higher than a single-particle inventory. This result indicates measureable release through intact coatings. Total Ce-144 fraction was $1.45 \times 10^{-4}$. Interpreted in conjunction with data from the other isotopes discussed here, this most likely is indicative of some release through the intact coatings.

The ICP-MS data for isotopes in the mass number ranges 85 to 116 and 128 to 154 were scrutinized for potential interferences when interpreting the data. Mass spectrometry has additional complications compared to gamma spectrometry in this context, including (a) the possibility of mass interferences (including multiple isotopes of the same atomic mass, or monoxide species forming in the plasma) and (b) the possibility of contributions from naturally-occurring contamination in the samples. The often very small quantities of analytes in the solutions also enhanced the possibility of small amounts of natural contamination significantly affecting the signal. After careful review of the data, it was determined that results for some of the mass numbers exhibited evidence of these issues. For example, mass ratios for isotopes of a particular element correlated very well with natural isotopic abundances, suggesting that trace contamination had been introduced during sample processing. In some instances, therefore, it was decided that the results were unlikely to represent fission products present in the compact outside the $\mathrm{SiC}$ layers. Table 5 lists the isotopes for which there was reasonable confidence in the values, within the limitations discussed below.

Several blank samples were analyzed along with aliquots of the DLBL solutions. These aided the interpretation of the ICP-MS data. In particular, the data aided in distinguishing signals that may have been dominated by contamination from those more likely to represent fission products originating from Compact 1-3-1.

The Ag-109 data in Table 5 are in good agreement with Ag-110m data (Table 3). Note that the cumulative compact fraction for Ag-109 is within less than a factor of two of the value for Ag- $110 \mathrm{~m}$. Palladium data are of significant interest due to its behavior in the particles, in particular the tendency to react with $\mathrm{SiC}$ and the observation that palladium can be found inside the $\mathrm{SiC}$ microstructure of irradiated particles (Demkowicz et al. 2016a; van Rooyen et al. 2014). The Pd-105 data in Table 5 suggest that an appreciable amount is released from the intact $\mathrm{SiC}$ layers (total fraction of $8.6 \times 10^{-3}$ found in the compact outside the $\mathrm{SiC}$ layers). While the cadmium values in Table 5 indicate significant inventory in the compact outside the $\mathrm{SiC}$ layers (ranging from 1.7 and $4.4 \%$ of the compact inventory), the values are suspect. The mass ratios in this range more closely resemble natural abundance than the predicted ratios expected from fission for most of the DLBL solutions, and there is a potential source of natural cadmium contamination in the AL hot cells or in the AL instrument used to process these specimens. The conclusion is that these values may be heavily influenced by sample contamination and do not accurately represent release of cadmium isotopes through the intact $\mathrm{SiC}$ layers. 
The compact fraction of Ce-140 in Table 5 is about 3.5 times larger than the Ce-144 value in Table 3 . The compact fractions for the lanthanides La-139, Nd-143, and Nd-145 in Table 5 are all similar (approximately $2 \times 10^{-4}$ ), and are in a similar range as the cerium isotopes Ce-140 and Ce-144. Therefore, a tentative conclusion is that these data represent a small but measureable level of release from the particles. The fraction of Sm-152 is relatively high $\left(1.0 \times 10^{-3}\right)$, and is between the values for the europium isotopes and $\mathrm{Sr}-90$.

There is a conspicuous increase in measured inventory in the first post-burn leach solution for most isotopes in Table 3, Table 4, and Table 5. Relatively high isotopic inventory in the first post-burn leach solution has been observed previously (Demkowicz et al. 2012; Demkowicz et al. 2016b), and is believed to be due to conversion of various carbon-rich phases into more soluble oxides during the burn step and subsequent dissolution in the first post-burn leach.

\section{PARTICLE VISUAL INSPECTION AND GAMMA COUNTING 3.1 Particle Visual Inspection}

Details about the equipment and procedures for particle visual inspection and gamma spectrometry of individual particles are given in Appendix B. General inspection of the post-burn-leach particles showed primarily unblemished gray spheres with uniform surface finish and minimal asphericity or distortion.

\subsection{Particle Gamma Counting}

A total of 60 particles from Compact 1-3-1 were gamma counted following the second post-burn leach. Individual particles were selected using the inspection system described in Appendix B. Each particle was placed in a glass vial for gamma counting. Nominal counting time for individual particles was 6 hours. However, to improve counting statistics and quantify the very low activity of Ag-110m in the particles, counting times were increased to 14 hours (overnight counting) and 72 hours (several days over a weekend) for some of the particles. Gamma counting was performed between August 14 and December 3, 2012. Details about the gamma counting equipment and procedure are given in Appendix B.

Table 6 provides the decay-corrected activity of each isotope measured in the particles (all activity values are decay corrected to EOI plus 1 day, as discussed in Section 2). Thirty-eight of the particles analyzed had Ag-110m activity below detection limits. The detection limit for these particles was used to calculate the decay-corrected activities listed in Table 6 preceded by " $<$ ". These values were used in calculating the average and standard deviation for Ag-110m activity in Table 6.

Table 6. Decay-corrected activity (Bq) for isotopes measured by gamma counting of particles from irradiated Compact 1-3-1.

\begin{tabular}{|cccccccccc|}
\hline Particle No. & $\begin{array}{c}\text { Count Time } \\
\text { (hr) }\end{array}$ & Ag-110m & Ce-144 & Cs-134 & Cs-137 & Eu-154 & Eu-155 & Ru-106 & Sb-125 \\
\hline AGR1-131-001 & 6 & $<1.2 \mathrm{E}+4$ & $4.81 \mathrm{E}+7$ & $4.50 \mathrm{E}+6$ & $3.87 \mathrm{E}+6$ & $1.27 \mathrm{E}+5$ & $8.92 \mathrm{E}+4$ & $1.05 \mathrm{E}+7$ & $1.96 \mathrm{E}+5$ \\
AGR1-131-002 & 6 & $<1.2 \mathrm{E}+4$ & $4.56 \mathrm{E}+7$ & $3.32 \mathrm{E}+6$ & $3.26 \mathrm{E}+6$ & $9.71 \mathrm{E}+4$ & $7.70 \mathrm{E}+4$ & $8.67 \mathrm{E}+6$ & $1.57 \mathrm{E}+5$ \\
AGR1-131-062 & 6 & $1.35 \mathrm{E}+4$ & $4.87 \mathrm{E}+7$ & $4.80 \mathrm{E}+6$ & $3.98 \mathrm{E}+6$ & $1.34 \mathrm{E}+5$ & $9.59 \mathrm{E}+4$ & $1.06 \mathrm{E}+7$ & $1.86 \mathrm{E}+5$ \\
AGR1-131-063 & 6 & $<1.2 \mathrm{E}+4$ & $4.48 \mathrm{E}+7$ & $3.85 \mathrm{E}+6$ & $3.52 \mathrm{E}+6$ & $1.10 \mathrm{E}+5$ & $7.76 \mathrm{E}+4$ & $8.83 \mathrm{E}+6$ & $1.59 \mathrm{E}+5$ \\
AGR1-131-064 & 14 & $1.57 \mathrm{E}+4$ & $4.34 \mathrm{E}+7$ & $3.38 \mathrm{E}+6$ & $3.43 \mathrm{E}+6$ & $1.00 \mathrm{E}+5$ & $7.28 \mathrm{E}+4$ & $8.34 \mathrm{E}+6$ & $1.58 \mathrm{E}+5$ \\
AGR1-131-065 & 6 & $<1.3 \mathrm{E}+4$ & $5.49 \mathrm{E}+7$ & $4.83 \mathrm{E}+6$ & $4.38 \mathrm{E}+6$ & $1.35 \mathrm{E}+5$ & $8.84 \mathrm{E}+4$ & $1.06 \mathrm{E}+7$ & $1.91 \mathrm{E}+5$ \\
AGR1-131-066 & 14 & $1.82 \mathrm{E}+4$ & $5.94 \mathrm{E}+7$ & $5.33 \mathrm{E}+6$ & $4.74 \mathrm{E}+6$ & $1.53 \mathrm{E}+5$ & $1.08 \mathrm{E}+5$ & $1.16 \mathrm{E}+7$ & $2.11 \mathrm{E}+5$ \\
AGR1-131-067 & 6 & $<6.3 \mathrm{E}+3$ & $5.05 \mathrm{E}+7$ & $4.84 \mathrm{E}+6$ & $4.18 \mathrm{E}+6$ & $1.33 \mathrm{E}+5$ & $9.47 \mathrm{E}+4$ & $1.06 \mathrm{E}+7$ & $2.20 \mathrm{E}+5$ \\
AGR1-131-068 & 14 & $<6.4 \mathrm{E}+3$ & $4.92 \mathrm{E}+7$ & $4.19 \mathrm{E}+6$ & $4.74 \mathrm{E}+6$ & $1.19 \mathrm{E}+5$ & $7.97 \mathrm{E}+4$ & $9.05 \mathrm{E}+6$ & $1.85 \mathrm{E}+5$ \\
AGR1-131-069 & 14 & $<5.1 \mathrm{E}+3$ & $4.67 \mathrm{E}+7$ & $4.48 \mathrm{E}+6$ & $4.54 \mathrm{E}+6$ & $1.27 \mathrm{E}+5$ & $9.20 \mathrm{E}+4$ & $9.86 \mathrm{E}+6$ & $1.92 \mathrm{E}+5$ \\
AGR1-131-070 & 6 & $<1.3 \mathrm{E}+4$ & $4.95 \mathrm{E}+7$ & $4.87 \mathrm{E}+6$ & $4.78 \mathrm{E}+6$ & $1.31 \mathrm{E}+5$ & $9.93 \mathrm{E}+4$ & $1.07 \mathrm{E}+7$ & $1.87 \mathrm{E}+5$ \\
\hline
\end{tabular}


Table 6. (continued).

\begin{tabular}{|c|c|c|c|c|c|c|c|c|c|}
\hline \multirow{2}{*}{ Particle No. } & \multirow{2}{*}{$\begin{array}{c}\text { Count Time } \\
\text { (hr) }\end{array}$} & \multicolumn{8}{|c|}{ Activity (Bq) ${ }^{a}$} \\
\hline & & Ag-110m & Ce-144 & Cs-134 & Cs-137 & Eu-154 & Eu-155 & Ru-106 & Sb-125 \\
\hline AGR1-131-071 & 14 & $1.22 \mathrm{E}+4$ & $4.43 \mathrm{E}+7$ & $4.22 \mathrm{E}+6$ & $4.30 \mathrm{E}+6$ & $1.20 \mathrm{E}+5$ & $8.48 \mathrm{E}+4$ & $9.55 \mathrm{E}+6$ & $1.72 \mathrm{E}+5$ \\
\hline AGR1-131-072 & 14 & $9.09 \mathrm{E}+3$ & $5.25 \mathrm{E}+7$ & $5.08 \mathrm{E}+6$ & $4.98 \mathrm{E}+6$ & $1.44 \mathrm{E}+5$ & $9.72 \mathrm{E}+4$ & $1.11 \mathrm{E}+7$ & $1.93 \mathrm{E}+5$ \\
\hline AGR1-131-073 & 6 & $<1.3 \mathrm{E}+4$ & $5.03 \mathrm{E}+7$ & $4.21 \mathrm{E}+6$ & $4.50 \mathrm{E}+6$ & $1.19 \mathrm{E}+5$ & $8.61 \mathrm{E}+4$ & $9.55 \mathrm{E}+6$ & $1.73 \mathrm{E}+5$ \\
\hline AGR1-131-074 & 14 & $1.76 \mathrm{E}+4$ & $5.17 \mathrm{E}+7$ & $3.84 \mathrm{E}+6$ & $4.54 \mathrm{E}+6$ & $1.13 \mathrm{E}+5$ & $8.22 \mathrm{E}+4$ & $9.71 \mathrm{E}+6$ & $1.91 \mathrm{E}+5$ \\
\hline AGR1-131-075 & 14 & $1.50 \mathrm{E}+4$ & $5.32 \mathrm{E}+7$ & $4.90 \mathrm{E}+6$ & $5.02 \mathrm{E}+6$ & $1.39 \mathrm{E}+5$ & $9.73 \mathrm{E}+4$ & $1.08 \mathrm{E}+7$ & $1.91 \mathrm{E}+5$ \\
\hline AGR1-131-076 & 6 & $6.60 \mathrm{E}+3$ & $4.99 \mathrm{E}+7$ & $3.70 \mathrm{E}+6$ & $4.35 \mathrm{E}+6$ & $1.09 \mathrm{E}+5$ & $8.46 \mathrm{E}+4$ & $9.00 \mathrm{E}+6$ & $1.72 \mathrm{E}+5$ \\
\hline AGR1-131-077 & 14 & $8.59 \mathrm{E}+3$ & $4.63 \mathrm{E}+7$ & $3.99 \mathrm{E}+6$ & $4.31 \mathrm{E}+6$ & $1.14 \mathrm{E}+5$ & $8.29 \mathrm{E}+4$ & $8.57 \mathrm{E}+6$ & $1.53 \mathrm{E}+5$ \\
\hline AGR1-131-078 & 6 & $1.26 \mathrm{E}+4$ & $5.29 \mathrm{E}+7$ & $4.46 \mathrm{E}+6$ & $4.86 \mathrm{E}+6$ & $1.28 \mathrm{E}+5$ & $9.69 \mathrm{E}+4$ & $1.03 \mathrm{E}+7$ & $1.88 \mathrm{E}+5$ \\
\hline AGR1-131-079 & 14 & $1.06 \mathrm{E}+4$ & $4.92 \mathrm{E}+7$ & $4.48 \mathrm{E}+6$ & $4.66 \mathrm{E}+6$ & $1.29 \mathrm{E}+5$ & $8.97 \mathrm{E}+4$ & $1.06 \mathrm{E}+7$ & $1.85 \mathrm{E}+5$ \\
\hline AGR1-131-080 & 6 & $<6.6 \mathrm{E}+3$ & $4.93 \mathrm{E}+7$ & $4.28 \mathrm{E}+6$ & $4.66 \mathrm{E}+6$ & $1.21 \mathrm{E}+5$ & $8.86 \mathrm{E}+4$ & $9.36 \mathrm{E}+6$ & $1.73 \mathrm{E}+5$ \\
\hline AGR1-131-081 & 14 & $<6.6 \mathrm{E}+3$ & $3.86 \mathrm{E}+7$ & $3.43 \mathrm{E}+6$ & $3.84 \mathrm{E}+6$ & $9.82 \mathrm{E}+4$ & $6.78 \mathrm{E}+4$ & $7.88 \mathrm{E}+6$ & $1.45 \mathrm{E}+5$ \\
\hline AGR1-131-082 & 6 & $<1.3 \mathrm{E}+4$ & $5.03 \mathrm{E}+7$ & $4.74 \mathrm{E}+6$ & $4.94 \mathrm{E}+6$ & $1.30 \mathrm{E}+5$ & $9.31 \mathrm{E}+4$ & $1.01 \mathrm{E}+7$ & $1.81 \mathrm{E}+5$ \\
\hline AGR1-131-083 & 72 & $1.34 \mathrm{E}+4$ & $5.32 \mathrm{E}+7$ & $4.67 \mathrm{E}+6$ & $4.90 \mathrm{E}+6$ & $1.34 \mathrm{E}+5$ & $8.75 \mathrm{E}+4$ & $1.03 \mathrm{E}+7$ & $1.88 \mathrm{E}+5$ \\
\hline AGR1-131-084 & 6 & $<6.7 \mathrm{E}+3$ & $4.94 \mathrm{E}+7$ & $3.56 \mathrm{E}+6$ & $4.39 \mathrm{E}+6$ & $1.10 \mathrm{E}+5$ & $7.47 \mathrm{E}+4$ & $9.45 \mathrm{E}+6$ & $1.77 \mathrm{E}+5$ \\
\hline AGR1-131-085 & 14 & $<5.4 \mathrm{E}+3$ & $4.76 \mathrm{E}+7$ & $4.55 \mathrm{E}+6$ & $4.62 \mathrm{E}+6$ & $1.27 \mathrm{E}+5$ & $9.10 \mathrm{E}+4$ & $9.93 \mathrm{E}+6$ & $1.71 \mathrm{E}+5$ \\
\hline AGR1-131-086 & 72 & $<3.6 \mathrm{E}+3$ & $4.26 \mathrm{E}+7$ & $3.78 \mathrm{E}+6$ & $4.12 \mathrm{E}+6$ & $1.07 \mathrm{E}+5$ & $7.71 \mathrm{E}+4$ & $8.40 \mathrm{E}+6$ & $1.66 \mathrm{E}+5$ \\
\hline AGR1-131-087 & 6 & $<7.3 \mathrm{E}+3$ & $5.14 \mathrm{E}+7$ & $4.91 \mathrm{E}+6$ & $4.99 \mathrm{E}+6$ & $1.37 \mathrm{E}+5$ & $9.65 \mathrm{E}+4$ & $1.05 \mathrm{E}+7$ & $2.01 \mathrm{E}+5$ \\
\hline AGR1-131-088 & 14 & $<7.3 \mathrm{E}+3$ & $4.56 \mathrm{E}+7$ & $3.87 \mathrm{E}+6$ & $4.28 \mathrm{E}+6$ & $1.09 \mathrm{E}+5$ & $8.18 \mathrm{E}+4$ & $8.40 \mathrm{E}+6$ & $1.55 \mathrm{E}+5$ \\
\hline AGR1-131-089 & 6 & $<1.5 \mathrm{E}+4$ & $4.63 \mathrm{E}+7$ & $3.89 \mathrm{E}+6$ & $4.43 \mathrm{E}+6$ & $1.09 \mathrm{E}+5$ & $8.18 \mathrm{E}+4$ & $9.26 \mathrm{E}+6$ & $1.93 \mathrm{E}+5$ \\
\hline AGR1-131-090 & 14 & $1.09 \mathrm{E}+4$ & $5.15 \mathrm{E}+7$ & $5.00 \mathrm{E}+6$ & $4.91 \mathrm{E}+6$ & $1.40 \mathrm{E}+5$ & $9.72 \mathrm{E}+4$ & $1.10 \mathrm{E}+7$ & $1.81 \mathrm{E}+5$ \\
\hline AGR1-131-091 & 72 & $<4.4 \mathrm{E}+3$ & $4.95 \mathrm{E}+7$ & $4.54 \mathrm{E}+6$ & $4.59 \mathrm{E}+6$ & $1.28 \mathrm{E}+5$ & $8.53 \mathrm{E}+4$ & $1.02 \mathrm{E}+7$ & $1.75 \mathrm{E}+5$ \\
\hline AGR1-131-092 & 6 & $1.41 \mathrm{E}+4$ & $4.73 \mathrm{E}+7$ & $3.69 \mathrm{E}+6$ & $4.28 \mathrm{E}+6$ & $1.10 \mathrm{E}+5$ & $7.69 \mathrm{E}+4$ & $9.34 \mathrm{E}+6$ & $1.71 \mathrm{E}+5$ \\
\hline AGR1-131-093 & 14 & $<7.4 \mathrm{E}+3$ & $4.29 \mathrm{E}+7$ & $3.64 \mathrm{E}+6$ & $4.00 \mathrm{E}+6$ & $1.04 \mathrm{E}+5$ & $7.58 \mathrm{E}+4$ & $8.13 \mathrm{E}+6$ & $1.51 \mathrm{E}+5$ \\
\hline AGR1-131-094 & 6 & $1.04 \mathrm{E}+4$ & $5.29 \mathrm{E}+7$ & $5.04 \mathrm{E}+6$ & $4.87 \mathrm{E}+6$ & $1.40 \mathrm{E}+5$ & $9.91 \mathrm{E}+4$ & $1.10 \mathrm{E}+7$ & $2.01 \mathrm{E}+5$ \\
\hline AGR1-131-095 & 14 & $1.12 \mathrm{E}+4$ & $4.91 \mathrm{E}+7$ & $4.10 \mathrm{E}+6$ & $4.40 \mathrm{E}+6$ & $1.17 \mathrm{E}+5$ & $8.26 \mathrm{E}+4$ & $9.00 \mathrm{E}+6$ & $1.68 \mathrm{E}+5$ \\
\hline AGR1-131-096 & 6 & $<1.5 \mathrm{E}+4$ & $4.66 \mathrm{E}+7$ & $3.50 \mathrm{E}+6$ & $4.12 \mathrm{E}+6$ & $1.02 \mathrm{E}+5$ & $7.52 \mathrm{E}+4$ & $8.74 \mathrm{E}+6$ & $1.71 \mathrm{E}+5$ \\
\hline AGR1-131-097 & 14 & $1.34 \mathrm{E}+4$ & $5.14 \mathrm{E}+7$ & $4.69 \mathrm{E}+6$ & $4.79 \mathrm{E}+6$ & $1.32 \mathrm{E}+5$ & $8.49 \mathrm{E}+4$ & $1.03 \mathrm{E}+7$ & $1.89 \mathrm{E}+5$ \\
\hline AGR1-131-098 & 6 & $<1.5 \mathrm{E}+4$ & $5.57 \mathrm{E}+7$ & $5.33 \mathrm{E}+6$ & $5.19 \mathrm{E}+6$ & $1.47 \mathrm{E}+5$ & $1.03 \mathrm{E}+5$ & $1.17 \mathrm{E}+7$ & $2.07 \mathrm{E}+5$ \\
\hline AGR1-131-099 & 72 & $<2.2 \mathrm{E}+3$ & $4.98 \mathrm{E}+7$ & $3.80 \mathrm{E}+6$ & $4.32 \mathrm{E}+6$ & $1.10 \mathrm{E}+5$ & $7.24 \mathrm{E}+4$ & $8.90 \mathrm{E}+6$ & $1.64 \mathrm{E}+5$ \\
\hline AGR1-131-100 & 6 & $<1.5 \mathrm{E}+4$ & $5.43 \mathrm{E}+7$ & $4.32 \mathrm{E}+6$ & $4.68 \mathrm{E}+6$ & $1.26 \mathrm{E}+5$ & $9.03 E+4$ & $9.76 \mathrm{E}+6$ & $1.92 \mathrm{E}+5$ \\
\hline AGR1-131-101 & 14 & $<7.6 \mathrm{E}+3$ & $4.83 \mathrm{E}+7$ & $4.14 \mathrm{E}+6$ & $4.40 \mathrm{E}+6$ & $1.17 \mathrm{E}+5$ & $8.57 \mathrm{E}+4$ & $8.98 E+6$ & $1.67 \mathrm{E}+5$ \\
\hline AGR1-131-102 & 14 & $1.45 \mathrm{E}+4$ & $5.14 \mathrm{E}+7$ & $4.95 \mathrm{E}+6$ & $4.84 \mathrm{E}+6$ & $1.37 \mathrm{E}+5$ & $9.09 \mathrm{E}+4$ & $1.09 \mathrm{E}+7$ & $2.07 \mathrm{E}+5$ \\
\hline AGR1-131-103 & 6 & $<1.5 \mathrm{E}+4$ & $5.00 \mathrm{E}+7$ & $4.55 \mathrm{E}+6$ & $4.68 \mathrm{E}+6$ & $1.27 \mathrm{E}+5$ & $8.52 \mathrm{E}+4$ & $1.05 \mathrm{E}+7$ & $2.02 \mathrm{E}+5$ \\
\hline AGR1-131-104 & 72 & $<4.6 \mathrm{E}+3$ & $4.71 \mathrm{E}+7$ & $4.02 \mathrm{E}+6$ & $4.28 \mathrm{E}+6$ & $1.12 \mathrm{E}+5$ & $8.01 \mathrm{E}+4$ & $8.82 \mathrm{E}+6$ & $1.91 \mathrm{E}+5$ \\
\hline AGR1-131-105 & 6 & $<7.7 \mathrm{E}+3$ & $4.40 \mathrm{E}+7$ & $3.78 \mathrm{E}+6$ & $4.08 \mathrm{E}+6$ & $1.06 \mathrm{E}+5$ & $7.22 \mathrm{E}+4$ & $8.51 \mathrm{E}+6$ & $1.50 \mathrm{E}+5$ \\
\hline AGR1-131-106 & 14 & $<7.7 \mathrm{E}+3$ & $4.91 \mathrm{E}+7$ & $4.53 \mathrm{E}+6$ & $4.48 \mathrm{E}+6$ & $1.27 \mathrm{E}+5$ & $8.53 \mathrm{E}+4$ & $9.68 \mathrm{E}+6$ & $1.80 \mathrm{E}+5$ \\
\hline AGR1-131-107 & 14 & $<7.7 \mathrm{E}+3$ & $4.58 \mathrm{E}+7$ & $4.03 \mathrm{E}+6$ & $4.08 \mathrm{E}+6$ & $1.13 \mathrm{E}+5$ & $8.14 \mathrm{E}+4$ & $8.73 \mathrm{E}+6$ & $1.90 \mathrm{E}+5$ \\
\hline AGR1-131-108 & 6 & $<7.8 \mathrm{E}+3$ & $5.38 \mathrm{E}+7$ & $4.22 \mathrm{E}+6$ & $4.60 \mathrm{E}+6$ & $1.21 \mathrm{E}+5$ & $8.83 \mathrm{E}+4$ & $9.97 \mathrm{E}+6$ & $1.86 \mathrm{E}+5$ \\
\hline AGR1-131-109 & 14 & $<6.2 \mathrm{E}+3$ & $4.72 \mathrm{E}+7$ & $4.28 \mathrm{E}+6$ & $4.28 \mathrm{E}+6$ & $1.21 \mathrm{E}+5$ & $8.54 \mathrm{E}+4$ & $9.40 \mathrm{E}+6$ & $1.53 \mathrm{E}+5$ \\
\hline AGR1-131-110 & 6 & $<1.6 \mathrm{E}+4$ & $4.66 \mathrm{E}+7$ & $3.65 \mathrm{E}+6$ & $4.00 \mathrm{E}+6$ & $1.03 \mathrm{E}+5$ & $7.63 \mathrm{E}+4$ & $8.50 \mathrm{E}+6$ & $1.66 \mathrm{E}+5$ \\
\hline
\end{tabular}


Table 6. (continued).

\begin{tabular}{|c|c|c|c|c|c|c|c|c|c|}
\hline \multirow{2}{*}{ Particle No. } & \multirow{2}{*}{$\begin{array}{c}\text { Count Time } \\
\text { (hr) }\end{array}$} & \multicolumn{8}{|c|}{$\operatorname{Activity~}(\mathrm{Bq})^{\mathrm{a}}$} \\
\hline & & Ag-110m & Ce-144 & Cs-134 & Cs-137 & Eu-154 & Eu-155 & Ru-106 & Sb-125 \\
\hline AGR1-131-111 & 72 & $1.63 \mathrm{E}+4$ & $5.09 \mathrm{E}+7$ & $4.95 \mathrm{E}+6$ & $4.72 \mathrm{E}+6$ & $1.38 \mathrm{E}+5$ & $9.18 \mathrm{E}+4$ & $1.07 \mathrm{E}+7$ & $2.05 \mathrm{E}+5$ \\
\hline AGR1-131-112 & 6 & $<7.9 \mathrm{E}+3$ & $4.29 \mathrm{E}+7$ & $3.77 \mathrm{E}+6$ & $3.91 \mathrm{E}+6$ & $1.06 \mathrm{E}+5$ & $7.93 \mathrm{E}+4$ & $8.47 \mathrm{E}+6$ & $1.61 \mathrm{E}+5$ \\
\hline AGR1-131-113 & 14 & $1.10 \mathrm{E}+4$ & $4.84 \mathrm{E}+7$ & $3.49 \mathrm{E}+6$ & $4.05 \mathrm{E}+6$ & $1.05 \mathrm{E}+5$ & $7.70 \mathrm{E}+4$ & $9.00 \mathrm{E}+6$ & $1.63 \mathrm{E}+5$ \\
\hline AGR1-131-114 & 6 & $<7.9 \mathrm{E}+3$ & $4.89 \mathrm{E}+7$ & $3.59 \mathrm{E}+6$ & $4.13 \mathrm{E}+6$ & $1.06 \mathrm{E}+5$ & $7.47 \mathrm{E}+4$ & $9.23 \mathrm{E}+6$ & $1.79 \mathrm{E}+5$ \\
\hline AGR1-131-115 & 14 & $1.19 \mathrm{E}+4$ & $4.64 \mathrm{E}+7$ & $3.51 \mathrm{E}+6$ & $3.90 \mathrm{E}+6$ & $1.02 \mathrm{E}+5$ & $7.42 \mathrm{E}+4$ & $8.37 \mathrm{E}+6$ & $1.64 \mathrm{E}+5$ \\
\hline AGR1-131-116 & 72 & $<4.8 \mathrm{E}+3$ & $5.30 \mathrm{E}+7$ & $4.56 \mathrm{E}+6$ & $4.72 \mathrm{E}+6$ & $1.28 \mathrm{E}+5$ & $8.63 \mathrm{E}+4$ & $9.95 \mathrm{E}+6$ & $1.91 \mathrm{E}+5$ \\
\hline AGR1-131-117 & 6 & $<1.6 \mathrm{E}+4$ & $4.94 \mathrm{E}+7$ & $4.06 \mathrm{E}+6$ & $4.29 \mathrm{E}+6$ & $1.16 \mathrm{E}+5$ & $8.52 \mathrm{E}+4$ & $9.32 \mathrm{E}+6$ & $1.71 \mathrm{E}+5$ \\
\hline AGR1-131-118 & 6 & $<1.7 \mathrm{E}+4$ & $5.29 \mathrm{E}+7$ & $5.21 \mathrm{E}+6$ & $4.88 \mathrm{E}+6$ & $1.43 \mathrm{E}+5$ & $1.01 \mathrm{E}+5$ & $1.18 \mathrm{E}+7$ & $2.02 \mathrm{E}+5$ \\
\hline AGR1-131-119 & 14 & $1.42 \mathrm{E}+4$ & $4.77 \mathrm{E}+7$ & $3.74 \mathrm{E}+6$ & $4.09 \mathrm{E}+6$ & $1.09 \mathrm{E}+5$ & $7.36 \mathrm{E}+4$ & $8.82 \mathrm{E}+6$ & $1.74 \mathrm{E}+5$ \\
\hline Average & & $1.06 \mathrm{E}+4$ & $4.90 \mathrm{E}+7$ & $4.26 \mathrm{E}+6$ & $4.41 \mathrm{E}+6$ & $1.21 \mathrm{E}+5$ & $8.55 \mathrm{E}+4$ & $9.66 \mathrm{E}+6$ & $1.80 \mathrm{E}+5$ \\
\hline Standard deviation & & $4.06 \mathrm{E}+3$ & $3.68 \mathrm{E}+6$ & $5.50 \mathrm{E}+5$ & $4.10 \mathrm{E}+5$ & $1.38 \mathrm{E}+4$ & $8.93 \mathrm{E}+3$ & $9.75 \mathrm{E}+5$ & $1.72 \mathrm{E}+4$ \\
\hline $\begin{array}{r}\text { Relative standard } \\
\text { deviation }\end{array}$ & & $38.2 \%$ & $7.5 \%$ & $12.9 \%$ & $9.3 \%$ & $11.4 \%$ & $10.4 \%$ & $10.1 \%$ & $9.6 \%$ \\
\hline
\end{tabular}

An issue was identified with the background signal during counting of the first few particles listed in Table 6. The Cs-137 levels in the hot cell were unstable and increasing during this period (presumably due to contamination in the cell), and this caused minor problems applying background corrections and quantifying Cs-137 in the spectra. As a result, it appears that the Cs-137 results from the first eight particles in Table 6 are suspect. Figure 3 shows a plot of the Cs-137/Ce-144 decay-corrected activity ratios normalized to the mean for all 60 particles plotted in order of analysis. Note the spuriously low values for the first eight particles. However, since the Cs-134 activities did not exhibit similar behavior (see companion plot in Figure 3), it was determined that the low Cs-137 values for the first eight particles were due to a bias in the measurement of Cs-137, and are not an indication of higher cesium release from these particles during irradiation. Therefore, no particles in this sample were identified with evidence of abnormally low cesium retention.
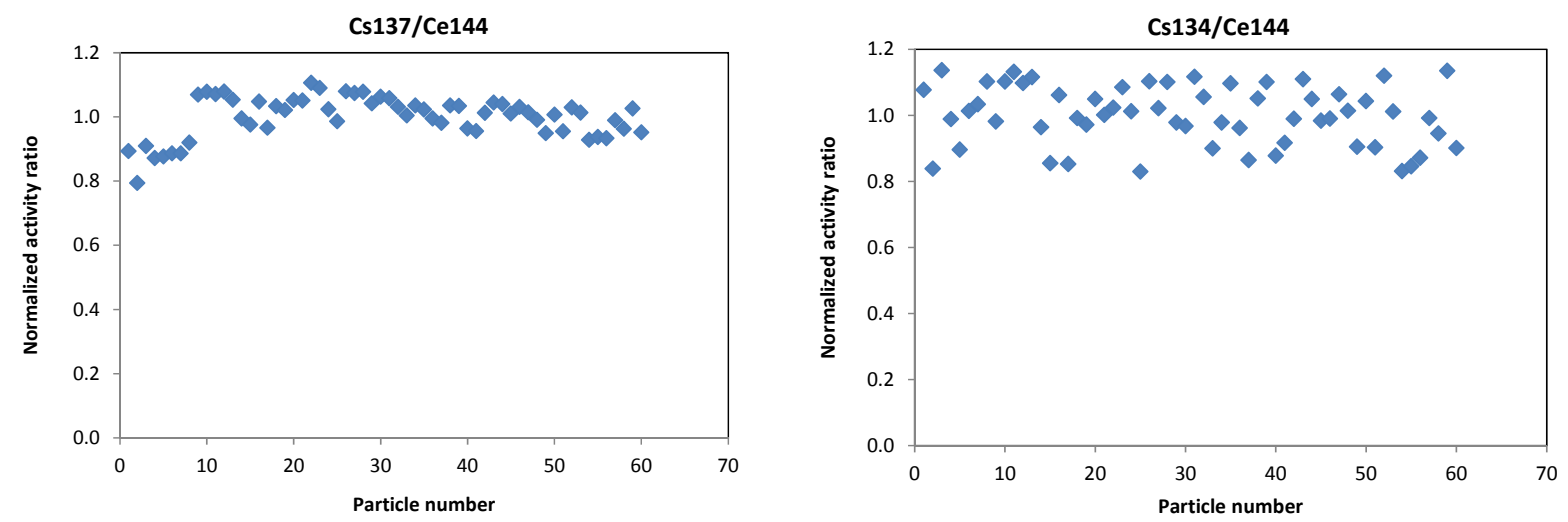

Figure 3. Cs-137/Ce-144 and Cs-134/Ce-144 decay-corrected activity ratios, normalized to the mean and plotted in the order they were gamma counted. Note the low Cs-137/Ce-144 values for the first eight particles, suspected to have been influenced by changes in Cs-137 levels in the hot cell. 
For each isotope, $X$, the measured inventory in each particle $\left(A_{i}^{X}\right)$ was compared with the value predicted by physics calculations (Sterbentz 2013). The predicted activity in a particle was determined by dividing the predicted activity for Compact 1-3-1 $\left(A_{131(\mathrm{calc})}^{X}\right)$ by the average number of particles per AGR-1 Variant 3 compact $(4,126)$. A normalization was then applied to this value to minimize the particle-to-particle variation in the starting fissile content (i.e., the result of variation in as-fabricated kernel characteristics such as diameter, density, and stoichiometry) and burnup. For most isotopes, this was accomplished by dividing by the ratio of the measured Ce-144 activity in particle $i\left(A_{i}^{C e 144}\right)$ to the average measured Ce-144 activity for all $n$ particles measured $\left(\sum_{i=1}^{n}\left(\frac{1}{n}\right) A_{i}^{C e 144}\right)$. The result is a ratio of measured-to-calculated $(\mathrm{M} / \mathrm{C})$ isotope activity, normalized for variations in fissile content and burnup as shown in Equation (2). In certain instances, this ratio can be used to represent an estimate of the fraction of the original inventory that was retained in the particle. However, it is subject to errors due to the biases in the predicted inventory in the compact.

$\frac{\left[A_{i}^{X} /\left(\frac{A_{131(\text { calc })}^{X}}{4126}\right)\right]}{A_{i}^{C e 144} / \sum_{i=1}^{n}\left(\frac{1}{n}\right) A_{i}^{\text {Ce144 }}}$

Cs-137 activity is more commonly used to normalize the values (Demkowicz et al. 2016a; Demkowicz et al. 2016c). However, due to the suspect Cs-137 values for several particles (discussed above), Ce-144 was used instead. In the case of Ce-144, Ru-106 activity was used in denominator in Equation (2) to normalize the Ce-144 values for variation in fissile content and burnup.

Table 7 lists the average $\mathrm{M} / \mathrm{C}$ activity ratio for several isotopes in Compact 1-3-1. These are the average of the individual values calculated for each particle. Note that the value for Cs-137 is the average for all 60 particles (eliminating the first eight particles from the mean had a minimal effect on the values). Two values are provided for Ag-110m. The first value ("high") includes the decay-corrected activities based on detection limits in Table 6 when calculating the $\mathrm{M} / \mathrm{C}$ ratio for each particle and the values are included in the average. The second value ("low") assumes an activity of zero in all particles with no detectable $\mathrm{Ag}-110 \mathrm{~m}$ activity, and therefore uses $\mathrm{M} / \mathrm{C}=0$ for these particles in determining the average. Thus these two values will bound the actual average $\mathrm{M} / \mathrm{C}$ value.

Table 7. Average measured-to-calculated activity ratios for 60 gamma-counted particles.

\begin{tabular}{|cccc|}
\hline Isotope & Average M/C & Standard Deviation & Coefficient of Variation \\
\hline Ag-110m (high) & 0.28 & $1.0 \mathrm{E}-01$ & $36.5 \%$ \\
Ag-110m (low) & 0.11 & $1.5 \mathrm{E}-01$ & $142.4 \%$ \\
Ce-144 & 0.98 & $5.8 \mathrm{E}-02$ & $5.9 \%$ \\
Cs-134 & 0.96 & $8.7 \mathrm{E}-02$ & $9.0 \%$ \\
Cs-137 & 1.09 & $7.0 \mathrm{E}-02$ & $6.5 \%$ \\
Eu-154 & 0.83 & $6.0 \mathrm{E}-02$ & $7.2 \%$ \\
Eu-155 & 0.81 & $5.7 \mathrm{E}-02$ & $7.0 \%$ \\
Ru-106 & 0.84 & $5.0 \mathrm{E}-02$ & $6.0 \%$ \\
Sb-125 & 0.62 & $4.1 \mathrm{E}-02$ & $6.6 \%$ \\
\hline
\end{tabular}


The Cs-134 and Ce-144 values in Table 7 are close to 1.0, indicating reasonably good agreement between the predicted inventory per particle and the measurements. Ag-110m values are very low, suggesting a large amount of release during the irradiation, as discussed further below. Values for Eu-154, $\mathrm{Eu}-155, \mathrm{Ru}-016$, and Sb-125 are all significantly lower than 1.0. Low M/C values for these isotopes are commonly observed in gamma-counted particles from other AGR-1 compacts (Demkowicz et al. 2016a; Demkowicz et al. 2016c), and are a consequence of a high bias in the predicted isotopic inventories in Table 2 (Sterbentz 2013), rather than extensive release during the irradiation.

The distribution of Ag- $110 \mathrm{~m} \mathrm{M} / \mathrm{C}$ activity ratios is presented in Figure 4. Of the original 60 particles gamma counted, a total of 38 had no detectable Ag-110m (see Table 6). This is not surprising given the elapsed time between the end of the irradiation and gamma counting of the particles (greater than 1000 days for all particles, equal to about four half-lives of Ag-110m) and the relatively low $\mathrm{Ag}-110 \mathrm{~m}$ inventory measured in the intact compact by gamma scanning (the $\mathrm{M} / \mathrm{C}$ ratio of in the intact compact was 0.24, as described in Harp 2014). The reported detection limit for each particle was used to calculate the $\mathrm{M} / \mathrm{C}$ ratio, and these values are plotted in red in Figure 4. These values are considered an upper bound on the actual $\mathrm{M} / \mathrm{C}$ ratio for these particles.

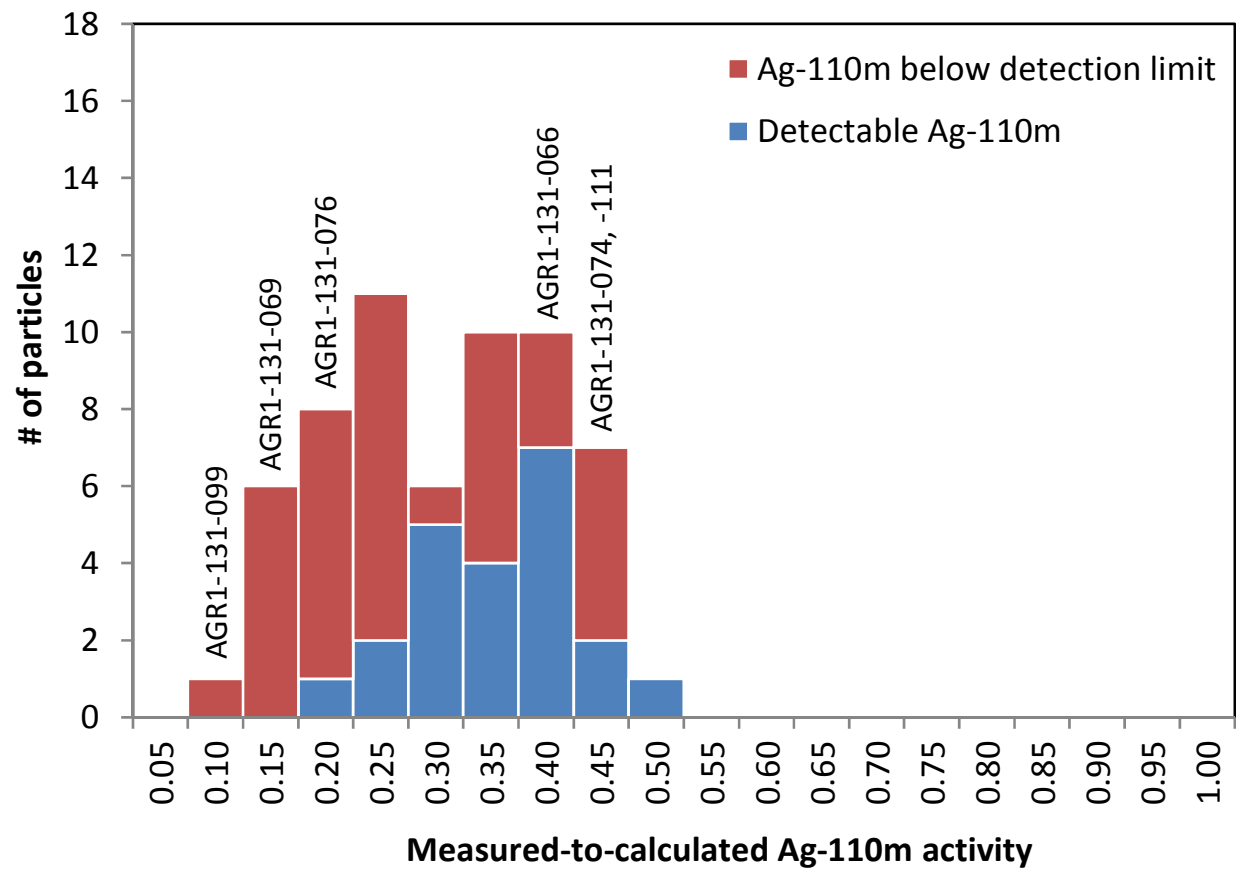

Figure 4. Measured-to-calculated activity ratios for 60 gamma-counted particles from AGR-1 Compact 1-3-1. Red data represent particles for which no Ag-110m was detected; the minimum detectable activity was therefore used to calculate the $\mathrm{M} / \mathrm{C}$ ratio. The location of specific particles chosen for mounting and microanalysis is labeled on distribution.

As suggested by the distribution in Figure 4, even for particles with detectable Ag-110m activity, the measured values are very close to the detection limits. The data indicate that a 6 -hour counting time was marginal for quantifying the Ag-110m activity in most particles. In the subpopulation of particles counted for 6 hours, only 5 of 28 had detectable Ag-110m activity. Counting for longer times (14 or 72 hours) clearly reduced the reported detection limit for particles with no detectable Ag-110m and also reduced the percentage of particles with no detectable activity. Figure 5 shows the average reported minimum detectable activity for the particles with Ag- $110 \mathrm{~m}$ below the detection limit as a function of counting time. 


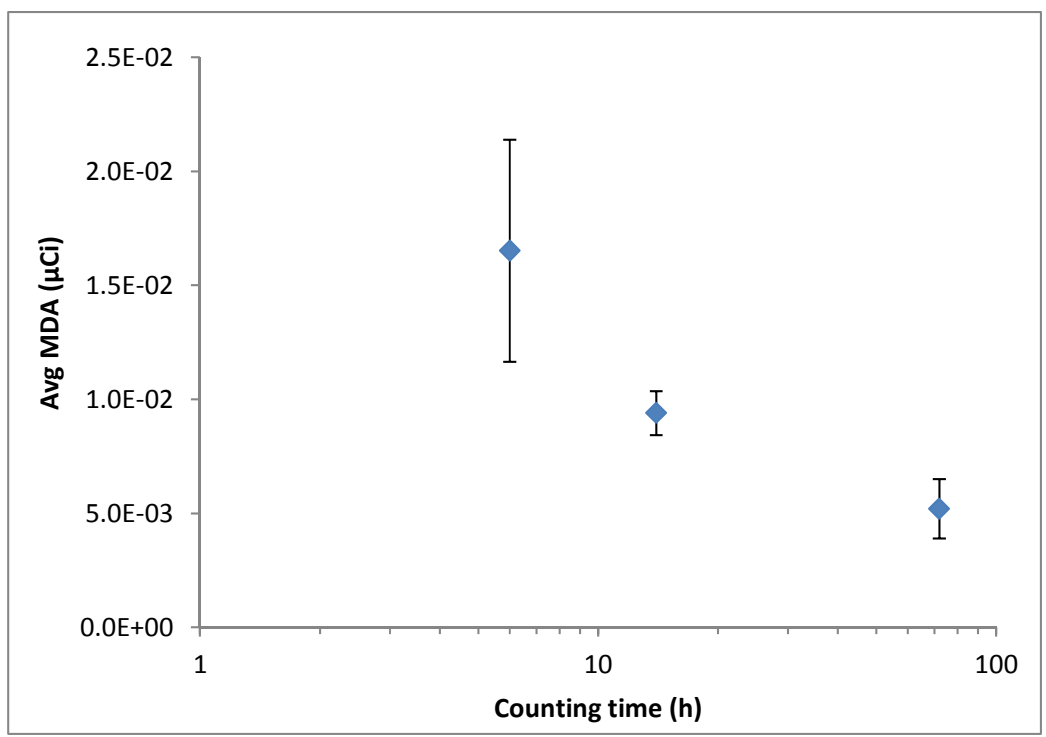

Figure 5. Average reported minimum detectable activity for particles with Ag-110m activity below detection limit as function of counting time. Error bars are 1 sigma.

If particles counted for 6 hours are removed from the population, roughly half of the remaining particles (17 out of 32) had detectable Ag-110m activity. The distribution for these 32 particles gamma counted for 14 or 72 hours is shown in Figure 6. Removing the 6-hour particles from the population has a small effect on the $\mathrm{M} / \mathrm{C}$ values reported in Table 7. The "high" $\mathrm{M} / \mathrm{C}$ value becomes 0.25 and the "low" value becomes 0.18 . These values agree reasonably well with the ratio of measured-to-predicted Ag-110m inventory in the intact compact (0.24, Harp 2014). Note that there was a small amount of $\mathrm{Ag}-110 \mathrm{~m}$ detected in the compact but outside the SiC layers (about $0.4 \%$ of the compact inventory, as shown in Table 3).

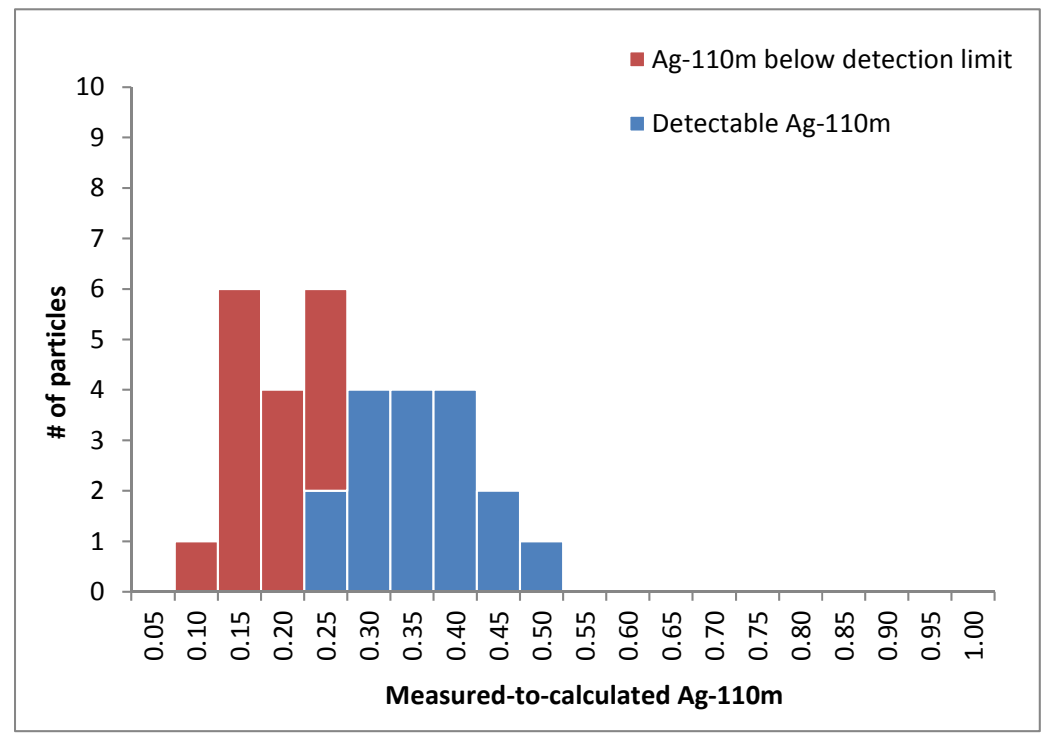

Figure 6. Measured-to-calculated activity ratios for 32 particles from AGR-1 Compact 1-3-1 gamma counted for 14 or 72 hours. Red data represent particles for which no Ag-110m was detected; the minimum detectable activity was therefore used to calculate the $\mathrm{M} / \mathrm{C}$ ratio. 


\section{BURNUP ANALYSIS}

The burnup of Compact 1-3-1 was determined using measurements from ICP-MS. For this analysis, an effort was made to explore the optimum approach for sample preparation of the ICP-MS solutions, after results from previous analyses indicated that the preparation methods may not result in complete recovery of all actinides from the dissolved kernels (Demkowicz et al. 2016b; Demkowicz et al. 2016c). Nine sets of 20 burned-back particles were randomly selected. Each set was crushed to expose the fuel kernels, oxidized in air to convert insoluble carbides to soluble oxides, and the residue leached in an acid solution to recover all actinides and fission products present in the kernels.

Three different ICP-MS solution preparation techniques were investigated, each utilizing three sets of 20 particles. In Method 1, the crushed particles were oxidized in air at $400^{\circ} \mathrm{C}$ for 24 hours in a muffle furnace. The particles were leached in $8 \mathrm{M}$ nitric acid heated near boiling for approximately 1 hour. This method is similar to what was used for Compact 6-3-2 (Demkowicz et al. 2012). In Method 2, the crushed particles were oxidized in air at $400^{\circ} \mathrm{C}$ for 24 hours in a muffle furnace. The particles were then leached in $8 \mathrm{M}$ nitric acid with three drops of hydrofluoric acid (HF) added and heated near boiling for approximately 1 hour. Method 3 was identical to the method used for Compact 5-3-1 (Demkowicz et al. 2016b). The crushed particles were oxidized in air at $750^{\circ} \mathrm{C}$ for 24 hours in an air-atmosphere muffle furnace and then were leached in $8 \mathrm{M}$ nitric acid with three drops of HF added and heated near boiling for approximately 1 hour. Table 8 summarizes the conditions for the oxidation and leaching steps for each of the three different sample sets. For all techniques, diluted aliquots of the final leach solution were analyzed using ICP-MS to determine the mass of actinides and fission products in each sample. The masses of the actinides and fission products in each sample were used to determine the burnup of Compact 1-3-1, and the measured burnup values were compared to simulations and burnup values from gamma spectrometry measurements.

Table 8. Description of sample processing steps used for each set of three particle batches (identified by Analytical Laboratory log number).

\begin{tabular}{|cccl|}
\hline Analysis method & Log No. & Oxidation Step & \multicolumn{1}{c|}{ Leach Step } \\
\hline 1 & 94889 & $400^{\circ} \mathrm{C}$ in air for 24 hr & $8 \mathrm{M}$ nitric acid for 1 hr \\
2 & 96017 & $400^{\circ} \mathrm{C}$ in air for 24 hr & $8 \mathrm{M}$ nitric acid plus three drops of HF for 1 hr \\
3 & 96018 & $750^{\circ} \mathrm{C}$ in air for 24 hr & $8 \mathrm{M}$ nitric acid plus three drops of HF for 1 hr \\
\hline
\end{tabular}

Burnup is calculated from ICP-MS measurements by using the measured mass of a specific fission product in the fuel, the cumulative fission yield of that specific fission product, and the total mass of actinides present in the sample. Ideally, the fission products used in the calculations should have a small neutron absorption cross section, high cumulative fission yield, and similar fission yield for that isobar (same atomic number) between uranium and plutonium fission. Chemically, the fission product must also readily dissolve during the leaching process. This technique uses the following equation to calculate burnup based on a specific fission product detected in the ICP-MS spectrum:

$$
B U=\frac{\left(N_{f p} / y_{f p}\right)}{\left(\left(N_{f p} / y_{f p}\right)+N_{A c t}\right)} \times 100
$$

where $B U$ is the burnup, $N_{f p}$ is number of atoms of a specific fission product $f p$ measured in the sample, $y_{f p}$ is the cumulative fission yield of fission product $f p$ in the studied fuel, and $N_{A c t}$ is the number of atoms of actinides in the sample. For the AGR-1 test, most of the fission occurred in U-235, so it is reasonable to use the U-235 cumulative fission yields for the various fission products. However, detailed simulations 
of the AGR-1 experiment (Sterbentz 2013) allow for creation of effective cumulative fission product yields that are a weighted average of the different fission product yields based on the relative amount of fission that occurred in different actinides over the course of the experiment. The correction due to effective fission products can be as much as 5\% for some isotopes, which is on the order of the uncertainty in the measurements. The effective cumulative fission product yields were used in these calculations.

There are six isotopes that work reliably well for the ICP-MS technique in the AGR-1 fuel: La-139, Ce-140, Ce-142, Pr-141, Nd-145, and Nd-146. These isotopes occur on the higher atomic number peak of the bimodal fission product distribution. The differences between U-235 yield and Pu-239 yield are fairly small in this region as well. All these isotopes are nonradioactive and have relatively small neutron absorption cross sections except for Nd-145. Because of its cross section, the number of Nd-145 and Nd-146 atoms in the samples and their respective yields are usually summed to determine the cumulative mass at 145 and 146 for the burnup measurement. In this calculation the burnup measurement was found by taking the average result from Equation (3) for La-139, Ce-140, Ce-142, Pr-141, and the Nd-145/Nd-146 combined result.

The mass spectrometry data were provided in the AL reports for AL Log Nos. 94889, 96017, and 96018 (dated September 11, 2013; September 11, 2013; and June 3, 2013, respectively). Using the approach outlined in the previous paragraphs, the burnup of Compact 1-3-1 was found to be 16.3\% FIMA. This is the average of the values determined from the third technique, the samples which were oxidized at $750^{\circ} \mathrm{C}$ and processed using HF addition to the nitric acid leach solution. The measured actinide values from the third technique exhibited the best agreement with predicted actinide inventory of the three techniques used for Compact 1-3-1 (discussed below). The third technique is also most consistent with the dissolution techniques used for determining burnup for 2 of the 3 other AGR-1 compacts analyzed (compacts 3-2-1 and 5-3-1).

The mass spectrometry burnup value of $16.3 \%$ FIMA compares well with both the predicted value of 15.98\% FIMA (Sterbentz 2011) ${ }^{1}$ and the two values of $15.6 \%$ and $16.0 \%$ FIMA derived from gammascanning the intact compact (Harp et al. 2014). The estimated uncertainty on the burnup value determined by mass spectrometry is $5 \%$ and the uncertainty on the values determined by gamma spectrometry is $3 \%$ for the ratio method and 5\% for the direct method (details in Harp et al. 2014). Table 9 summarizes the burnup results for Compact 1-3-1 determined from the various methods. Comparisons between empirical burnup values and predicted values for four AGR-1 compacts are presented in Harp et al. 2014.

Table 9. Mass spectrometry burnup data for Compact 1-3-1 compared to other techniques in \% FIMA.

\begin{tabular}{|ccccc|}
\hline Compact & $\begin{array}{c}\text { Mass Spectrometry } \\
\text { (\% FIMA) }\end{array}$ & $\begin{array}{c}\text { Gamma Spectrometry Direct } \\
\text { (\% FIMA) }\end{array}$ & $\begin{array}{c}\text { Gamma Spectrometry Ratio } \\
\text { (\% FIMA) }\end{array}$ & $\begin{array}{c}\text { Simulation } \\
\text { (\% FIMA) }\end{array}$ \\
\hline $1-3-1$ & $16.3( \pm 0.8)$ & $16.0( \pm 0.8)$ & $15.6( \pm 0.5)$ & 15.98 \\
\hline
\end{tabular}

It is also constructive for the purposes of evaluating the AGR-1 physics simulations to compare the actinide mass of each isotope measured by ICP-MS to the mass predicted by simulation. The expected masses of 20 TRISO particles for several different actinide isotopes were determined based on Sterbentz (2013), and compared to the ICP-MS results. The predicted mass per kernel was determined by taking the predicted total mass in the compact from Sterbentz (2013) and dividing by the estimated number of particles in the compact $(4,126)$. Since the mass of the individual kernels used for the measurement was not known, it was assumed that each particle had an average mass. The ratio of calculated values to values determined experimentally (calculated-to-experimental [C/E] ratios) for each of the samples is detailed in Table 10. There is a clear bias in the results from Method 2 (AL Log No.

\footnotetext{
${ }^{1}$ Note that the AGR-1 physics predictions in ECAR-958 Revision 1 (Sterbentz 2011), instead of Revision 2 (Sterbentz 2013), were used in the burnup comparisons presented in this section and in Harp 2014 and Harp et al. 2014. This is the reason for the discrepancy between the predicted values from simulation in Tables 1 and 9.
} 
96017) especially samples A and C. It is not clear if this is due to the dissolution technique utilized, other issues with preparation of the samples, or if it is a real bias in inventories in these particular 20-particle samples. The plutonium $\mathrm{C} / \mathrm{E}$ values are closest to 1.0, on average, in Method 3. This prompted the use of these samples for determining the Compact 1-3-1 burnup, as discussed above. The plutonium $\mathrm{C} / \mathrm{E}$ values suggest an overprediction of plutonium in the kernels by 10 to $35 \%$ for Method 3 as compared to 13 to $118 \%$ for the other methods. It is noteworthy that the uranium $\mathrm{C} / \mathrm{E}$ values obtained using Method 1 are fairly close to 1.0 for two of the three sample sets processed, and the averages for the uranium $\mathrm{C} / \mathrm{E}$ values are very similar to those obtained using method 3. However, the average plutonium $\mathrm{C} / \mathrm{E}$ values are slightly closer to 1.0 for Method 3. Considering all the data sets in Table 10, the third dissolution technique (Method 3) is likely the preferred method based both on the comparison of measurements to simulations and best practices in the nuclear community (nitric acid with HF is typically used when trying to get plutonium oxides into solution). However, the discrepancy between prediction and measurement is also likely to arise due to sample preparation errors, sample variability, and inaccuracies in the simulation.

Table 10. Comparison of measured actinide content to simulation for Compact 1-3-1.

\begin{tabular}{|c|c|c|c|c|c|}
\hline & \multicolumn{5}{|c|}{ Actinide Content ( $\mu \mathrm{g} / \mathrm{sample})$} \\
\hline & $\mathrm{U}-235$ & U-236 & $\mathrm{U}-238$ & Pu-239 & Pu-240 \\
\hline Predicted $^{\mathrm{a}}$ & 159.0 & 113.6 & 3376 & 38.07 & 20.2 \\
\hline 94889-1,1A & 117 & 89.7 & 2570 & 23.4 & 13.4 \\
\hline 94889-2,1B & 151 & 111 & 3210 & 30.5 & 17.3 \\
\hline $94889-3,1 \mathrm{C}$ & 154 & 116 & 3330 & 31.3 & 17.7 \\
\hline $96017-1,2 \mathrm{~A}$ & 83.1 & 62.3 & 1790 & 17.3 & 9.72 \\
\hline $96017-2,2 \mathrm{~B}$ & 135 & 108 & 3090 & 30.1 & 17 \\
\hline $96017-3,2 \mathrm{C}$ & 109 & 81.7 & 2340 & 23.1 & 13.1 \\
\hline $960183 \mathrm{~A}$ & 140 & 108 & 3100 & 32.1 & 18.3 \\
\hline $960183 \mathrm{~B}$ & 137 & 94.2 & 2730 & 27.9 & 15.9 \\
\hline $960183 \mathrm{C}$ & 140 & 105 & 3030 & 29.8 & 16.8 \\
\hline & \multicolumn{5}{|c|}{ C/E Values for Each Sample } \\
\hline $94889-1,1 \mathrm{~A}$ & 1.36 & 1.27 & 1.31 & 1.62 & 1.51 \\
\hline 94889-2,1B & 1.05 & 1.02 & 1.05 & 1.25 & 1.17 \\
\hline $94889-3,1 \mathrm{C}$ & 1.03 & 0.98 & 1.01 & 1.21 & 1.14 \\
\hline Average & 1.15 & 1.09 & 1.13 & 1.36 & 1.27 \\
\hline $96017-1,2 \mathrm{~A}$ & 1.91 & 1.82 & 1.89 & 2.20 & 2.08 \\
\hline $96017-2,2 B$ & 1.18 & 1.05 & 1.09 & 1.26 & 1.19 \\
\hline $96017-3,2 \mathrm{C}$ & 1.46 & 1.39 & 1.44 & 1.65 & 1.54 \\
\hline Average & 1.52 & 1.42 & 1.47 & 1.70 & 1.60 \\
\hline $960183 \mathrm{~A}$ & 1.14 & 1.05 & 1.09 & 1.18 & 1.10 \\
\hline $960183 \mathrm{~B}$ & 1.16 & 1.21 & 1.24 & 1.36 & 1.27 \\
\hline $960183 \mathrm{C}$ & 1.14 & 1.08 & 1.11 & 1.28 & 1.20 \\
\hline Average & 1.14 & 1.11 & 1.15 & 1.27 & 1.19 \\
\hline
\end{tabular}




\section{PARTICLE MOUNT PREPARATION AND CERAMOGRAPHY}

Deconsolidated, burned-back particles from AGR-1 Variant 3 Compact 1-3-1 were loaded into eight cylindrical mounts and encapsulated with Buehler EpoHeat epoxy at the MFC AL. The mounts are listed in Table 11 with details on the particles (including identifiers corresponding to those in Table 6 for gamma-counted particles) and mount characteristics. All mounts were pneumatically transferred to MFC HFEF for surface preparation and ceramography. Except for Mounts $31 \mathrm{~V}$ and 32V, all mounts were intended as candidates for additional studies at the Electron Microscopy Laboratory (EML), if successfully prepared and if warranted by particle features.

Table 11. Compact 1-3-1 particle mounts.

\begin{tabular}{|c|c|c|c|c|c|}
\hline $\begin{array}{c}\text { Mount } \\
\text { Identification } \\
\end{array}$ & $\begin{array}{l}\text { Particle } \\
\text { Nos. }\end{array}$ & $\begin{array}{c}\mathrm{Ag}-110 \mathrm{~m} \\
\mathrm{M} / \mathrm{C}\end{array}$ & Mount Design & Primary Purpose & Status \\
\hline $25 \mathrm{~V}$ & 111 & 0.41 & $\begin{array}{l}\text { 25-mm OD stainless steel } \\
\text { with annular ID groove and } \\
\text { central Lexan pedestal }\end{array}$ & $\begin{array}{l}\text { Microstructural influences } \\
\text { on fission product behavior }\end{array}$ & $\begin{array}{l}\text { Ceramography complete, } \\
\text { transferred to EML }\end{array}$ \\
\hline $26 \mathrm{~V}$ & 66 & 0.39 & $\begin{array}{l}\text { 25-mm OD stainless steel } \\
\text { with annular ID groove and } \\
\text { central Lexan pedestal }\end{array}$ & $\begin{array}{l}\text { Microstructural influences } \\
\text { on fission product behavior }\end{array}$ & $\begin{array}{l}\text { Ceramography complete, } \\
\text { transferred to EML }\end{array}$ \\
\hline $27 \mathrm{~V}$ & 69 & $<0.14$ & $\begin{array}{l}\text { 25-mm OD stainless steel } \\
\text { with annular ID groove and } \\
\text { central Lexan pedestal }\end{array}$ & $\begin{array}{l}\text { Microstructural influences } \\
\text { on fission product behavior }\end{array}$ & $\begin{array}{l}\text { Ceramography complete, } \\
\text { stored in HFEF }\end{array}$ \\
\hline $28 \mathrm{~V}$ & 74 & 0.43 & $\begin{array}{l}\text { 25-mm OD stainless steel } \\
\text { with annular ID groove and } \\
\text { central Lexan pedestal }\end{array}$ & $\begin{array}{l}\text { Microstructural influences } \\
\text { on fission product behavior }\end{array}$ & $\begin{array}{l}\text { Ceramography complete, } \\
\text { stored in HFEF }\end{array}$ \\
\hline $29 \mathrm{~V}$ & 76 & 0.17 & $\begin{array}{l}\text { 25-mm OD stainless steel } \\
\text { with annular ID groove and } \\
\text { central Lexan pedestal }\end{array}$ & $\begin{array}{l}\text { Microstructural influences } \\
\text { on fission product behavior }\end{array}$ & $\begin{array}{l}\text { Ceramography complete, } \\
\text { transferred to EML }\end{array}$ \\
\hline $30 \mathrm{~V}$ & 99 & $<0.06$ & $\begin{array}{l}\text { 25-mm OD stainless steel } \\
\text { with annular ID groove and } \\
\text { central Lexan pedestal }\end{array}$ & $\begin{array}{l}\text { Microstructural influences } \\
\text { on fission product behavior }\end{array}$ & $\begin{array}{l}\text { Ceramography complete, } \\
\text { transferred to EML }\end{array}$ \\
\hline $31 \mathrm{~V}$ & $\begin{array}{l}\text { Not } \\
\text { applicable } \\
(\mathrm{N} / \mathrm{A})^{\mathrm{a}}\end{array}$ & $\mathrm{N} / \mathrm{A}^{\mathrm{a}}$ & $\begin{array}{l}\text { 32-mm OD Micarta with } \\
\text { annular ID groove and } \\
\text { central Lexan pedestal }\end{array}$ & $\begin{array}{l}\text { Multi-level optical } \\
\text { characterization of TRISO } \\
\text { layer behavior on } 99 \\
\text { random particles }\end{array}$ & $\begin{array}{l}\text { Examined at four levels } \\
\text { for internal morphology, } \\
\text { stored in HFEF }\end{array}$ \\
\hline $32 \mathrm{~V}$ & $\mathrm{~N} / \mathrm{A}^{\mathrm{a}}$ & $\mathrm{N} / \mathrm{A}^{\mathrm{a}}$ & $\begin{array}{l}\text { 32-mm OD Micarta with } \\
\text { annular ID groove and } \\
\text { central Lexan pedestal }\end{array}$ & $\begin{array}{l}\text { Multi-level optical } \\
\text { characterization of TRISO } \\
\text { layer behavior on } 99 \\
\text { random particles }\end{array}$ & $\begin{array}{l}\text { Examined at two levels } \\
\text { for internal morphology, } \\
\text { stored in HFEF }\end{array}$ \\
\hline
\end{tabular}

\subsection{Single-Particle Mounts 25V Through 30V}

The design used for Mounts $25 \mathrm{~V}$ through $30 \mathrm{~V}$ is shown in Figure 7. Each particle was loaded through a narrow funnel while a central pedestal forced the particle away from the mount center. Thick, double-sided adhesive tape (backed by a glass slide) was used to hold the particle in place while Buehler EpoHeat two-part epoxy was poured into the mount. The epoxy was cured in a furnace for 90 minutes at $55^{\circ} \mathrm{C}$. An annular groove in the lower interior of the mount prevented the epoxy from sliding inside the steel during handling and grinding. In combination with the glass-backed tape, the annular groove also encouraged most of the epoxy meniscus (caused by epoxy shrinkage during curing) to form at the mount top. Nevertheless, the epoxy still receded slightly inward at the mount base during curing, pulling the particle and the pedestal inward in the process. A circular recess in the mount base limited the amount of steel that had to be ground off while approaching the particle midplane. 


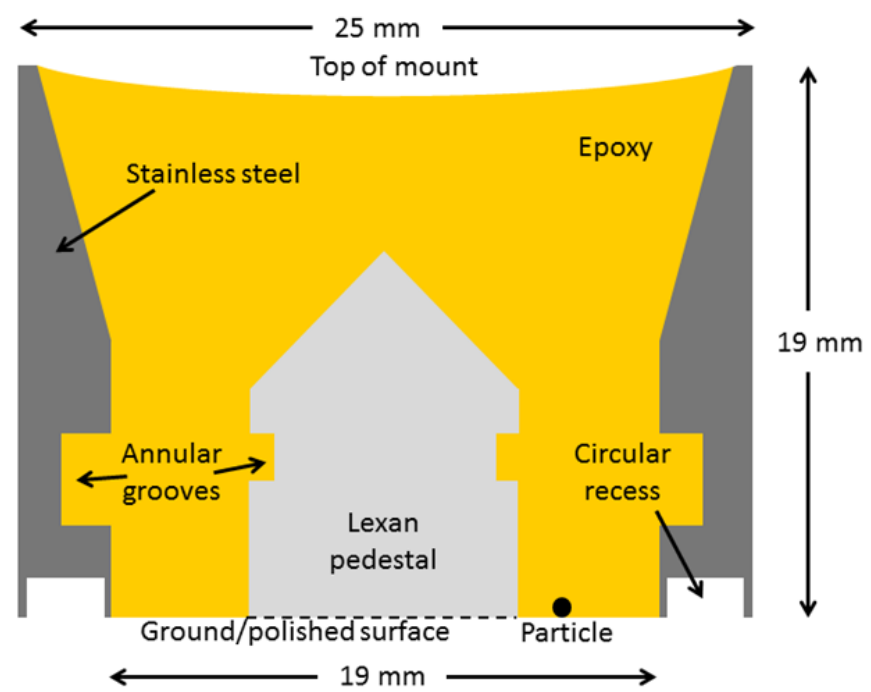

Figure 7. Cross-sectional diagram through center of a Compact 1-3-1 single-particle mount.

The glass slide and tape were left in place for pneumatic transfer to HFEF, and were subsequently remotely pried off of the mounts with a putty knife at the HFEF Containment Box. The circular recess in each steel mount was filled with epoxy to reduce the number of steel fragments that tore loose to abrade mount surfaces during grinding. Coarse grinding was conducted with a Struers MD-Piano 600-grit diamond disc until each particle was contacted. At this point the mount thicknesses were measured at their centers with a dial indicator-based gauge. These reference thicknesses were compared to additional measurements made as coarse grinding continued to roughly estimate how much of each particle had been ground away (complementing periscope inspections of exposed layers). Well before midplane was reached, a silhouette image of each particle was obtained on the HFEF metallograph for a trigonometric comparison to the $\mathrm{SiC}$ radius at the ground plane for calculating more accurate distances to midplane.

All mounts were incrementally impregnated with epoxy under vacuum (back-potted) to stabilize internal particle structures. The initial back-pot was done shortly after coarse grinding through the $\mathrm{SiC}$ and IPyC layers, which opened radial gaps between the IPyC and buffer layers for epoxy penetration. A second back-pot was normally performed after grinding into the kernels to fill any buffer-kernel gaps and further stabilize kernels. A foam-tipped swab was used to smooth eyedropper-applied back-potting epoxy in advance of vacuum impregnation, which reduced the thickness of surplus epoxy that had to be ground off before continuing to abrade the mount surface.

After the second back-pot, coarse grinding was performed with a Struers MD-Piano 500-grit disc because the supply of older 600-grit discs had been exhausted. No obvious differences in grinding behavior were observed during a metallograph check. Grinding continued on all mounts until thickness gauge measurements indicated each particle had been ground to approximately $25 \mu \mathrm{m}$ of midplane. Fine grinding was then performed with an MD-Piano 1200-grit diamond disc, typically for a total of 16 minutes at a $10-\mathrm{N}$ force. The subsequent polish with a $3-\mu \mathrm{m}$ diamond suspension was performed on MD-Dur polishing pad, typically for a total of 12 minutes at 40-N force. All of the Compact 1-3-1 singleparticle mounts were then polished with an MD-Nap pad and a 1- $\mu \mathrm{m}$ diamond suspension (6 minutes at $20-\mathrm{N}$ force). They were finished with an MD-Chem pad and $0.04-\mu \mathrm{m}$ colloidal silica suspension (6 minutes at $20-\mathrm{N}$ force).

Ceramographic investigations were aimed at conspicuous behavior of TRISO layers during irradiation. These studies were conducted on a Leitz metallograph using a variable resolution Jenoptik ProgRes C14+ camera. Highlights are presented below. Particles are classified here according to a morphological scheme (see Appendix C) developed previously (Ploger et al. 2012) to analyze particles in cross-sectioned AGR-1 fuel compacts. Type A particles exhibit a continuous gap between the buffer and 
IPyC layers in the plane of polish, Type B particles show bonding between the buffer and IPyC layers along the entire interface, and Type $\mathrm{AB}$ particles display partial debonding between these layers. These three basic particle types are subdivided according to whether the buffer stayed intact or fractured. Appendix C, Figure C-1, presents representative examples of all six characteristic morphologies.

\subsubsection{Particle AGR1-131-111 (Mount 25V)}

Particle AGR1-131-111 (above average Ag-110m inventory) was ground within $28 \mu \mathrm{m}$ of its SiC midplane, based on a trigonometric comparison of its measured radius in the polished plane $(353.6 \mu \mathrm{m})$ to the radius of its silhouette image $(354.7 \mu \mathrm{m})$. As shown in the left side of Figure 8, this particle is classified as Type Ai (intact buffer that delaminated completely from the IPyC layer in the observed plane). In addition, the buffer separated from the kernel along the exterior of a thin, low porosity layer surrounding the kernel that is referred to as a uranium carbide "skin," which forms during particle fabrication (Hunn et al. 2005). More often in irradiated AGR-1 particles, the uranium carbide skin adhered to the buffer and a distinct boundary may be observed between the porous kernel and relatively dense skin. Figure 8 also reveals fractures inside the kernel periphery. As is typically the case, kernel pores are somewhat larger in the interior than along the periphery (Ploger et al. 2012).

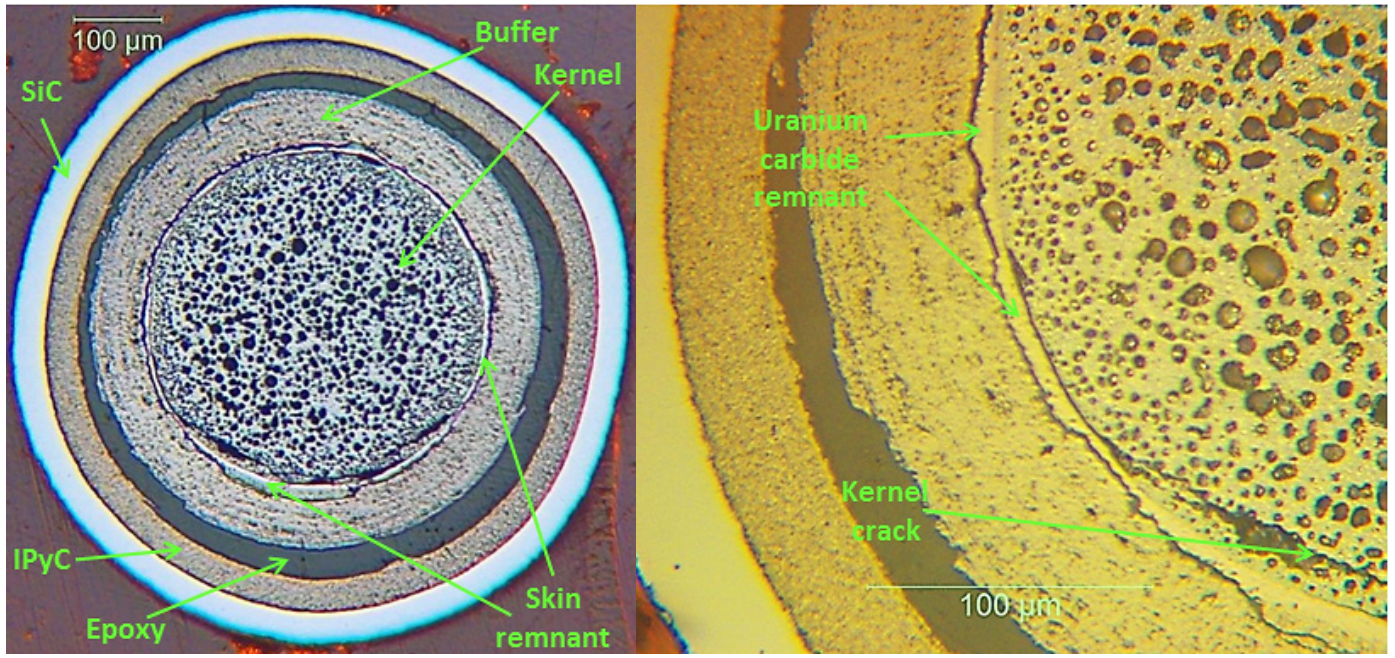

Figure 8. Type Ai morphology in particle AGR1-131-111 (left) and complex fracture pattern near its kernel-buffer interface (right).

\subsubsection{Particle AGR1-131-066 (Mount 26V)}

Particle AGR1-131-066 (above average Ag-110m inventory) was ground within approximately $45 \mu \mathrm{m}$ of its $\mathrm{SiC}$ midplane (359.2- $\mu \mathrm{m}$ silhouette radius, very close to the nominal as-fabricated SiC radius for Variant 3 fuel of $358.3 \mu \mathrm{m}$ ). As shown in the left side of Figure 9, the intact buffer is still bonded to the IPyC layer along the right portion of the interface (Type ABi), while a large gap (partially filled with back-potted epoxy) formed between these layers on the faceted side. In this particle, the kernel and buffer separated with the uranium carbide skin attached to the buffer, as is often observed. 


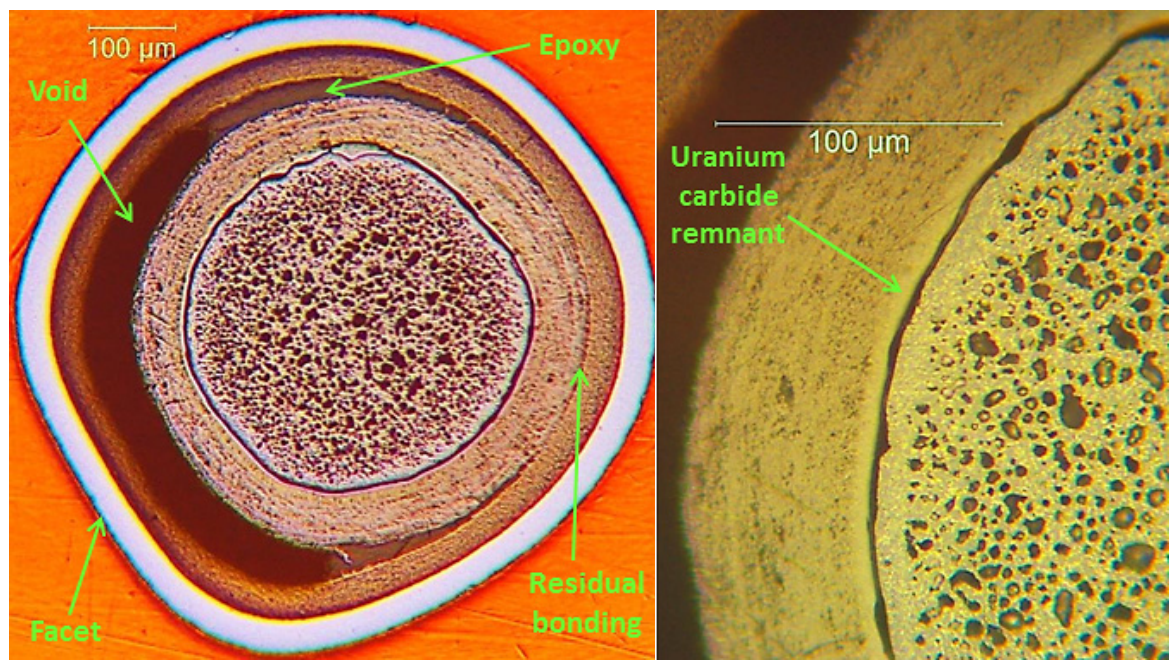

Figure 9. Aspherical Type ABi particle AGR1-131-066 (left) and gap between kernel and residual uranium carbide skin (right).

\subsubsection{Particle AGR1-131-069 (Mount 27V)}

Type Ai particle AGR1-131-069 (below average Ag-110m inventory) was ground within $44 \mu \mathrm{m}$ of its $\mathrm{SiC}$ midplane, based on the radii measured in the polished plane $(339.5 \mu \mathrm{m})$ and in its silhouette $(336.7 \mu \mathrm{m})$. As shown in Figure 10, this particle is similar to particle AGR1-131-111 (Figure 8) in that the buffer and IPyC layer have completely delaminated in the polished plane and the uranium carbide skin adhered to the kernel rather than the buffer. However, the close proximity of the buffer to the IPyC layer on the lower-left side suggests that some bonding may have persisted above or below this plane. Had the buffer and kernel been completely free within the IPyC layer, they likely would have moved under gravity into the mount before being stabilized by back-potted epoxy. If so, the radial gap between the buffer and IPyC layers would probably display a more even thickness (assuming the hidden portion of the particle is also nearly spherical).
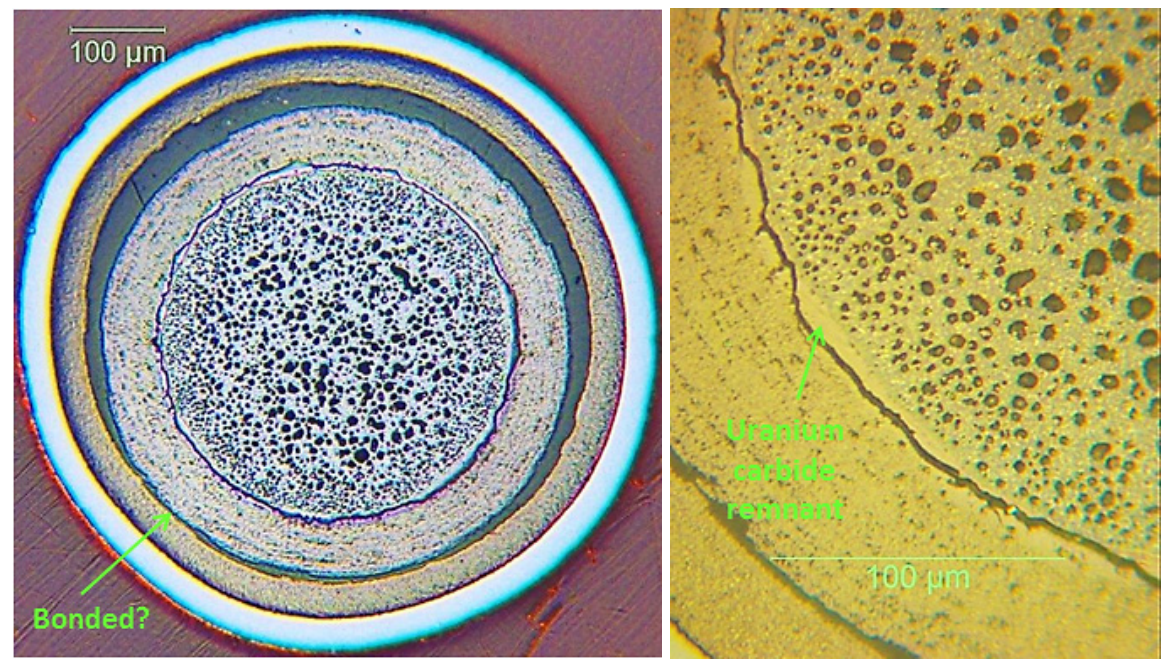

Figure 10. Type Ai morphology in particle AGR1-131-069. 


\subsubsection{Particle AGR1-131-074 (Mount 28V)}

Type ABi particle AGR1-131-074 (above average Ag-110m inventory) was ground within $28 \mu \mathrm{m}$ of its $\mathrm{SiC}$ midplane based on radii in the polished plane $(347.4 \mu \mathrm{m})$ and in its silhouette $(348.5 \mu \mathrm{m})$. As shown in the left image in Figure 11, thin strips of buffer intermittently remained attached to the IPyC layer where bonding was locally stronger than the internal strength of the buffer. The right portion of Figure 11 highlights a low porosity kernel periphery that may be a remnant of a uranium oxide rind (Hunn et al. 2012).
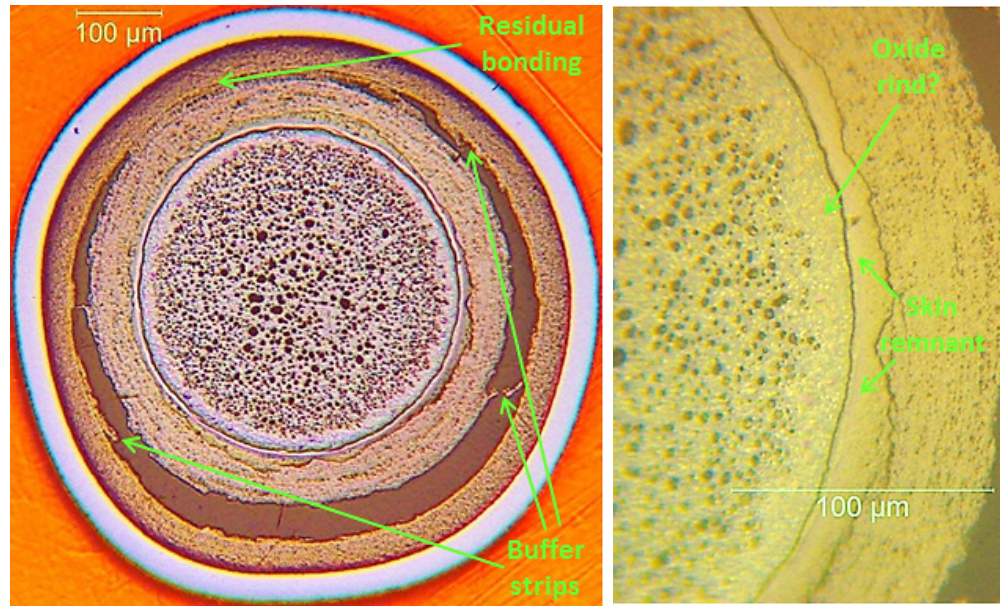

Figure 11. Buffer tearing and kernel porosity in Type ABi particle AGR1-131-074.

\subsubsection{Particle AGR1-131-076 (Mount 29V)}

Type ABi particle AGR1-131-076 (below average Ag-110m inventory) was ground close to its SiC midplane (within approximately $29 \mu \mathrm{m}$ ) based on radii in the polished plane $(360.3 \mu \mathrm{m})$ and in its silhouette $(361.5 \mu \mathrm{m})$. As with particle AGR1-131-074 (Figure 11), Figure 12 reveals incomplete buffer-IPyC delamination and a kernel periphery with little or no porosity that may be related to a uranium oxide rind. However, the low porosity region is much thicker in this particle, which may represent a relatively thick as-fabricated rind (Hunn et al. 2012). Note that the residual buffer-IPyC bonding in this Type ABi particle held the kernel midplane at approximately the same mount elevation as the $\mathrm{SiC}$ midplane, so the thickness of the low porosity region is not exaggerated in Figure 12 due to lack of concentricity between kernel and SiC.
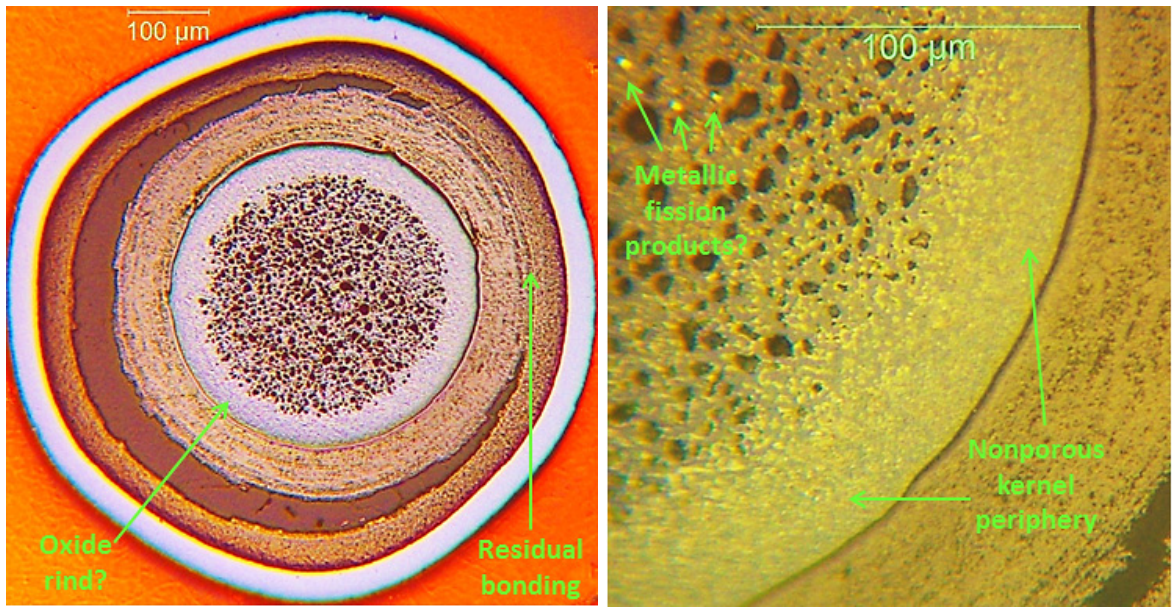

Figure 12. Thick low porosity periphery in kernel of Type ABi particle AGR1-131-076. 


\subsubsection{Particle AGR1-131-099 (Mount 30V)}

Type Ai particle AGR1-131-099 (below average Ag-110m inventory) was ground within $35 \mu \mathrm{m}$ of its $\mathrm{SiC}$ midplane according to radii measured in the polished plane $(359.2 \mu \mathrm{m})$ and in its silhouette image (360.9 $\mu \mathrm{m})$. As with particle AGR1-131-069 (Figure 10), the proximity of the buffer to the faceted side of the IPyC in Figure 13 suggests that these layers may still have been locally bonded away from the polished plane (i.e., this particle may actually be Type ABi). Alternatively, the lack of a corresponding facet on the buffer surface may indicate that the buffer and enclosed kernel rotated during early grinding before the initial back-pot. Most IPyC cracks that have been observed in irradiated AGR-1 particles have been wider on the IPyC interior than the exterior (Ploger et al. 2012), so the hairline crack in Figure 13 may possibly have been caused by mount preparation. In any case, the kernel in particle AGR1-131-099 has a thick periphery with little or no porosity that is very similar to the kernel in Figure 12, along with some connected porosity near the kernel center.

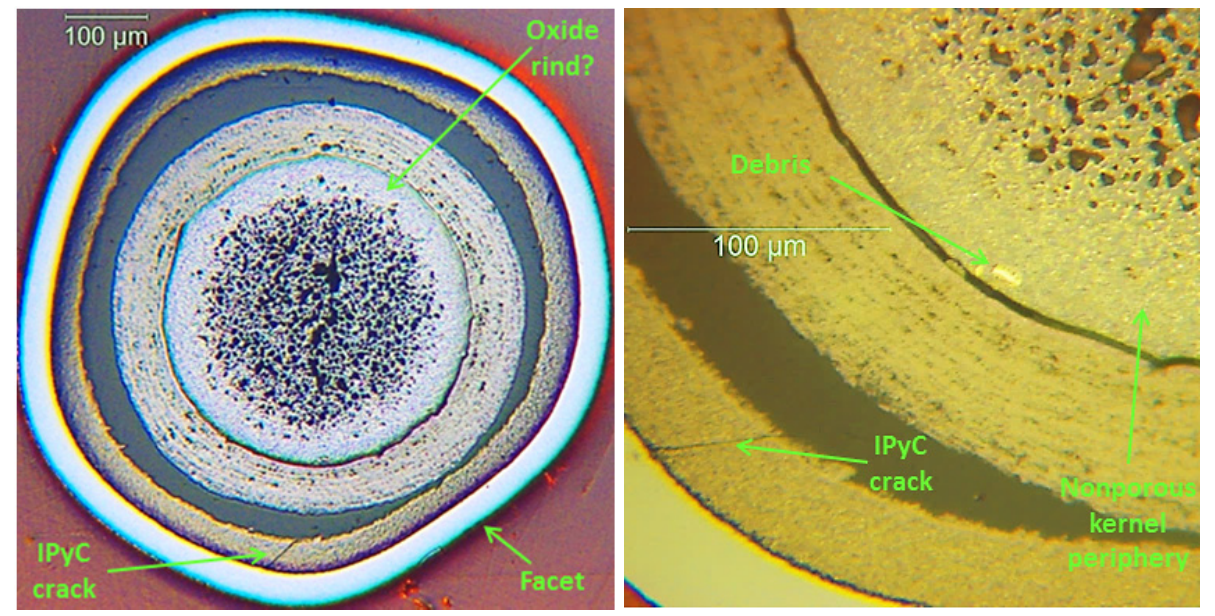

Figure 13. Thick low porosity kernel periphery and IPyC crack in Type Ai particle AGR1-131-099.

\subsubsection{Fission Product Behavior}

Ceramography was unable to uncover any definite relationship between Ag-110m inventory and internal particle morphology in Mounts 25V through 30V. For example, particles AGR1-131-076 and AGR1-131-099 both had thick low porosity kernel peripheries and lower Ag-110m inventories. However, particle AGR1-131-069 retained similarly little Ag-110m but its kernel exhibited porosity all the way to its edge.

\subsection{9-Particle Mounts 31V and 32V}

The width of the radial buffer-IPyC gap is of special interest for modeling heat transfer from the kernel to the compact matrix (Collin and Ploger 2013). Gap width is jointly determined by kernel swelling and buffer densification because dimensions of the outer three TRISO layers change relatively little during irradiation. Accordingly, an attempt was made to measure both kernel and buffer areas on particle images from transverse cross sections through three representative compacts, as well as to measure the average gap thicknesses (Ploger et al. 2012). Although kernels clearly swelled, buffers definitely densified, and radial gaps certainly opened, computed average changes from as-fabricated averages were not sufficiently reliable for quantitative modeling purposes. This was true even after excluding particles with fractured buffers and protruding kernels that deviated strongly from spherical geometries. Key reasons included cross-sectioning particles too far from midplane, lack of concentricity between loose buffers/kernels and outer TRISO layers, and the substantial variability in kernel size and TRISO layer thicknesses among as-fabricated AGR-1 particles. 
Consideration of these difficulties created the concept of cross-sectioning a planar array of many particles at multiple elevations, followed by fitting the radial measurements to spheres to estimate their true radii. Along with eliminating the staggered particle elevations in cross-sectioned compacts, this approach would allow decoupling kernels and buffers from outer TRISO shells so that internal concentricity was no longer important. In addition, mounting particles in translucent epoxy (as opposed to an opaque compact matrix) would permit measuring silhouette radii for comparison to outer particle radii for determining distances between levels on an individual particle basis. Lastly, cross-sectioning particles at multiple elevations would provide more insight on morphological features such as layer fracture patterns and debonding between layers.

\subsubsection{Mount Preparation and Examination}

The 99 particles loaded into each of Mounts $31 \mathrm{~V}$ and 32V were extracted from a bin containing approximately 4000 particles and thus were chosen on a nominally random basis. Several mount designs had been tested previously for evenly securing a large ensemble of particles in epoxy. The iteration ultimately implemented for this proof-of-principle demonstration is shown in Figure 14. A thick piece of glass-backed, double-sided tape (not shown) was first attached to the base of a Micarta laminate mount. The Lexan polycarbonate pedestal was then pressed into the tape at the center of the opening, followed by loading ten zirconia spheres as possible aids for checking grinding depth. After this assembly was inserted in an AL hot cell, the irradiated particles were poured through a funnel and distributed around the annulus by the pedestal. Tape adhesion prevented particles from floating upward as Buehler EpoHeat two-part epoxy was gradually added to fill the annulus. Most of the air trapped as bubbles between particles was removed by applying a vacuum, which was done in two brief cycles to limit preferential evacuation of the especially volatile hardening agent. The vacuum also removed air trapped in the annular gaps, which locked the epoxy to both the Micarta and Lexan as it was cured in a furnace for 90 minutes at $55^{\circ} \mathrm{C}$. The epoxy shrank somewhat during curing, forming a conspicuous meniscus at the mount tops. A slight meniscus also formed at the bases, despite the glass-backed double-sided tape. However, distributing the particles around an annulus diminished the effect of the bottom meniscus and kept most particles close to co-planar during curing.

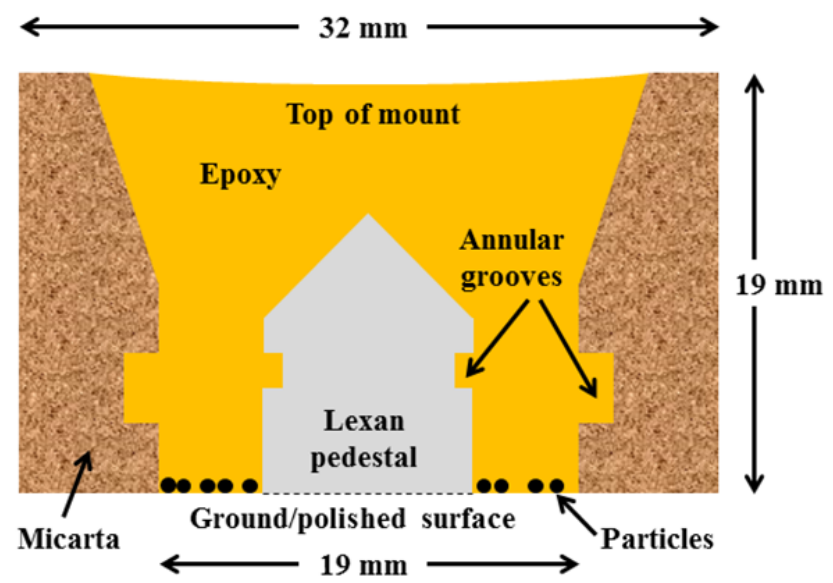

Figure 14. Cross-section diagram showing the design and particle loading arrangement in Mounts $31 \mathrm{~V}$ and $32 \mathrm{~V}$.

The cured mounts were transferred pneumatically to HFEF for grinding, polishing, and ceramography. Grinding and polishing were conducted in the HFEF containment box, which isolates loose contamination and water lubricant vapor from the remainder of the inert atmosphere facility. The glass and tape were pried off upon arrival, followed by grinding with a Struers MD-Piano 1200-grit disc at 15 - to $20-\mathrm{N}$ force over 2-minute intervals until buffer-IPyC gaps could be seen through the periscope in some of the particles. 
5.2.1.1 Mount 31V. All 99 particles in Mount 31V had been exposed by the time some buffer-IPyC gaps became conspicuous, but the particles with open gaps were concentrated in one quadrant of the annulus. The epoxy recessed farther inward while curing on the opposite quadrant, pulling particles off the tape into a crescent-shaped recess. Fortunately, as shown in Figure 15, this recessed region contained relatively few particles. Although gaps had not yet been opened in many particles, Mount $31 \mathrm{~V}$ was vacuum-impregnated with a thin layer of EpoHeat epoxy to stabilize buffers in the particles with open gaps. Before the back-potted epoxy was cured under a lamp, the surplus epoxy was swabbed to preferentially cover the particles that had received the most grinding. This deliberately introduced a slight tilt to the mount base in an effort to improve the depth uniformity for most particles in the ground plane. Grinding continued with the 1200-grit disc in short intervals until buffer-IPyC gaps were apparent through the periscope in virtually all particles, including those within the recessed region. At this point kernels could be seen in only five of these particles, so particles outside the recessed crescent were nearly at the same elevation after tilting the base. Mount $31 \mathrm{~V}$ was then vacuum-impregnated with epoxy for a second time to fill the recently opened gaps and lock the buffers and enclosed kernels in place. This time the surplus back-potted epoxy was left in a uniformly thin layer before curing.

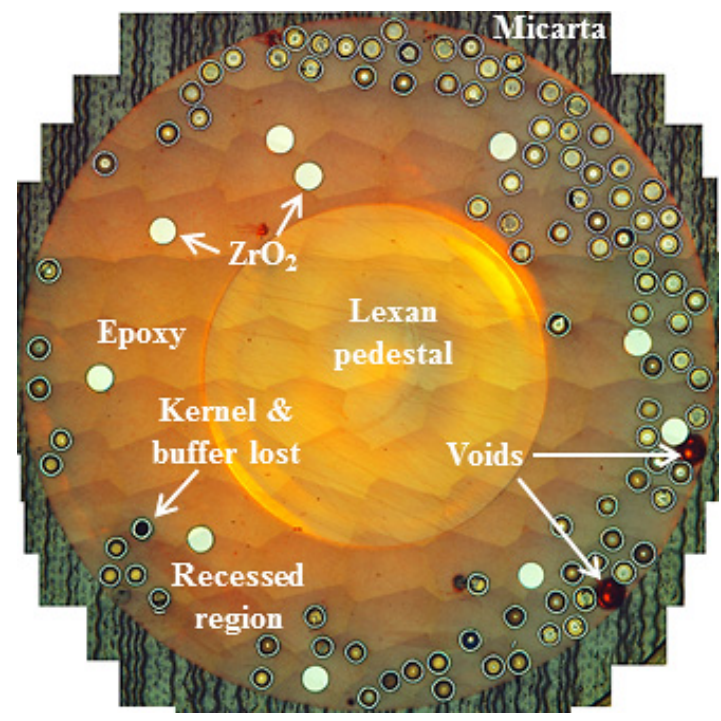

Figure 15. Montage of the first polished level on Mount 31V.

Grinding continued with the 1200-grit disc in short intervals with minimal 10-N force until kernels could be seen by periscope in the vast majority of the particles outside the recess. Mount $31 \mathrm{~V}$ was then polished with a 3- $\mu \mathrm{m}$ diamond suspension on a Struers MD-Mol cloth. Minimal force was used for a relatively brief 9-minute duration, which adequately defined layer edges without prohibitively rounding any of them. Finer polishing steps that typically are performed on TRISO particle mounts prior to ceramography were skipped in the interest of time, as the primary focus of these analyses was not detailed microstructural features but rather gross particle interior morphology. After pneumatic transfer to the shielded Leitz metallograph, low magnification images were taken of all particles (except one whose buffer and kernel were lost) with a Jenoptik ProgRes C14+ camera and assembled into a montage (Figure 15) with Adobe Photoshop. After assigning numeric identifiers, 1.4-megapixel images were taken of individual particles at the largest available magnification that would capture each one within the field of view. A silhouette image of each particle was also taken at the same magnification with the aid of a flashlight with six light-emitting diodes and a diffuser plate, both of which rested inside a fixture on the mount top to backlight the particles. 
Three more levels were ground, polished, and examined on Mount 31V. Distances between planes were controlled with the aid of a dial indicator-based height gauge that made measurements close to the mount center on the Lexan pedestal. The ten zirconia spheres were not found to be helpful in estimating the distance between polish planes. The same general approach used for the first level was followed for the other levels except that the second level was accidentally polished with a Dur cloth for 12 minutes at a 40-N force (along with several other mounts requiring these parameters). This different polish on the second level did not noticeably compromise layer edges in particle images but, as depicted in Figure 16, the $\mathrm{SiC}$ layer in the second level was rougher than in other levels - evidently because of abrasive contaminants on the Dur cloth. As shown in Figure 16, the four levels were constrained within the upper kernel halves, which maintained lateral support by back-potted epoxy on the buffers and thus limited buffer/kernel pullout during grinding to only one of the 99 particles.

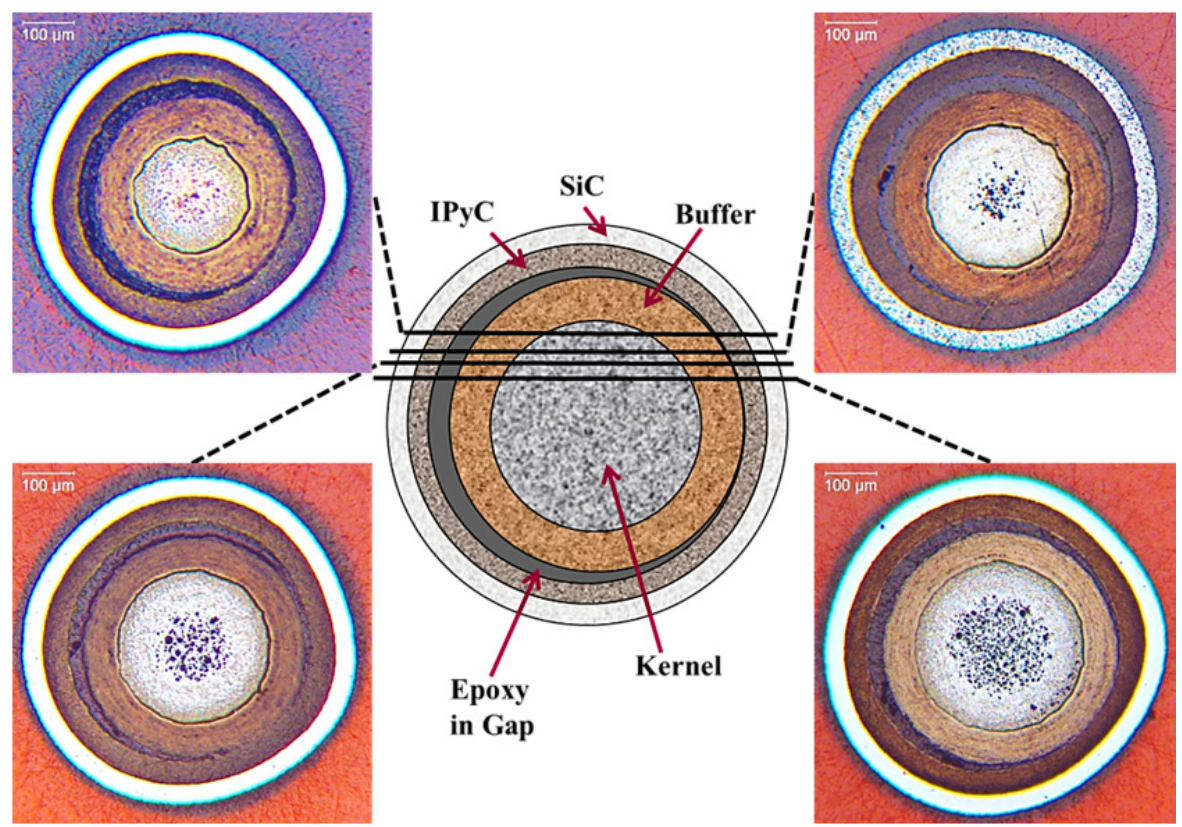

Figure 16. Images of AGR1-131-031 at all four levels examined along with approximate positions of these cross sections within a depth diagram for this particle.

5.2.1.2 Mount 32V. Mount $32 \mathrm{~V}$ was prepared much like Mount $31 \mathrm{~V}$, with grinding done by a 1200-grit disc, two back-pots before reaching the first examination level, and polishing confined to a 3- $\mu \mathrm{m}$ diamond suspension on a Mol pad. As shown in Figure 17, Compact 1-3-1 fuel particles and zirconia spheres were distributed uniformly around the annulus in Mount 32V. Despite a recessed region where some particles were pulled inward during epoxy curing and a tilting of the Lexan pedestal to allow some epoxy between it and the adhesive tape, this mount was initially the preferred candidate for examination at multiple levels. However, trigonometric comparison on the zirconia particles in the first and second levels established that material was being preferentially ground away on one side of the mount - the right side of Figure 17 where particles were already ground deeper in the first level. It appeared unlikely that sufficient Mount $32 \mathrm{~V}$ particles could be examined in the fashion shown in Figure 16 for adequate statistical confidence on kernel swelling and buffer densification. Consequently, only two levels were examined on Mount $32 \mathrm{~V}$ and no further levels were exposed by grinding. 


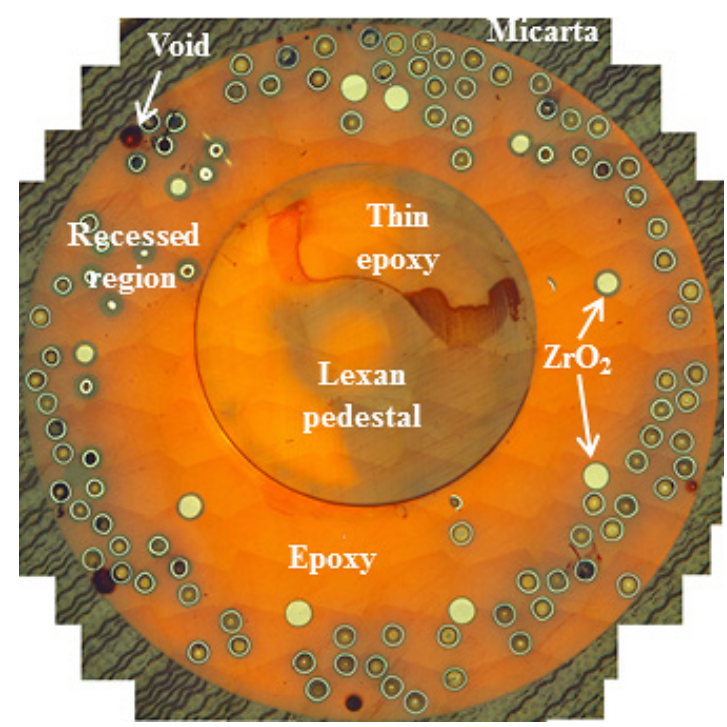

Figure 17. Montage of the first polished level on Mount 32V.

\subsubsection{Morphology Results from Ceramography on Mounts 31V and 32V}

Based on analysis of particles in irradiated compact cross sections (Ploger et al. 2012), it was anticipated that some particles classified as Type Ai based on only a single polish plane would reveal local buffer-IPyC bonding if sectioned at other levels, resulting in them being reclassified as Type ABi. This speculation is supported by Figure 18, which compares classification results from 98 particles in Mount $31 \mathrm{~V}$ to results from the 58 particles in Mount $32 \mathrm{~V}$ that could be classified. In Mount $31 \mathrm{~V}$ most of the kernels were exposed in all four levels examined, which meant that 3.7 levels were examined per particle on average. Although Mount 32V was ground and polished at two levels, half of the kernels in the 58 classifiable particles were not exposed until the second level, which produced an average examination level of 1.5. As expected, substantially fewer Type Ai particles and more Type ABi particles were identified in the mount with more levels examined. Figure 18 further indicates substantially more Type ABf particles in Mount $31 \mathrm{~V}$ than $32 \mathrm{~V}$, which suggests that more examination levels improve the likelihood of detecting fractured buffers. However, no significant difference was found in the frequency of Type Af particles between the two mounts, which may be an artifact of their relative rarity (only four Type Af particles in Mount 32V).

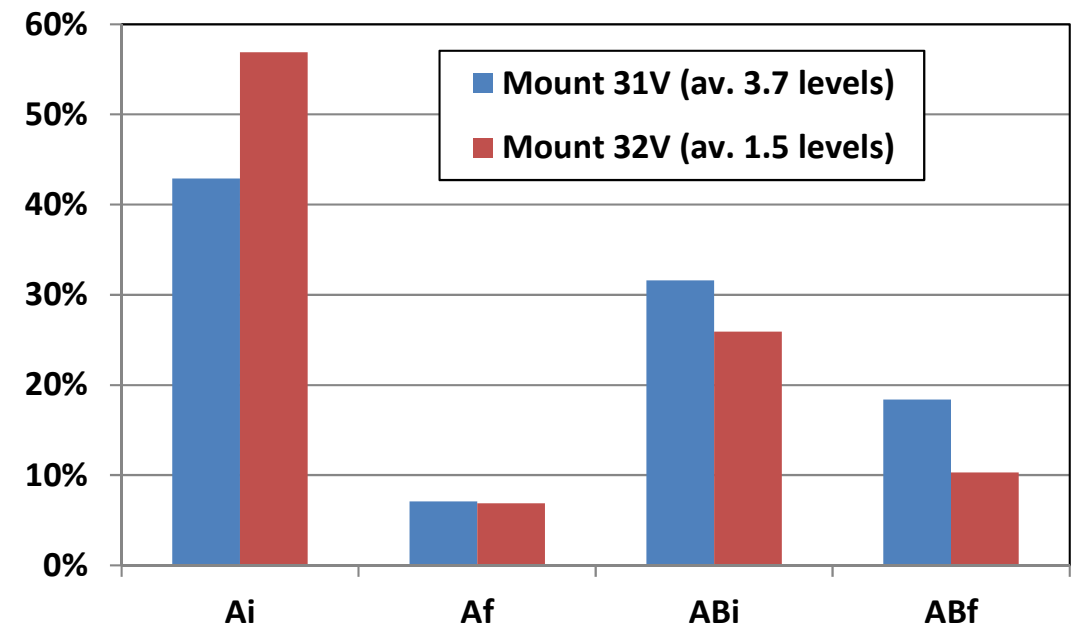

Figure 18. Multi-level classification results for particles in Mounts $31 \mathrm{~V}$ and $32 \mathrm{~V}$. 
Particles in Mounts 31V and 32V were also studied for defects such as IPyC fractures, IPyC-SiC debonds, and $\mathrm{SiC}$ fractures. No IPyC-SiC debonds or $\mathrm{SiC}$ fractures were discovered, but two particles in Mount $31 \mathrm{~V}$ contained fractures through the entire IPyC layer. The IPyC fracture shown in the left side of Figure 19 is where buffer-IPyC debonding evidently was terminated by strong local bonding, and the stress that accumulated there propagated the fracture through the IPyC layer. This morphology was relatively common in instances of IPyC fractures found during compact ceramography (Ploger et al. 2012). The arrangement in the right side of Figure 19 is far less common in Type ABf particles. Here the IPyC fractured at the tip of a radial buffer fracture well within a region of residual buffer-IPyC bonding. As such, it resembles the "spearhead" fractures typically observed in Type Bf particles with a fully bonded buffer-IPyC interface (Ploger et al. 2012).
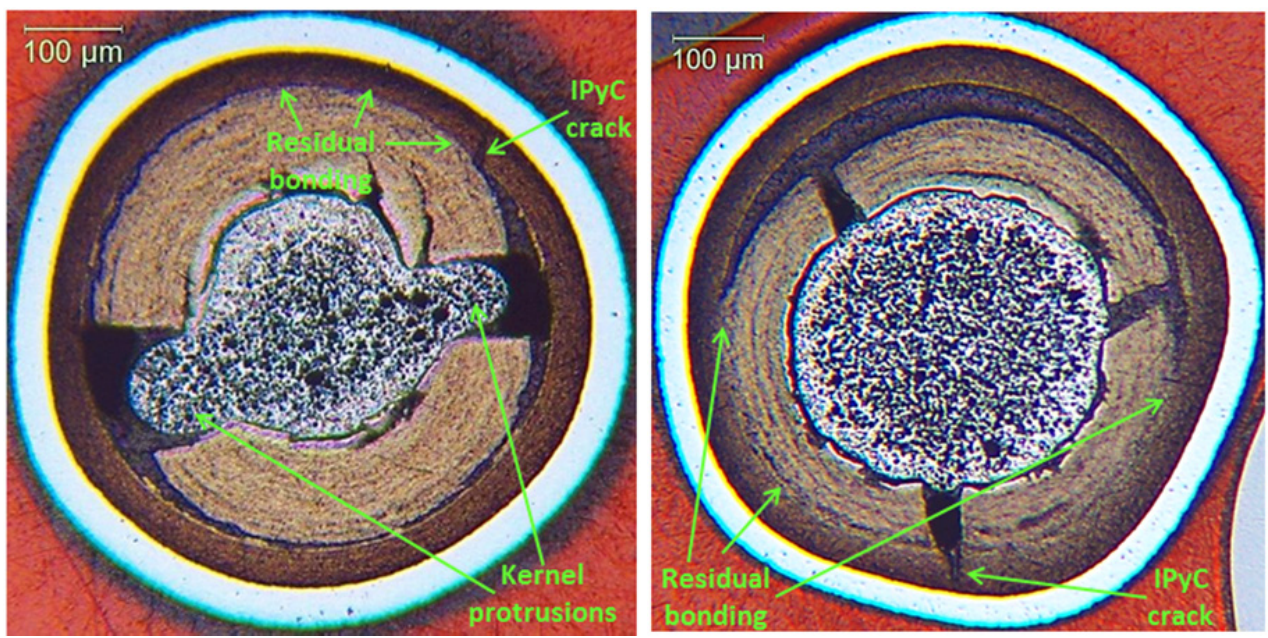

Figure 19. IPyC fractures in two Type ABf particles in Mount $31 \mathrm{~V}$.

The two IPyC fractures in Figure 19 are the first found in irradiated Variant 3 fuel, as shown in Figure 20. Although compact cross-sectional results in Ploger et al. (2012) inferred that Variant 3 fuel might have superior IPyC strength, the new findings from deconsolidated Compact 1-3-1 establish that the fracture resistance of Variant 3 IPyC layers is reasonably consistent with IPyC layers in irradiated Baseline and Variant 2 particles. However, Figure 20 demonstrates that Variant 1 particles are definitely more prone to IPyC fractures, presumably because of the lower Variant 1 IPyC density (Ploger et al. 2012).

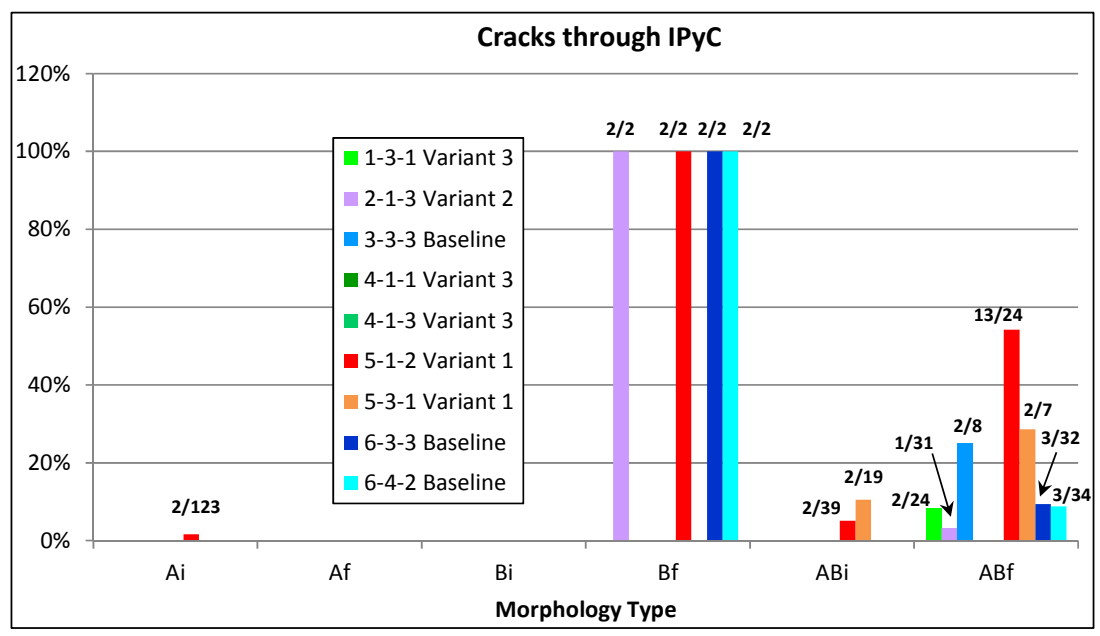

Figure 20. Frequency of IPyC cracks by particle type for six cross-sectioned AGR-1 compacts and deconsolidated particles from Compacts 4-1-1, 5-3-1, and 1-3-1. 
As mentioned above regarding Figure 11, Figure 12, and Figure 13, many of the single-particle mounts showed kernels with a periphery of substantial thickness that contained little or no porosity. This was also the case in Mounts $31 \mathrm{~V}$ and 32V. Based on Level 4 of Mount 31V, where grinding approached midplane on most kernels, approximately $9 \%$ of the kernels had a relatively thin low porosity periphery similar to Figure 11 and approximately $52 \%$ of the kernels exhibited a thick low porosity periphery similar to Figure 12 and Figure 13. Furthermore, while all of the kernels in Figure 11, Figure 12, and Figure 13 are round and symmetrical, low porosity kernel exteriors were also conspicuous inside fractured buffers with bulged kernels, as shown in Figure 21. Note that the kernel protrusions always contain considerable porosity. The total of $61 \%$ of particles exhibiting low porosity periphery is in rough agreement with a limited study of uranium oxide rinds in as-fabricated AGR-1 Baseline fuel, where approximately $68 \%$ of kernel cross sections revealed rinds of substantial thickness on their peripheries (Hunn et al. 2012). Consequently, the low porosity kernel peripheries are likely irradiated remnants of these as-fabricated rinds.
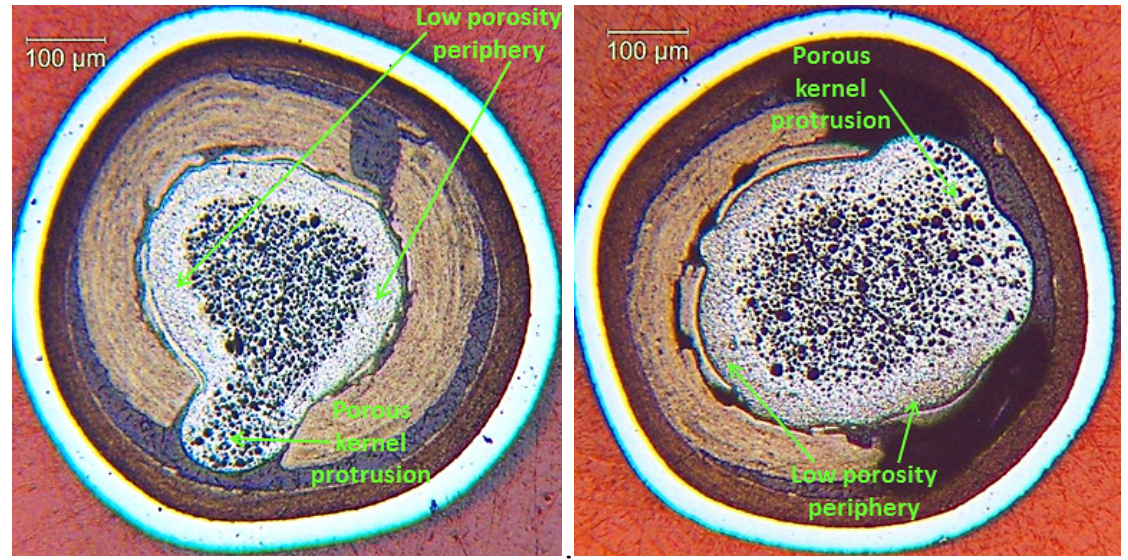

Figure 21. Regions of little or no porosity inside two particles from Mount 31V with fractured buffers.

Nevertheless, currently there is no satisfactory explanation for why the very low porosity kernel peripheries are much more common in Compact 1-3-1 particles than in irradiated particles from other compacts. Few (if any) such kernels were conspicuous in cross sections of Compacts 2-1-3, 3-3-3, 4-1-3, and 5-1-2, where outer kernel regions typically contained substantial fine porosity (Ploger et al. 2012). Thick kernel peripheries of low porosity were occasionally observed in Compact 6-3-3 particles, as demonstrated in Figure 22. But, even such unusual Compact 6-3-3 kernels (relative to frequent Compact 1-3-1 kernels) revealed some fine porosity upon metallograph examinations at higher magnifications.
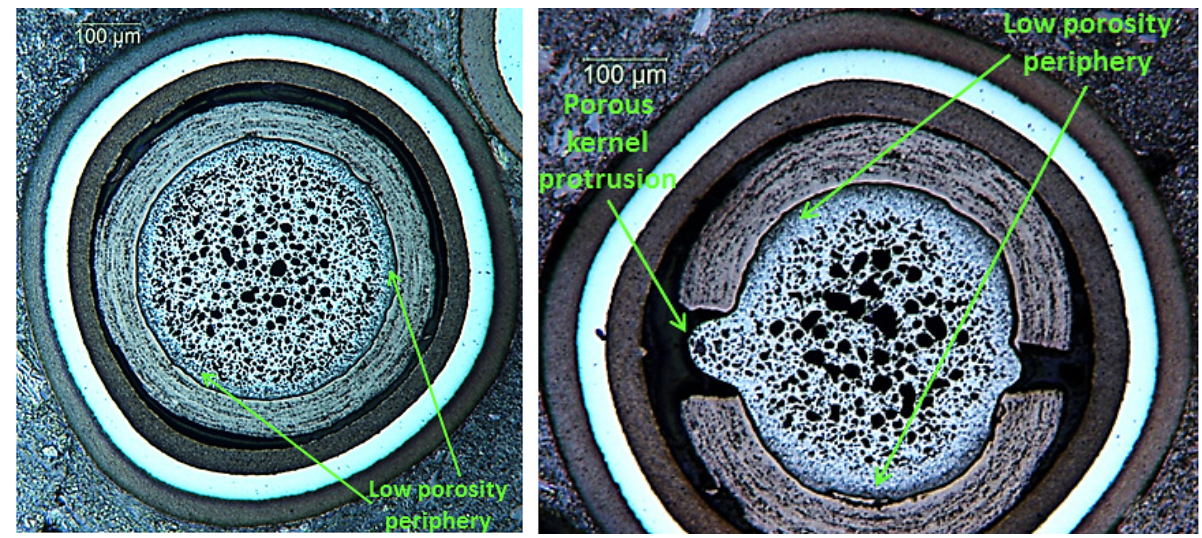

Figure 22. Isolated examples of kernels with low porosity peripheries in Compact 6-3-3 cross sections. 


\subsubsection{Radial Measurements on Mount 31V Images}

The geometry in Figure 16 with all four levels well inside the kernel was achieved for 81 of the 98 intact particles in Mount $31 \mathrm{~V}$. Although 81 particles possessed sufficient exposed kernel for measuring kernel radius in all four levels, 25 of these particles had fractured buffers and protruding kernels whose irregular shapes did not conform to a spherical geometry. Consequently, 56 particles in Mount $31 \mathrm{~V}$ were fully suitable for radial measurements.

Radii were extracted from images using PAX-it software from Midwest Information Systems, Inc. after calibrating pixel size to an image of a stage micrometer taken at the same magnification as the particle images. Kernel radii and outer buffer radii were measured on particle cross sections for later assessments of their respective swelling and densification. Inner buffer radii were assumed identical to the kernel radii. Radii were measured on inner IPyC layers to estimate the width of buffer-IPyC gaps. In the absence of the OPyC layers, outer $\mathrm{SiC}$ layer radii were measured on both cross-sectional images and particle silhouettes as indicators of overall particle sizes. Inner $\mathrm{SiC}$ radii could also have been measured on cross sections, but these measurements were not made because both the $\mathrm{SiC}$ and IPyC layers are considered far more stable during irradiation than the kernel and buffer of primary interest for this study.

Each radius was computed by the PAX-it software from a circle fit to sixteen manually selected points. An attempt was made to make the point selection process consistent to diminish subjectivity. The general approach adopted was to first select points at the top, bottom, left side, and right side of each object. Upper-left, upper-right, lower-left, and lower-right points were then picked by visually interpolating midway between the first set of four points. The last eight points were obtained by visually interpolating midway between the previous eight points. To eliminate transcription errors, computed radii from each particle were automatically exported by PAX-it onto a Microsoft Excel template, along with the five analyzed images and their identifiers. An example of a results spreadsheet is presented in Figure 23.
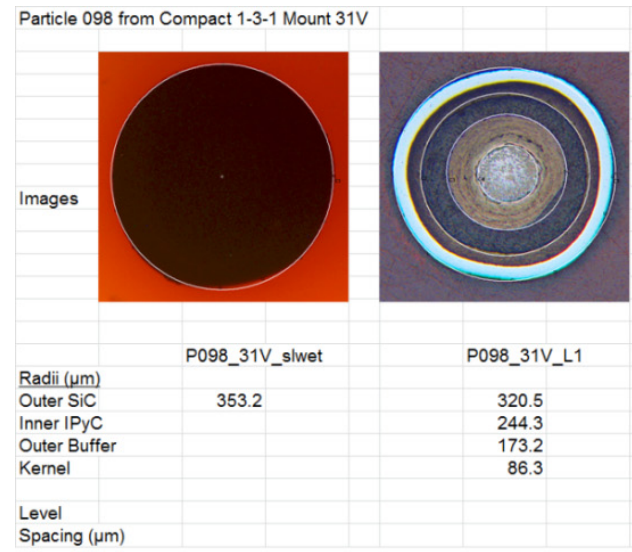
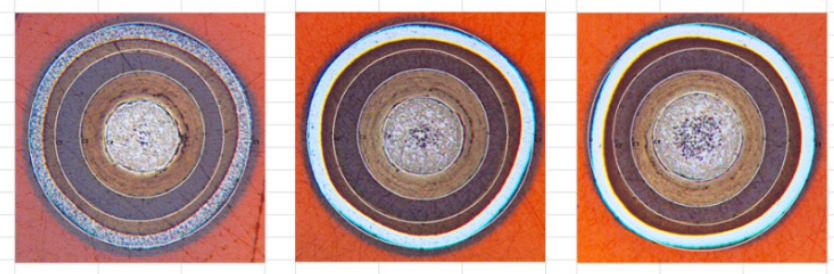

Figure 23. Output with radial results from the silhouette and four polished layers in particle AGR1-131-098.

Distances between polished layers were computed for each of the 56 particles by preliminary trigonometric comparisons between the polished $\mathrm{SiC}$ radii and the silhouette radius. Although these preliminary results were reasonably consistent within measurement error among nearby particles, slightly more material was ground off the mount portion with more particles (right side of Figure 15) than the portion with fewer particles. Grinding force evidently was preferentially applied to that same side of the mount by the centered pneumatic ram despite randomly loading the mount in the holding fixture before each grind (two or three iterations between each layer). Another surprising finding was that somewhat more material was removed from particles closer to the Lexan pedestal than along the periphery of the annulus. Nevertheless, uneven grinding had no definite adverse impact on subsequent analyses because 
particles were analyzed individually, independent of their positions within the mount.

The approach outlined above for selecting the sixteen points could not be followed in all cases, especially on some buffers. It was not unusual for a thin layer of buffer to intermittently adhere to the IPyC interior after most of the buffer shrank onto the kernel. An extreme example of this behavior is presented in Figure 24, where stringers of buffer also bridge between the IPyC and buffer bulk. Efforts were made to compensate for such separated buffers when picking points along buffer exteriors. One technique was to move the point outward by an amount that visually corresponded to the buffer thickness attached to the IPyC interior directly across the radial gap. In other situations, the preferred azimuths were shifted slightly to capture the full buffer thickness and avoid local regions where the buffer separated. All of these efforts were unavoidably subjective and likely injected more error in fitting circles to buffer exteriors than elsewhere within the particles where point selection was straightforward.

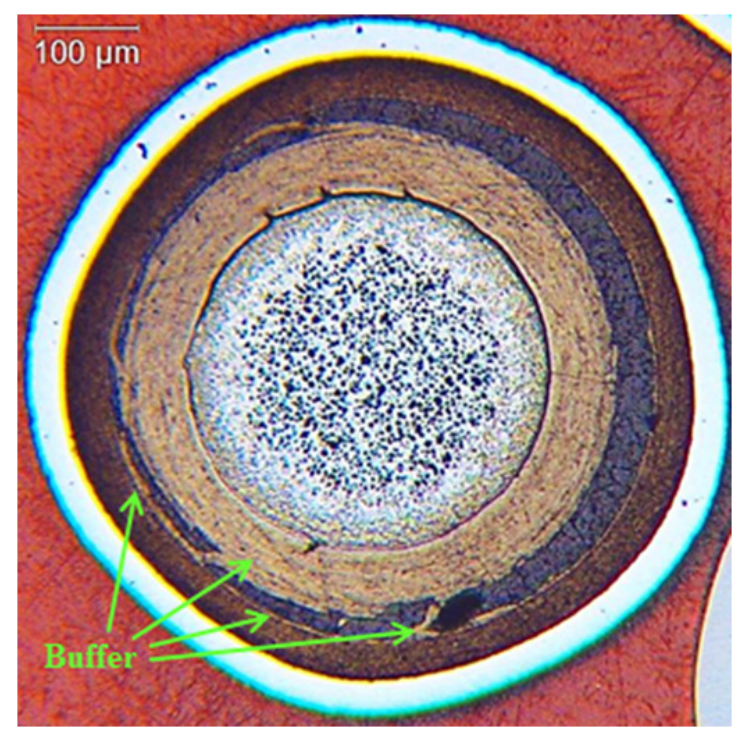

Figure 24. Buffer separation across the buffer-IPyC gap in Level 4 of particle AGR1-131-041 in Mount 31V.

As mentioned above, the inner buffer surface was assumed to be identical to the measured outer kernel surface, despite the very narrow kernel-buffer gap observed in some particles (e.g., Figure 16). These kernel-buffer gaps often appear to be an artifact of sample preparation where the brittle uranium carbide skin breaks out during grinding (Ploger et al. 2012). As discussed in Subsection 5.1, a region that appears to be the uranium carbide skin was found in some cases attached to the buffer, and in others attached to the kernel. Furthermore, there was no sharply defined boundary between the skin and the buffer, just a subtle difference in porosity and reflectivity. For these reasons, no attempt was made to divide the thickness of any residual skin between the kernel and buffer in the kernel measurements used for this study. This necessarily introduced some additional uncertainty into the kernel radius measurements. Scoping calculations suggest that this approach affects the perceived extents of both kernel swelling and buffer densification by at most a few percent.

True kernel radii and outer buffer radii were estimated by a mathematical model (Bower et al. 2016) that considered all seventeen measurements listed in Figure 23. Then the computed radii were converted into volumes assuming spherical geometry. Kernel results are presented in Figure 25. Relative to the nominal as-fabricated volume, the 56 kernels expanded during irradiation by approximately $26 \%$ on 
average. ${ }^{2}$ Buffer results in Figure 26 indicate an average volume reduction during irradiation of approximately $39 \%$. As indicated in many of the sectioned particle micrographs above, shrinkage of the intact buffer away from the IPyC layer opened a gap between the two layers. This gap was rarely uniform, due to various factors, including the fact that the kernel and buffer were not concentric with the outer TRISO layers. An average gap size in the particles analyzed was determined by taking the difference in the estimated buffer outer diameter and IPyC inner diameter. The resulting average gap was $26 \mu \mathrm{m}$, as shown in Figure 27.

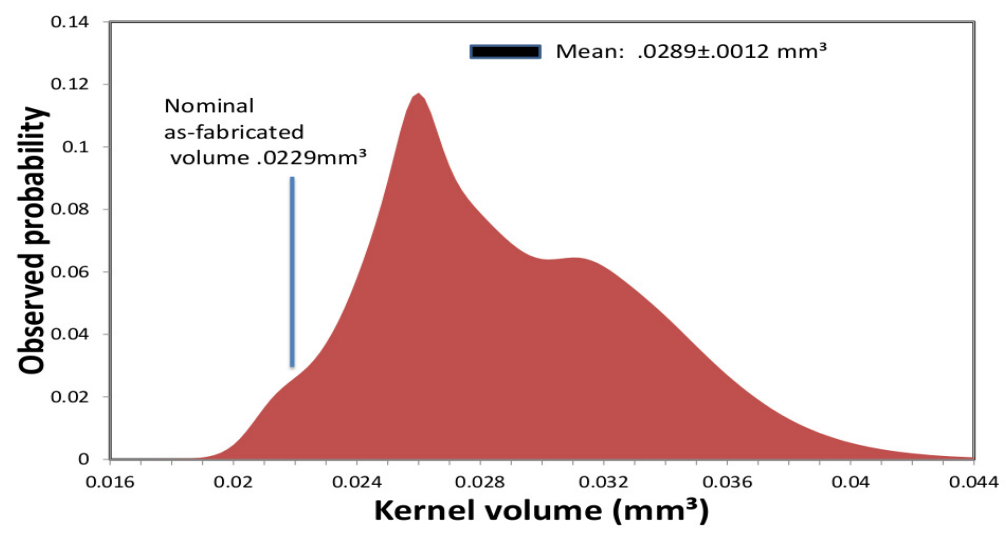

Figure 25. Distribution of irradiated kernel volumes from 56 particles cross sectioned at four levels.

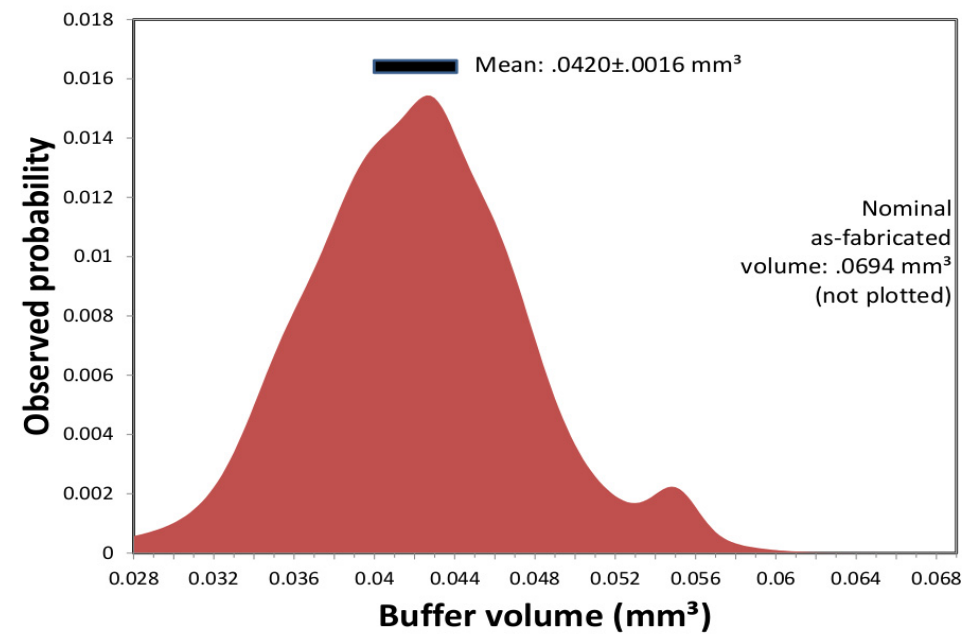

Figure 26. Irradiated buffer volumes from 56 particles cross sectioned at four levels.

\footnotetext{
${ }^{2}$ The as-fabricated kernel radii were determined based on cross section measurements on coated particles from the batch used to fabricate Compact 1-3-1, and this analysis included the carbide skin as part of the kernel. The average as-fabricated kernel radius from this method was determined to be $176.1 \mu \mathrm{m}$ (see additional discussion in Bower et al. 2016).
} 


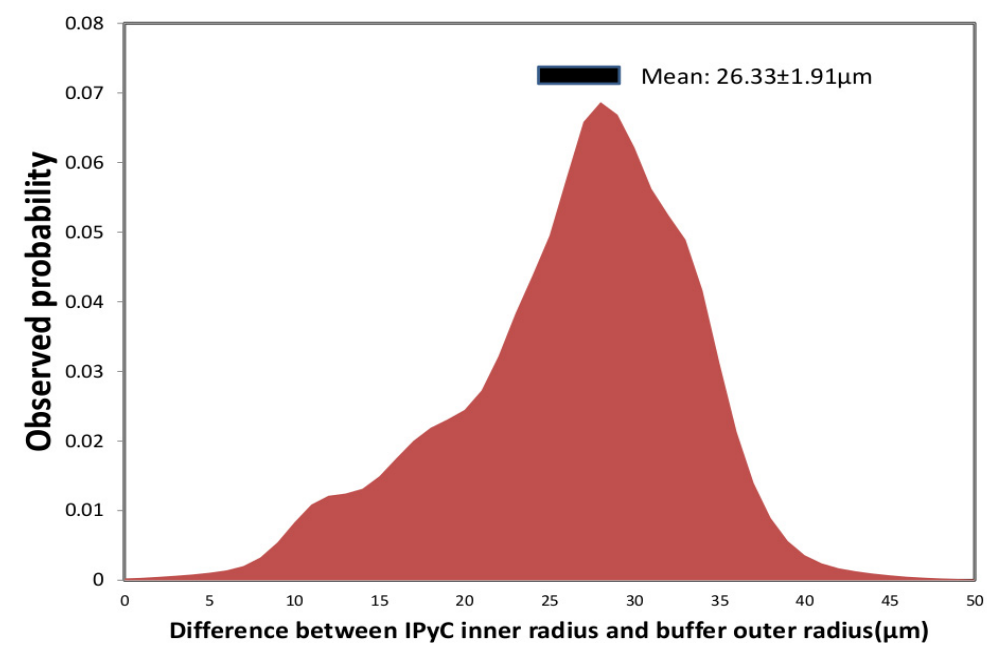

Figure 27. Distribution of buffer-IPyC gaps in the 56 irradiated particles.

\subsection{Advanced Particle Microanalysis}

Mounts $25 \mathrm{~V}, 26 \mathrm{~V}, 29 \mathrm{~V}$, and $30 \mathrm{~V}$ were transferred to EML for further analysis. This will include scanning electron microscopy and elemental analysis, preparation of specimens using the focused ion beam, transmission electron microscopy, scanning transmission electron microscopy with elemental analysis, and other characterization techniques as appropriate. These analyses will be primarily focused on determining the location of fission products in the kernels and coating layers to better understand fission product transport mechanisms. Of particular interest is the transport behavior of fission products in $\mathrm{SiC}$. Results from these analyses will be presented in detail in a separate report.

\section{RESULTS SUMMARY}

Key findings from the destructive PIE of Compact 1-3-1 are summarized as follows:

- The compact contained no particles with failed SiC or failed TRISO layers, based on DLBL analysis results.

- Approximately $0.4 \%$ of the predicted inventory of Ag- $110 \mathrm{~m}$ was retained in the compact outside the $\mathrm{SiC}$ layers. Silver release from all particles appeared to be high. Ag-110m M/C ratios values ranged from 0.46 to less than 0.06 in a sample of 60 gamma-counted particles. The average $\mathrm{M} / \mathrm{C}$ ratio was determined to be between 0.28 and 0.11 , confirming previous observations (based on gammascanning the intact compact) that this compact released a majority of its silver inventory during irradiation. No obvious correlations between kernel and coating morphology and silver release were observed. While this is based on a very small sample size (six particles analyzed), it is consistent with similar observations from other AGR-1 compacts.

- Cesium inventory in the compact outside the SiC layers was very low $\left(5.36 \times 10^{-6}\right.$ and $6.03 \times 10^{-6}$ for Cs-134 and Cs-137, respectively).

- Based on the inventory measured in the compact from DLBL analysis, the rare earth metals and strontium exhibited modest but measureable release through the intact TRISO coatings, with the amount varying by the specific element. Values determined for radioactive isotopes were $1.5 \times 10^{-4}$ for $\mathrm{Ce}-144,6.3 \times 10^{-3}$ for Eu-154, $7.9 \times 10^{-3}$ for Eu-155, and 2.6 $\times 10^{-3}$ for Sr-90. Values for lanthanum, 
neodymium, and samarium isotopes determined from mass spectrometry were in a similar range.

- DLBL analysis data indicate appreciable release of palladium through intact coatings and subsequent retention in the compact matrix. The Pd-105 inventory in the compact outside the SiC layers was approximately $0.8 \%$ of the predicted compact inventory, which is similar to the fraction determined for Ag-110m.

- The burnup of Compact 1-3-1 determined by mass spectrometry (16.3\% FIMA) was in good agreement with the predicted burnup and values determined from gamma spectrometry measurements.

- The morphology of kernel, buffer layer, and IPyC layer in the deconsolidated Compact 1-3-1 particles examined was generally similar to that observed during ceramography of AGR-1 compact cross sections. Specifically, many particles displayed a continuous gap between the buffer and IPyC layers in the observed plane that was driven by buffer densification and followed by buffer-IPyC debonding during irradiation. Partial debonding occurred in many other particles along the observable bufferIPyC interface. Approximately one-fourth of the particles exhibited fractures in the buffer layer. However, over half of the Compact 1-3-1 kernels exhibited a thick peripheral region with little to no porosity. Although this region may be a remnant of a uranium oxide rind, few cross-sectioned kernels from other AGR-1 compacts had such an appearance.

- Two particles with fractures through the entire IPyC layer were discovered in the Compact 1-3-1 particle cross sections. Combing the statistics for Compact 1-3-1 with those of other AGR-1 compacts analyzed previously, it appears that Variant 3 IPyC had approximately the same fracture resistance as Baseline and Variant 2 IPyC layers (all significantly better than lower-density Variant 1 IPyC).

- The feasibility of mounting coplanar ensembles of deconsolidated, burned-back particles and then grinding and polishing the particles for examination at closely spaced intervals was demonstrated. Mounting the particle ensembles in translucent epoxy and then backlighting them enabled sharp silhouette images of $\mathrm{SiC}$ exteriors to be obtained, which aided in determining the distance of the polish plane from the true particle midplane.

- Examining particles at multiple cross-sectional levels was more likely to reveal small areas of residual buffer-IPyC bonding compared to examining a single polish plane. Examining more levels also apparently increased the likelihood of detecting buffer fractures.

- A total of 56 particles with intact buffers received radial measurements at four levels. After fitting the radii to spheres, it was determined that the average kernel volume expanded during irradiation by approximately $26 \%$ and their buffer volumes decreased by approximately $39 \%$ on average. In the process, an average gap thickness of $26 \mu \mathrm{m}$ was opened between the buffer exterior and IPyC interior.

\section{REFERENCES}

Barnes, C.M., W.C. Richardson, D. Husser, M. Ebner, 2008, "Fabrication processes and product quality improvements in Advanced Gas Reactor UCO kernels," Proceedings of the 4th International Topical Meeting on High Temperature Reactor Technology, HTR2008, Washington, DC, U.S.A., September 28-October 2, 2008, HTR2008-58039.

Bower, Gordon R., Scott A. Ploger, Paul A. Demkowicz, and John D. Hunn, 2016, "Measurement of kernel swelling and buffer densification in irradiated UCO TRISO particles," submitted to Journal of Nuclear Materials, November 2016

Chadwick, M.B. et al., 2011, ENDF/B-VII.1: Nuclear Data for Science and Technology: Cross-Sections, Covariances, Fission Product Yields and Decay Data, Nuclear Data Sheets, Volume 112, Issue 12, December 2011, pp. 2887-2996. Specific decay data accessed at: http://www.nndc.bnl.gov/exfor/endf00.jsp. 
Collin, Blaise P., 2015, AGR-1 Irradiation Test Final As-Run Report, INL/EXT-10-18097, Rev. 3, Idaho National Laboratory.

Collin, Blaise P., and Scott A. Ploger, 2013, AGR-1 PIE Measurement of Kernel Swelling and Buffer Densification, and Comparison to Model Predictions by PARFUME, ECAR-2206, Rev. 0, Idaho National Laboratory.

Demkowicz, Paul, Jason Harp, Philip Winston, and Scott Ploger, 2012, AGR-1 Fuel Compact 6-3-2 Post-Irradiation Examination Results, INL/EXT-12-27123, Idaho National Laboratory.

Demkowicz, Paul, Lance Cole, Scott Ploger, and Philip Winston, 2011, AGR-1 Irradiated Test Train Preliminary Inspection and Disassembly First Look, INL/EXT-10-20722, Idaho National Laboratory.

Demkowicz, Paul A., 2010, “AGR-1 Post-Irradiation Examination Plan,” PLN-2828, Rev. 1, Idaho National Laboratory.

Demkowicz, Paul A., Jason M. Harp, Philip L. Winston, and Scott A. Ploger, 2013, Analysis of Fission Products on the AGR-1 Capsule Components, INL/EXT-13-28483, Idaho National Laboratory.

Demkowicz, Paul A., Jason M. Harp, Philip L. Winston, Scott A. Ploger, and Isabella J. van Rooyen, 2016a, AGR 1 Compact 4-1-1 Post-Irradiation Examination Results, INL/EXT-15-36169, Idaho National Laboratory.

Demkowicz, Paul A., Philip L. Winston, Jason M. Harp, Scott A. Ploger, 2016b, AGR-1 Compact 5-3-1 Post-Irradiation Examination Results, INL/EXT-15-36354, Idaho National Laboratory.

Demkowicz, Paul A., Scott A. Ploger, Philip L. Winston, Jason M. Harp, 2016c, AGR-1 Compact 3-2-1 Post-Irradiation Examination Results, INL/EXT-15-36352, Idaho National Laboratory.

Grover, S. Blaine, David A. Petti, and John T. Maki, 2010, "Completion of the First NGNP Advanced Gas Reactor Fuel Irradiation Experiment, AGR-1, in the Advanced Test Reactor," INL/CON-10-18032, Proceedings of HTR-2010, Prague, Czech Republic, October 18-20, 2010, Paper 104.

Harp, Jason M., 2014, "Analysis of Individual Compact Fission Product Inventory and Burnup for the AGR-1 TRISO Experiment Using Gamma Spectrometry,” ECAR-1682, Rev. 3, Idaho National Laboratory.

Harp, Jason M., Paul A. Demkowicz, Philip L. Winston, and James W. Sterbentz, 2014, “An analysis of nuclear fuel burnup in the AGR-1 TRISO fuel experiment using gamma spectrometry, mass spectrometry, and computational simulation techniques," Nuclear Engineering and Design, Volume 278, pp. 395-405.

Hawkes, Grant L., 2014, “AGR-1 Daily As-Run Thermal Analyses,” ECAR-968, Rev. 4, Idaho National Laboratory.

Hunn, J.D., G.E. Jellison Jr., and R.A. Lowden, 2008, "Increase in pyrolytic carbon optical anisotropy and density during processing of coated particle fuel due to heat treatment," Journal of Nuclear Materials, Volume 374, Issue 3, pp. 445-452.

Hunn, J.D., R.N. Morris, C.A. Baldwin, F.C. Montgomery, G.W. Chinthaka Silva, and T.J. Gerczak, 2012, AGR-1 Irradiated Compact 6-1-1 PIE Report: Evaluation of As-Irradiated Fuel Performance Using Leach Burn Leach, IMGA, Materialography, and X-ray Tomography, ORNL/TM-2012/233-R0, Oak Ridge National Laboratory.

Hunn, John D., Andrew K. Kercher, Paul A. Menchhofer, and Jeffery R. Price, 2005, Results from ORNL Characterization of Nominal $350 \mu \mathrm{m}$ NUCO Kernels from the BWXT 59344 Batch, ORNL/TM-2005/541, Oak Ridge National Laboratory. 
Hunn, John D., and Richard A. Lowden, 2006, Data Compilation for AGR-1 Variant 3 Coated Particle Composite LEU01-49T, ORNL/TM-2006/022, Rev. 1, Oak Ridge National Laboratory.

Hunn, John D., Fred C. Montgomery, and Peter J. Pappano, 2006, Data Compilation for AGR-1 Variant 3 Compact Lot LEU01-49T-Z, ORNL/TM-2006/510, Oak Ridge National Laboratory.

INL, 2015, “Technical Program Plan for INL Advanced Reactor Technologies Technology Development Office/Advanced Gas Reactor Fuel Development and Qualification Program,” PLN-3636, Rev. 4, Idaho National Laboratory.

Maki, John T., 2009, AGR-1 Irradiation Experiment Test Plan, INL/EXT-05-00593, Rev. 3, Idaho National Laboratory.

Ploger, Scott A., Paul A. Demkowicz, John D. Hunn, and Jay S. Kehn, 2012, Ceramographic Examinations of Irradiated AGR-1 Fuel Compacts, INL/EXT-12-25301, Rev. 1, Idaho National Laboratory.

Sterbentz, J.W., 2011, "JMOCUP As-Run Daily Depletion Calculation for the AGR-1 Experiment in the ATR B-10 Position,” ECAR-958, Rev. 1, Idaho National Laboratory.

Sterbentz, J.W., 2013, "JMOCUP As-Run Daily Depletion Calculation for the AGR-1 Experiment in the ATR B-10 Position,” ECAR-958, Rev. 2, Idaho National Laboratory.

van Rooyen, I.J., D.E. Janney, B.D. Miller, P.A. Demkowicz, and J. Riesterer, 2014, “Electron microscopic evaluation and fission product identification of irradiated TRISO coated particles from the AGR-1 experiment: A preliminary review," Nuclear Engineering and Design, Volume 271, pp. 114-122. 


\section{Appendix A}

\section{Deconsolidation-leach-burn-leach Procedure}

The majority of the functions performed by the Materials and Fuels Complex Analytical Laboratory (AL) in support of an Advanced Gas Reactor post-irradiation examination occur in AL Hot Cells 1 through 6, also known as the Junior Caves. Each of the six cells has a nominal $6 \times 5$-ft floor area, 2 -ft-thick concrete walls, a shielding window, and two Central Research Laboratory manual manipulators. They are supplied with compressed air, vacuum connections, and miscellaneous electrical and electronic connections integral to the cell. Tubing is available to provide liquid chemicals if direct flow is required. The cells have an air atmosphere and are maintained at a negative pressure to provide contamination control. Materials from the Materials and Fuels Complex Hot Fuel Examination Facility or Fuel Conditioning Facility may be received via a pneumatic rabbit in AL Hot Cell 1 and transferred to other hot cells by a chain-driven cart that connects AL Hot Cells 1 through 6.

The AL performs the deconsolidation and leach-burn-leach cycles according to Laboratory Instruction AL-5000-LI-018, "Electrolytic Deconsolidation and Leach-Burn-Leach Method." The task is to deconsolidate the compact, electrochemically breaking down the compact carbonaceous matrix and releasing the tristructural isotropic particles. The particles and matrix debris are then subjected to two 24-hour cycles submerged in hot concentrated nitric acid in a Soxhlet extractor. The particles and debris are transferred to a muffle furnace, where all exposed carbon is oxidized at $750^{\circ} \mathrm{C}$ in air for 72 hours. The burned-back particles and any remaining residue are then returned to the Soxhlet extractor for another two 24-hour extraction cycles in 16M nitric acid.

The compact is received via the pneumatic rabbit in AL Hot Cell 1 and transferred to Hot Cell 5 by the chain-driven cart that connects Hot Cells 1 through 6 . The compact is removed from the modified, aluminum Swagelok bulkhead fitting that serves as a container and weighed on the remote function balance in Hot Cell 4. The weight is taken by placing the compact in a clean, tared glass scintillation vial and transferring it to the balance for measurement.

Once the compact weight is recorded, the compact is returned to Hot Cell 5 and put into a clean, single-use deconsolidation tube (see Figure A-1 for entire deconsolidation setup). The deconsolidation tube is a $28-\mathrm{mm}$ outer diameter glass tube with a grating that supports the compact while the acid and applied electrical current break down the matrix. Based on experimentation during process development, it was concluded that a grating with 4-mm perforations allows the particles to drop through with minimal plugging by the partially decomposed matrix. The deconsolidation tube fits loosely inside the Soxhlet thimble, which is a fused silica tube that has a porous No. 2 fused silica frit in the bottom that allows acid to flow through, but traps the majority of solids. The deconsolidation tube containing the compact is placed inside the thimble, which is in turn placed inside a glass tallform beaker. The two electrodes for the deconsolidation step are made of 20-gauge platinum-rhodium wire. The cathode is placed in the acid, either between the thimble and deconsolidation tube, or between the thimble and tallform beaker. The anode is a platinum-rhodium wire that has been threaded through a glass tube that is flared at the base to form an "elephant foot." The anode wire is coiled at the bottom end to increase the contact area where it sits on the compact. The beaker is filled with $4 \mathrm{M}$ nitric acid to nearly the level of the bottom of the compact. The Tenma Model 72-6908 direct current power supply is energized and the current set at 1 A. Acid is added until current flow is established, and filled to cover approximately the bottom $1 \mathrm{~mm}$ of the compact. During system development and testing, it was determined that more coverage led to larger quantities of the matrix flaking off and partially plugging the perforated support in the deconsolidation tube. An open crossbar support test showed large pieces falling through before the matrix was uniformly broken down. The 4-mm perforated support was chosen as an effective compromise. 


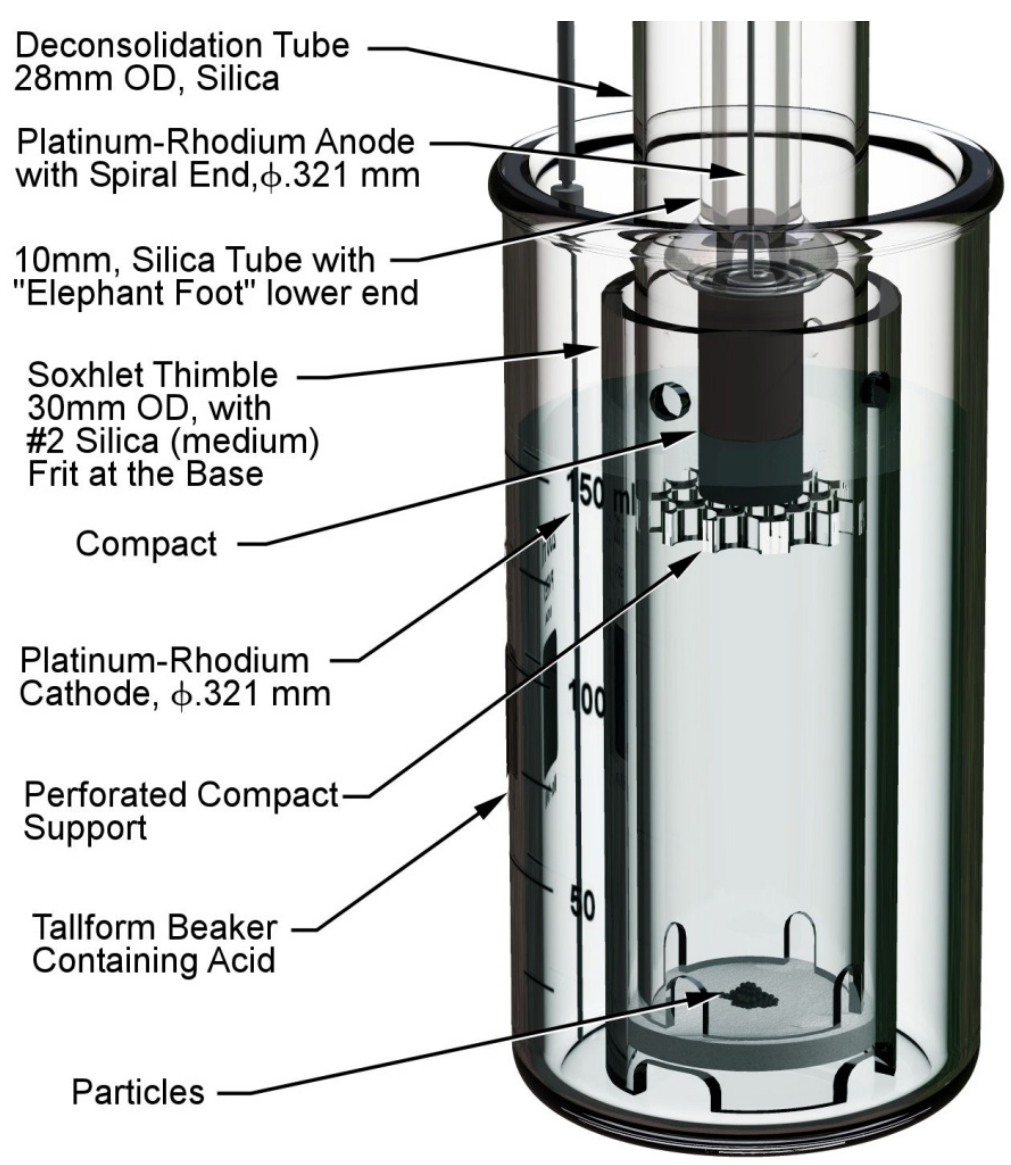

Figure A-1. Deconsolidation configuration.

The Soxhlet extractor system is composed of two standard glass units made in three sections: the boiling flask, situated in a heating mantle; center section in which the thimble containing the specimen is located and condensate collects and periodically drains through siphon action; and water-cooled condenser located on top. Two units were installed in Hot Cell 5 on the basis that it might be necessary to perform leach cycles in parallel. By procedure, the boiling flask is filled with $150 \mathrm{~mL}$ of concentrated nitric acid and placed in the heating mantle, the center section is inserted in the boiling pot, and the thimble is placed inside the center section. The condenser is then attached and chilled water flow initiated. The chiller is installed outside the cell, at the rear, and maintains water temperature at $10^{\circ} \mathrm{C}$ with a flow of approximately $3.8 \mathrm{~L}$ per minute. The chiller is interlocked so that the heating mantles cannot be energized unless a minimum water flow is maintained. The acid vapor rises to the top, is condensed, and drains down to fill the volume containing the thimble. Periodically this volume fills to the level of a siphon tube that drains the collection volume back to the boiling flask. In this manner the specimen is continually flushed with freshly-condensed acid solution. The assembly is shown in Figure A-2. 


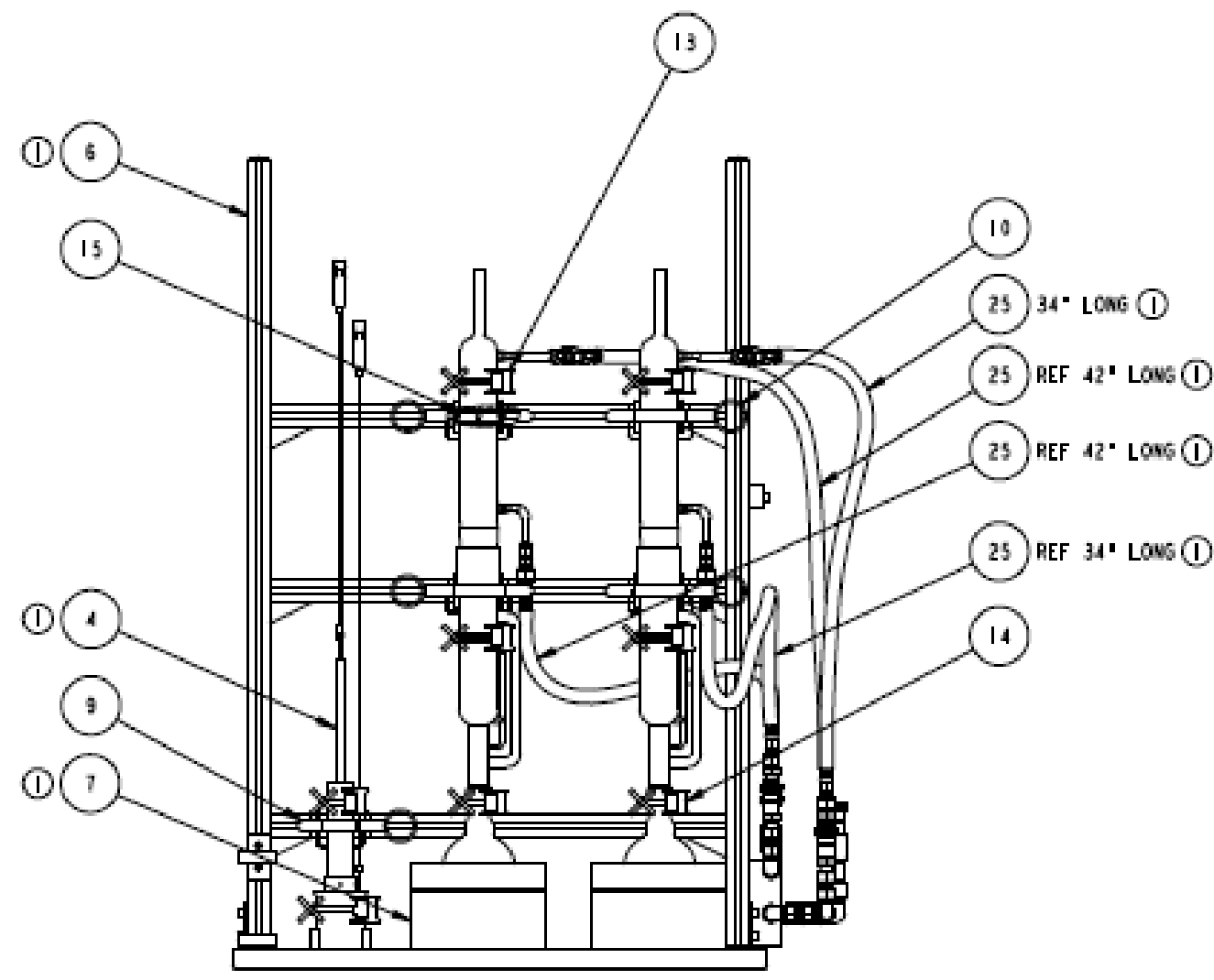

\section{- I ASSEMBLY}

Figure A-2. Framework with deconsolidation tube/vial (left) and two Soxhlet extractor stations.

For heating, the Soxhlet boiling flasks are placed into electrical resistance mantles. The heating mantles are installed in Hot Cell 5 and shown as Item 7 in Figure A-2. The heater is operator controlled and monitored outside the cell at the Hot Cell 5 and 6 power control panel.

The muffle furnace used for the burn-back phase is a Vulcan Model 3-55A bench top furnace, modified for installation in Hot Cell 5. An out-of-cell controller was fabricated to keep the electronics out of the radiation field. In this application, the furnace uses two $120-\mathrm{V}$ elements that are operated as individual heaters, departing from the manufacturer's configuration where the elements are wired in series and operated at $240 \mathrm{~V}$. In the manufacturer's arrangement, failure of either heater element would disable the furnace. The manufacturer's data indicate that one heater element is capable of maintaining the oven at $750^{\circ} \mathrm{C}$. Using the elements independently minimizes the need for heating element replacement in the event of failure. The furnace is equipped and controlled by a Type $\mathrm{K}$ thermocouple that is connected via the existing Hot Cell 5 Type K thermocouple wiring. An additional backup thermocouple has been installed in the furnace. The furnace is equipped with a door interlock switch and fan. The door interlock switch de-energizes the heaters when the furnace door is not closed. The low-voltage direct current fan is powered by the temperature controller. 
Following the two pre-burn leach cycles, the Soxhlet thimble containing the particles is transferred to the muffle furnace. The furnace is heated to $750^{\circ} \mathrm{C}$ and held at this temperature for 72 hours. Air flow is maintained by adjusting the fan voltage on the external control panel to provide a detectable movement of the pinwheel mounted over the exhaust chimney. Once the desired duration is reached, the furnace is allowed to cool to less than $70^{\circ} \mathrm{C}$ and the thimble is returned to the Soxhlet extractor to perform the post-burn leaches.

The two post-burn leaching steps are performed with the same procedure described above for the pre-burn leaches. The particles are allowed to air dry in the thimble following completion of the final post-burn leach cycles When dry, the particles are transferred to a metal storage container from which fractions are removed for particle inspection and selection.

The deconsolidation and two pre-burn leaches are expected to provide information on fission products that were external to the silicon carbide ( $\mathrm{SiC}$ ) layer and leached from the remaining matrix debris. These leach solutions would also provide information on any failed particles present in the compact, as the kernels would be exposed following deconsolidation and would be dissolved in the nitric acid solution. The post-burn leaches provide two basic pieces of information. If any particles are present with defective or otherwise failed $\mathrm{SiC}$ layers (cracked or porous $\mathrm{SiC}$ but intact pyrocarbon), the kernels will be exposed by the burning of intact pyrocarbon and dissolved in the nitric acid solution. As the burn step will also burn all of the remaining matrix debris as well as the OPyC layers, the post-burn leaches will also dissolve any fission products that remained in these components and could not be dissolved during the pre-burn leaches. In the absence of any particles with defective $\mathrm{SiC}$, the total of all leach solutions should provide a total measure of fission products that were present outside the $\mathrm{SiC}$ layers in the compact. 


\section{Appendix B}

\section{Particle Visual Inspection and Irradiated Microsphere Gamma Analysis}

Following any of the deconsolidation-leach-burn-leach steps, particles can be visually inspected using a custom-designed optical macroscopy system. Individual particles can then be selected for specific purposes such as gamma spectrometry, burnup analysis, or microscopy. After completion of the second post-burn leach step, the particles are allowed to air dry and then transferred from the thimble to a metal can for storage and handling. A fraction of the particles contained in the can (nominally 200 to 500 particles at a time) is transferred to an inspection dish, which is viewed on the shielded Leica macroscope that is installed in Materials and Fuels Complex Analytical Laboratory Hot Cell 5. The macroscope is connected to the control computer through a custom wall penetration that maintains shielding integrity.

A Leica Z16APO modular macroscope is oriented horizontally, viewing the sample array from below by a front surface mirror (Figures B-1 and B-2). The horizontal reflex configuration allows shielding to be installed to protect the camera. It also requires a minimal working footprint. Viewing from below allows a clear overhead for particle manipulation and reduces interference with master slave manipulators. The Leica Z16 is equipped with an 8-megapixel DFC-490 CCD color camera that allows live video imaging at medium resolution and still image acquisition at high resolution. The unit is equipped with a $0.5 \times$ objective lens that allows a working distance of $187 \mathrm{~mm}$, maximizing distance between the radiation source and the optics and electronics while minimizing the working envelope. The lens combination provides a 16:1 zoom capability that yields a field of view ranging from approximately $26 \times 26 \mathrm{~mm}$ to 1.6 $\times 1.6 \mathrm{~mm}$, meaning that a maximum of about 1000 particles could be viewed at the minimum magnification of $9 \times$, and four particles at the maximum of $144 \times$. The digital image is communicated via a combination Firewire-Ethernet cable to the computer located outside the cell and displayed on the computer monitor. Images are captured and saved on the computer.

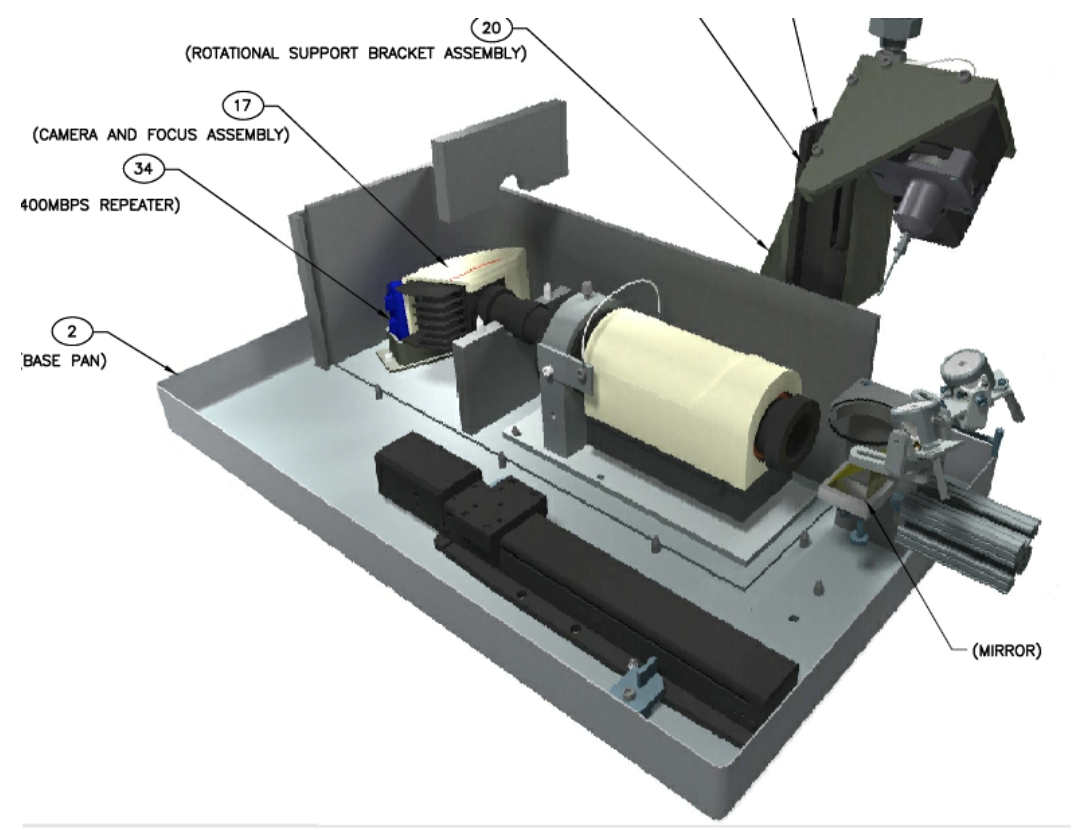

Figure B-1. Cutaway view of camera optical orientation without shielding. 


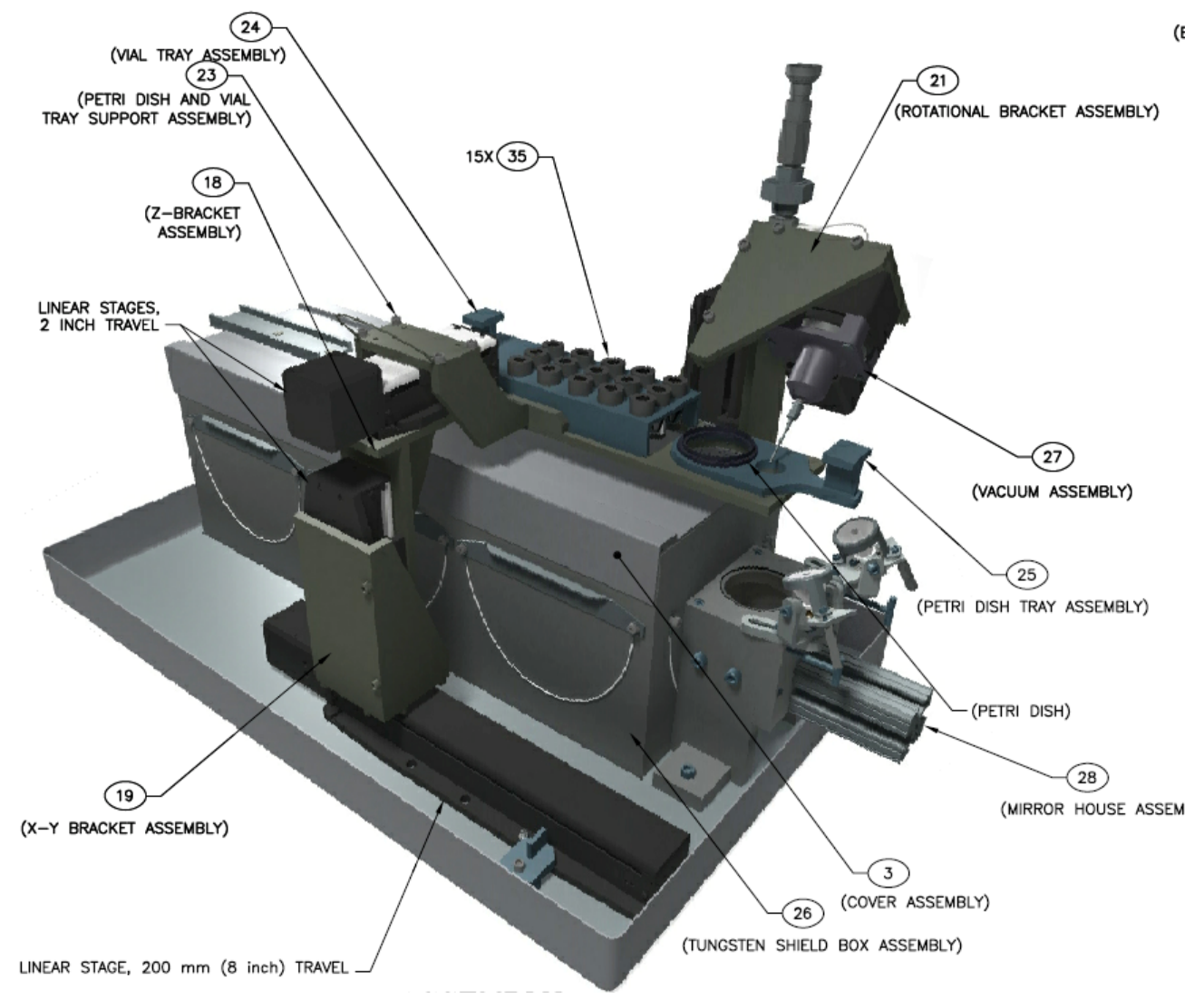

Figure B-2. Assembled isometric view of macroscope stages and shielding.

Particles placed on the optically-flat glass inspection dish are viewed from below, which allows the selection needle to operate for picking up particles from above. Lighting is provided by two high-intensity variable light-emitting diodes that are mounted in pivot posts on top of the macroscope mirror box. This arrangement allows for some adjustment of shadow and highlight, but imperfect uniformity. When particles are placed on the inspection dish for viewing, the dish stage can be translated to view the dish and the focus adjusted as needed. Newmark stepper motor-driven linear stages are used to position the viewing dish and vial tray platform in the $\mathrm{x}, \mathrm{y}$, and $\mathrm{z}$ directions as well as to raise and lower the vacuum needle during particle selection. The stages are controlled with joysticks that are able to achieve a nominal 0.2-mm precision of movement. Manual control using visual input from the macroscope and through the cell window allows the operator to achieve consistent needle and visualization position, minimizing the need for electronic positioning tracking. Selected particles are picked up using a vacuum tweezer needle and photographed, then placed in glass V-vials for gamma spectrometry measurements. The needle stage moves up and down and can rotate the needle to allow a 360-degree view. Figure B-3 shows a particle attached to the vacuum needle. 


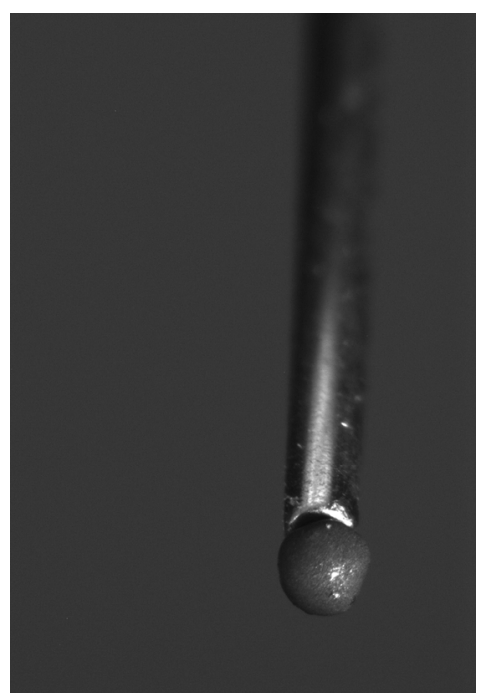

Figure B-3. Post-deconsolidation particle viewed on end of vacuum tweezer needle.

Once particles have been selected from the inspection dish, they can be moved to individual Wheaton 0.3-mL V-vials, which are held in a rack on the inspection dish stage as shown in Figure B-4. Fifteen vials are arranged in the rack, which has an open bottom through which the V-vials can be viewed from below using the camera. The vacuum needle that is holding a particle is raised above rack height and the stage is positioned to align the needle with an open V-vial. The needle is then lowered into the mouth of the vial, the vacuum is shut off, and as the vacuum leaks off, the particle drops into the vial. This is confirmed visually by watching the macroscope image on the computer screen.

Once particles have been selected and placed in the vials, the vials can be transferred to Analytical Laboratory Hot Cell 4, which is equipped with a gamma ray spectrometer located outside the hot cell, with gamma radiation transmitted through a port in the rear of the cell as shown in Figure B-4.

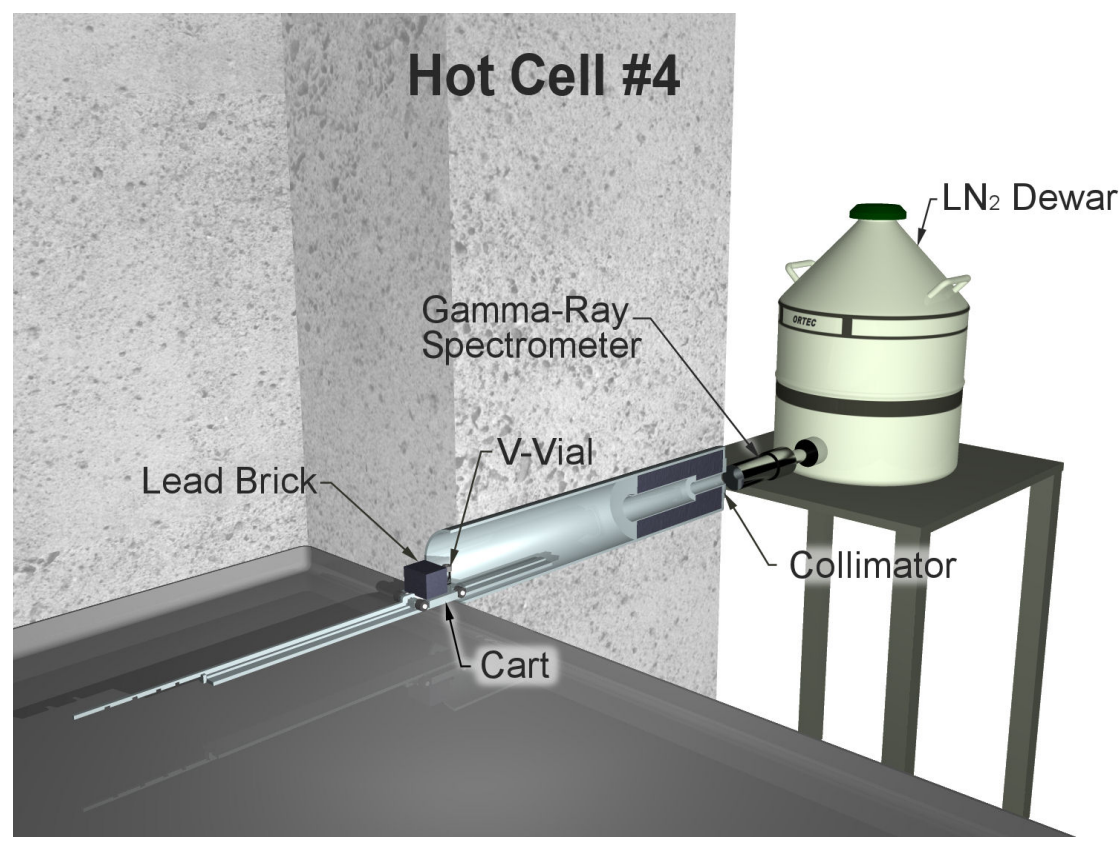

Figure B-4. Materials and Fuels Complex Analytical Laboratory Hot Cell 4 spectrometer configuration. 
The vial is positioned on the cart and moved to the position nearest the collimator to minimize the amount of background radiation from other sources inside the cell. The gamma spectrometer is an 18\%-efficient Canberra germanium-lithium crystal that generates a signal that is parsed into specific energies by a Canberra multi-channel analyzer and the spectrum is further analyzed using Apex software. The system is calibrated for particle measurement using a National Institute for Standards and Technology traceable Eu-152 source plated onto a polyethylene bead that approximates the size of a tristructural isotropic particle in a glass vial of the type used to hold the particles for counting.

The analysis in the Apex software quantifies any isotopes with measureable gamma emissions. The measured activity is based on a weighted average of all the detected gamma rays from a particular isotope, with weight given to the primary gamma-ray (typically the gamma ray with the highest branching ratio) and diminishing weight given to other gamma rays as their branching ratio decreases. Gamma rays with poor statistics or with known interferences are not used in the weighted average. Isotopes of particular interest include Ag-110m, Cs-134, Cs-137, Ce-144 (determined by measuring gamma emissions from Ce-144 and the daughter isotope Pr-144), Eu-154, Eu-155, and Ru-106 (determined by measuring gamma emissions from the daughter isotope Rh-106). After the collected irradiated microsphere gamma analysis spectra were initially surveyed to identify which fission products were available for analysis, an AGR-1 specific library was created containing isotope, primary gamma energy, secondary gamma energy, and branching ratio. It included the isotopes of particular interest listed above. The default Apex library values for these isotopes were used with some notable exceptions. The primary gamma ray energy for Ag-110m was changed from 657 to $884 \mathrm{keV}$ to alleviate difficulties in resolving the $657 \mathrm{keV} \mathrm{Ag-110m} \mathrm{gamma} \mathrm{from} \mathrm{the} \mathrm{leading} \mathrm{tail} \mathrm{of} \mathrm{the} \mathrm{much} \mathrm{more} \mathrm{intense} \mathrm{Cs-137} 662 \mathrm{keV}$ gamma. The other Ag-110m lines often had too few counts in the peak for quantification. In addition to the primary isotopes of interest, the activities of several other isotopes or their minimum detectable activities were reported including activation products Co-58, Co-60, Eu-152, and Mn-54, and fission products Zr95 (and its Nb-95 daughter) and Ru-103. 


\section{Appendix C}

\section{Ceramographic Morphology Classification}

A comprehensive scheme for classifying AGR-1 particle morphologies was developed for analysis of cross-sectional particle images taken during ceramography of cross sections from six irradiated AGR-1 fuel compacts (Ploger, Scott A., Paul A. Demkowicz, John D. Hunn, and Jay S. Kehn, 2012, Ceramographic Examinations of Irradiated AGR-1 Fuel Compacts, INL/EXT-12-25301, Rev. 1, Idaho National Laboratory). Several characteristic morphologies came to be recognized as these images were examined. The most common feature was a radial gap between the buffer and inner pyrolytic carbon (IPyC) layers where the buffer densified inward (outer surface moved toward kernel) during irradiation. In some particles with inward buffer densification, the radial buffer-IPyC gap was interrupted by regions where the buffer stayed firmly bonded to the IPyC layer. Many of these particles debonded along most of the interface, while debonding was much less extensive on some other particles when the AGR-1 irradiation ended. The rarest case was where a particle had no buffer-IPyC gap. In these cases, the buffer stayed bonded to the IPyC layer around the entire circumference in the plane of the cross section examined. The buffers in these particles still evidently densified, but the inner buffer surface moved radially outward rather than the outer buffer surface moving inward. Kernels in these particles often had larger pores than seen inside kernels within inwardly densified buffers.

The scheme for classifying irradiated AGR-1 particles by morphology in the plane of polish is presented with representative examples in Figure C-1. A radial buffer-IPyC gap around the entire circumference (completely detached buffer-IPyC interface) is designated as a Type A end-state morphology. Particles with fully bonded buffer and IPyC layers are termed Type B particles. Debonding along only part of the buffer-IPyC interface is called a Type $\mathrm{AB}$ morphology. Buffer fracturing occasionally occurred in Types $\mathrm{A}, \mathrm{B}$, and $\mathrm{AB}$, which resulted in the six characteristic morphologies shown in Figure C-1. 


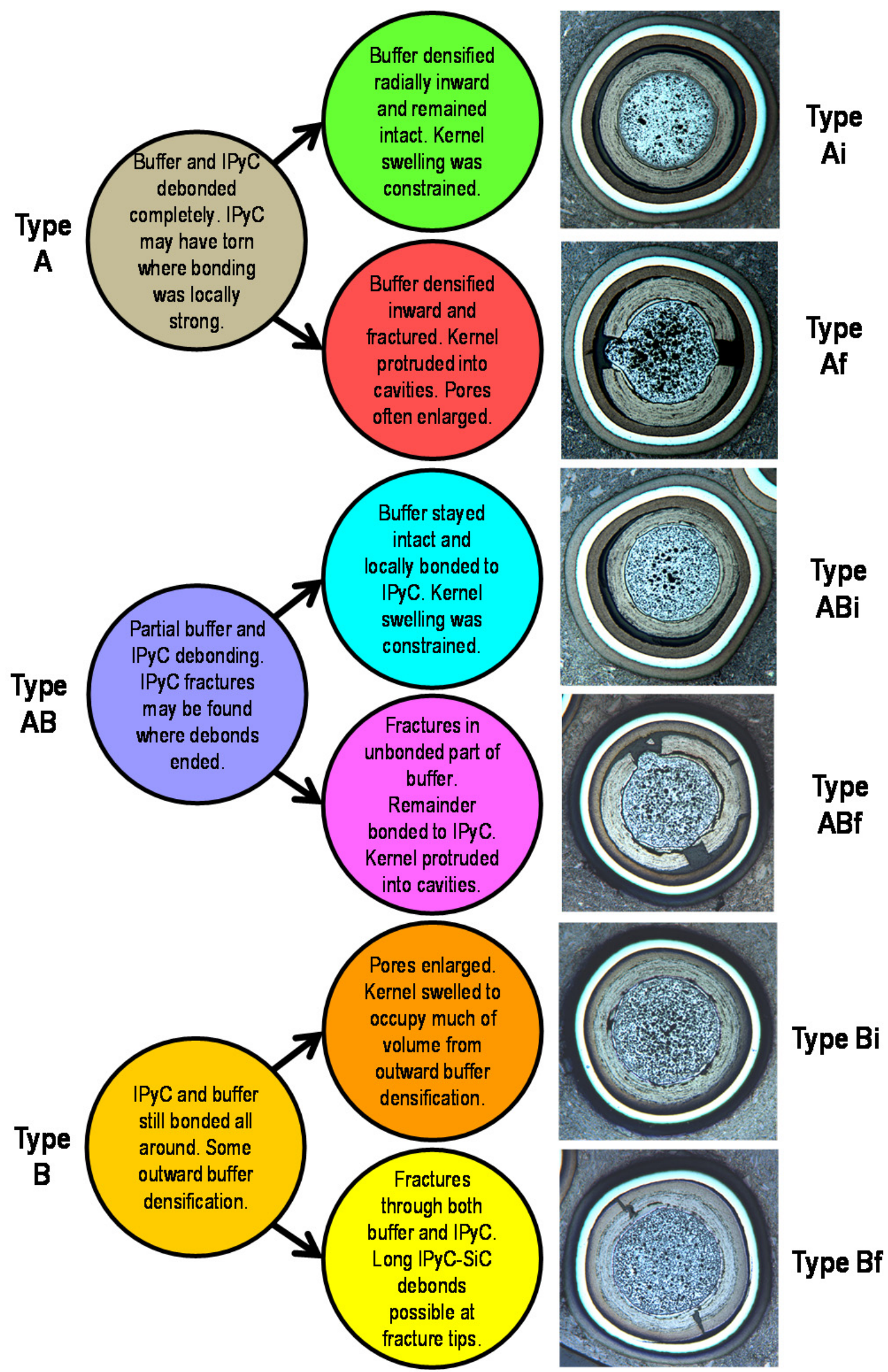

Figure C-1. Particle morphologies observed in AGR-1 fuel particle cross sections, where " $i$ " denotes intact buffer and "f" denotes fractured buffer (Ploger et al. 2012). 